\title{
NCSBN Regulatory Guidelines and Evidence-Based Quality Indicators for Nursing Education Programs
}

\author{
Nancy Spector, PhD, RN, FAAN \\ Director Regulatory Innovations \\ National Council of State Boards of Nursing \\ Josephine Silvestre, MSN, RN \\ Senior Associate, Regulatory Innovations \\ National Council of State Boards of Nursing \\ Maryann Alexander, PhD, RN, FAAN \\ Chief Officer, Nursing Regulation \\ National Council of State Boards of Nursing \\ Brendan Martin, PhD \\ Associate Director, Research \\ National Council of State Boards of Nursing \\ Janice I Hooper, PhD, RN, FRE, CNE, FAAN, ANEF \\ Lead Nursing Consultant for Education \\ Texas Board of Nursing \\ Allison Squires, PhD, RN, FAAN \\ Distinguished Nurse Scholar of the National Academy of Medicine 2019-2020 \\ Associate Professor, Rory Meyers College of Nursing, New York University \\ Melissa Ojemeni, PhD, RN \\ Leadership Fellow, Partners in Health, Boston, MA
}




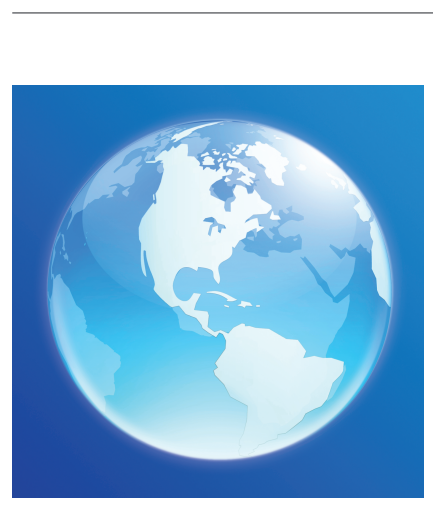

Advancing nursing excellence for public protection

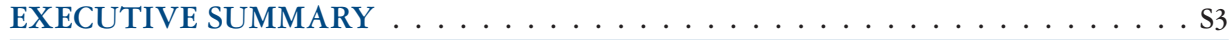
PART I

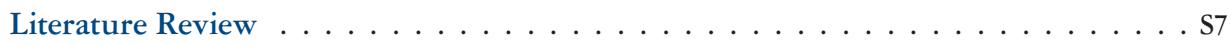
PART II

A National Mixed-Methods Study to Identify Quality Indicators and Warning

Signs of Nursing Education Program Performance . . . . . . . . . . . . . . S15

A National Delphi Study to Determine Quality Indicators and Warning

Signs of Nursing Education Program Performance . . . . . . . . . . . . S15

Methods . . . . . . . . . . . . . . . . . . . . . . . . s15

Defining Consensus . . . . . . . . . . . . . . . . . S15

Study Sample Selection. . . . . . . . . . . . . . . . . . . S15

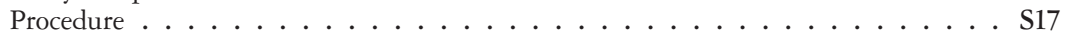

Statistical Analysis . . . . . . . . . . . . . . . . . . . S19

Results . . . . . . . . . . . . . . . . . . . . . . . . . . . . . . . . . . . . . . .

Discussion . . . . . . . . . . . . . . . . . . . . S20

Quality Indicators . . . . . . . . . . . . . . . . . . . S20

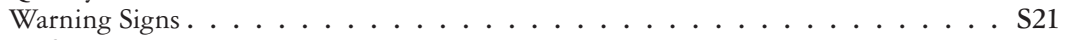

Performance metrics . . . . . . . . . . . . . . . . . S21

Achieving Consensus. . . . . . . . . . . . . . . . . . . . . . . . . . . . . . . . . . . . .

Limitations . . . . . . . . . . . . . . . . S22

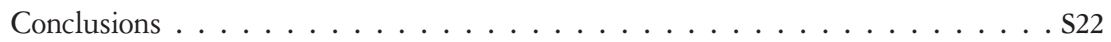

Acknowledgment . . . . . . . . . . . . . . . . . . . S22

A Quantitative Analysis of 5 years of BONs Annual Report Documents . . . . S23

Methods . . . . . . . . . . . . . . . . . . . . . . . S23

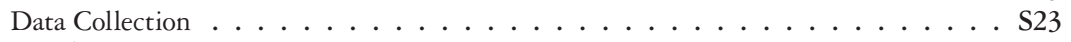

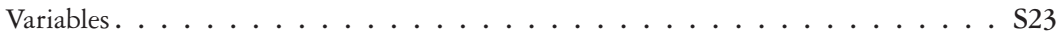

Statistical Methods. . . . . . . . . . . . . . . . . S25

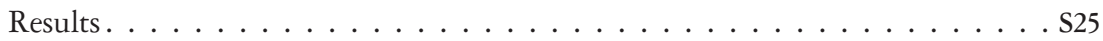

Program Demographics Characteristics . . . . . . . . . . . . . S25

Faculty Characteristics Related to Full Approval . . . . . . . . . . . . . . . . . S27

Program Characteristics Related to Full Approval . . . . . . . . . . . . . . . . . S27

Relationship Between NCLEX Pass Rates and Faculty Characteristics . . . . . . . . S28

Program Characteristics Related to NCLEX Pass Rates . . . . . . . . . . . . . . . . S29

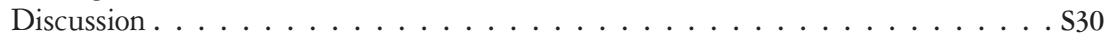

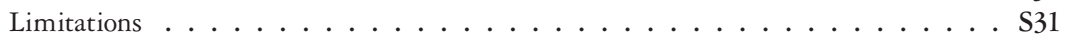

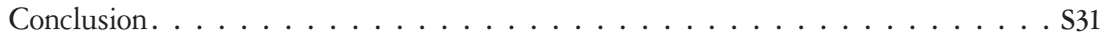

A Qualitative Analysis of 5 years of BONs Site Visit Documents . . . . . . . . S32

Methods . . . . . . . . . . . . . . . . . . . . . . . . S32

Document Sample Inclusion and Exclusion Criteria . . . . . . . . . . . . . S32

Data Analysis . . . . . . . . . . . . . . . . . S33

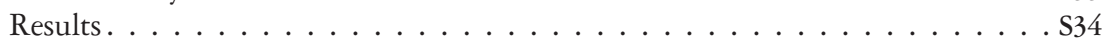

Emerging Themes . . . . . . . . . . . . . . . . . . S35

Categorical Findings Associated With the Theoretical Framework . . . . . . . . S36

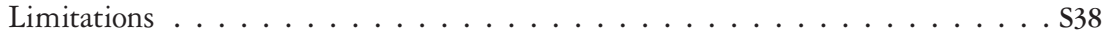

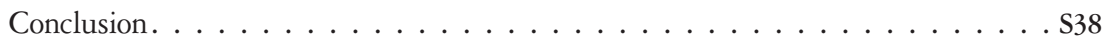

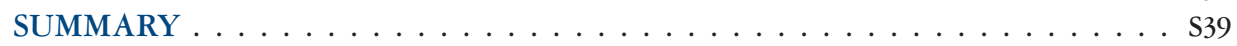

PART III

NCSBN Guidelines for Nursing Education Program Approval . . . . . . . . . . . S42

Quality Indicators. . . . . . . . . . . . . . . . . . . . . . . . . . . . . . . . . . . . . . . . . .

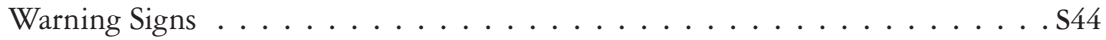

Supportive Evidence for the Approval Guidelines . . . . . . . . . . . . . . . . . S45

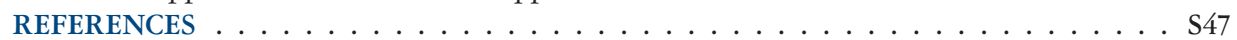

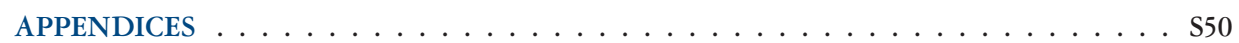

Appendix A: Definition of Terms . . . . . . . . . . . . . . . S50

Appendix B1: The Johns Hopkins Evidence Levels and Quality Ratings . . . . . . . . . .S51

Appendix B2: Evidence-Based Publications and Key Findings for Nursing Education

Performance Metrics . . . . . . . . . . . . . . . . . . . S52

Appendix C: Final Codebook for Program Analysis . . . . . . . . . . . . . . . . . S60

Appendix D: Site Visit Template. . . . . . . . . . . . . . . . . . . . . S60

Appendix E: Annual Report Core Data Template. . . . . . . . . . . . . . . . . S62 


\section{NCSBN Regulatory Guidelines and Evidence-Based Quality Indicators for Nursing Education Programs}

\section{EXECUTIVE SUMMARY}

Boards of nursing (BON) approval of nurse education programs is an integral part of their mission of public protection. In the United States, nursing education programs are required to be approved by the $\mathrm{BON}^{*}$ in the state where the program is officially located. The purpose of program approval is to ensure the program comprehensively covers the knowledge and skills students need to be licensed as a nurse and to practice safely as new graduate nurses, thereby providing society a competent nurse workforce.

To obtain BON nursing education program approval, nursing programs must meet the nursing education standards established by their BON. Only students graduating from officially recognized and approved programs are permitted to take the the NCLEX, the official nursing licensure exam in the US and Canada. (Spector \& Woods, 2013). To determine whether graduates are eligible to take the NCLEX, BONs rely on verification from the nursing education program that each student has successfully completed all program requirements, including successfully meeting clinical learning objectives.

BONs offer two types of nursing education program approval: initial approval of new programs before they open for enrollment and ongoing monitoring and continued approval of programs. For a new program, the approval process begins with an initial application and proposal to the BON. The BON conducts an extensive evaluation to ensure that the program has the proper facilities, resources, administration and faculty, curriculum, clinical agreements, policies, and procedures, among other requirements set forth in state regulations. The process for continued approval of established programs is based upon monitoring the programs' performance outcomes and compliance with BON rules over time (Spector et al., 2018).

BONs use different models for approving nursing programs, and nursing education rules and regulations are not always consistent across all jurisdictions. Most BONs hire graduate-prepared education consultants with experience in nursing education to make recommendations on the approval status of the nursing programs in their state. In a few states, the BON's executive officer and board members from the BON's education committee (or educators on the board) may make these recommendations. About half of the BONs make site visits as needed, while the other half make regular visits (National Council of State Boards of Nursing [NCSBN], 2016a). In most states, the approval status will be designated as (a) full approval when all requirements are met; (b) conditional or probationary when some, but not all, of the requirements are met; or (c) approval removal when programs fail to meet requirements of correct cited deficiencies (Spector et al., 2018).

The three most common performance outcome measures used by BONs and other health profession accreditors are employment rates, graduation rates, and NCLEX pass rates (Spector et al, 2018). Although BONs use different models for approving nursing programs, the approval process is well recognized overall. Questions have arisen from nursing education experts regarding valid measures of nursing program quality. One is the use of NCLEX pass rates (Bernier et al., 2005; Giddens, 2009; Taylor et al., 2014). Of the 36 states that require a percent of first-time pass rates, $* * 64 \%$ of them require an $80 \%$ pass rate (NSCBN, 2019). BONs are also questioning whether this method of measuring program performance is appropriate and asking whether other metrics exist that should amend or replace the current regulatory standards, which are set by each state.

A large mixed-method study was conducted by NCSBN starting in 2017 to answer these questions and, more specifically, to identify the quality indicators of approved nursing education programs and the warning signs indicating a program may be falling below required standards for approval.

\footnotetext{
* In Mississippi, the registered nurse programs are approved by the Mississippi Institutions of Higher Learning and the practical nursing programs are approved by the BON. In New York, the programs are approved by the New York Board of Regents. In Idaho, programs are approved as long as they are accredited by a national nursing accrediting agency recognized by the U.S. Department of Education, though the BON takes over if that accreditation is lost.

** Fifteen states require the national pass rate or a percentage thereof.
} 


\section{Methods and Selected Findings}

The study consists of a comprehensive literature review; a national Delphi study providing data on consensus of experts in nursing education, regulation, and practice; a study analysis of 5 years' worth of BON annual reports of nursing programs; and a study analysis of 5 years' worth of BON site visit documents.

\section{Literature Review}

The literature review yielded 65 relevant published articles that were reviewed and graded using the Johns Hopkins Levels of Evidence and Quality Guide. Overall, the literature review revealed a number of quality indicators and warning signs that may serve as metrics for evaluating higher education programs, although the identified articles did not provide the levels of evidence needed for making policy decisions (Loversidge, 2016).

\section{National Delphi Study Identifying Quality Indicators and Warning Signs of Nursing Education Program Performance}

For our national Delphi study, data were provided on consensus from experts in nursing education, regulation, and practice on nursing education quality indicators, warning signs when programs are beginning to fall below standards, and performance outcome measures of nursing education programs. Consensus among the experts was reached after 2 rounds of discussion. This Delphi study identified 18 quality indicators (characteristics of nursing programs that graduate safe and competent students), 11 warning signs when nursing programs begin to fall below standards, and eight program performance outcomes that nursing regulatory bodies could measure. The quality indicators fall into the categories of (a) school leadership and faculty support; (b) consistent and competent faculty; (c) quality, hands-on clinical experiences with meaningful collaboration with clinical partners; and (d) an evidence-based curriculum emphasizing quality and safety and critical thinking/clinical reasoning. Although the warning signs are similar to the quality indicators (only the opposite), there are additional ones that are of interest, including over-reliance on simulation to replace clinical experiences and refusal of clinical facilities to host clinical experiences. There were few surprises with the outcomes that were identified (NCLEX pass rates, graduation rates, employment rates, etc.).

\section{A Quantitative Analysis of 5 Years of BONs Annual Report Document}

This study was a retrospective cohort study of 11,378 annual report data collected over a 5-year period (2012-2017) by 43 BONs. This quantitative analysis examined data contained within the BONs' annual reports to learn about indicators associated with full approval of nursing education program performance and those associated with programs that have lost approval. Statistically significant characteristics of approved programs and those with $\geq 80 \%$ NCLEX pass rates included (a) national accreditation, (b) traditional or hybrid modalities, (c) longer-standing programs, (d) higher enrollment capacity, (e) multiple program sites, (f) private nonprofit or public institutions, (g) program director with a $\mathrm{PhD}$, (h) licensed practical nurse/licensed vocational nurse (LPN/LVN) and bachelor of science in nursing (BSN) programs, and (i) no more than three program directors in 5 years. A marginally significant finding was that programs with more than $35 \%$ full-time faculty had $\geq 80 \%$ first-time NCLEX pass rates and full approval. Importantly, the NCLEX was viewed as a lagging indicator in this study; meaning, lower licensure examination performance was considered indicative of other program deficiencies, not vice versa.

\section{A Quantitative Analysis of 5 Years of BONs Annual Report Documents}

The qualitative study of 5 years' of BONs' site visit documents was conducted to better understand the qualifiable descriptors of why programs either become at risk for failing or do fail. After the inclusion/exclusion criteria were applied, there were 1,278 site visit reports for LPN/LVN and registered nurse (RN) programs eligible for the analysis, which included documents from programs that were on probation, under review, or did not have full approval. Two researchers used MaxQDA qualitative data analysis software to analyze the documents. Considerable, specific data on what causes nursing programs to begin to fail or fail, were found in the site visit documents. The main signal for a "site visit trigger" was NCLEX pass rates $\leq 80 \%$ for four or more quarters. The length of time it took to trigger a site visit related to NCLEX performance concerns varied by state regulations. Administrative processes, such as a lack of policies and procedures, were found to be problematic for nursing programs. High faculty turnover and the inability to recruit qualified faculty were linked to poor NCLEX performance. Faculty with little training in basic pedagogies was a persistent theme found in failing programs. Similarly, heavy faculty workloads and limited faculty development opportunities were also identified. Many failing programs had no overarching philosophy and curricular framework that tied the curriculum together. This gap resulted in curricula that were task-oriented, which masked the curricula as being "competency-based." The issues identified in this study coalesce nicely with the data found in the literature, our Delphi study, and our quantitative study of annual reports.

\section{Guideline Development}

After all the evidence was collected, NCSBN invited experts from nursing regulation, education, research, and law to review the data and findings and to develop guidelines for BONs to use when approving nursing education programs that include evidence-based criteria, quality indicators, and warning signs. 


\section{Conclusion}

This study provides substantial evidence-based criteria for identifying quality indicators of successful nursing education programs as well as warning signs for high-risk programs. The quality indicators and warning signs can serve as the basis for legally defensible and evidence-based guidelines for nursing education approval.

It is hoped that these guidelines will enhance collaboration between educators and regulators. Together, they will be able to use the quality indicators to guide nursing programs to approval and to identify warning signs when the nursing program is beginning to fall below standards. This early intervention will assist nursing programs to act before $\mathrm{BON}$ sanctions or program closures, thus continuing to graduate safe and competent nurses, in adequate numbers, to care for patients. 


\section{NCSBN Regulatory Guidelines and Evidence-Based Quality Indicators for Nursing Education Programs}

Keywords: Nursing education program approval, nursing education quality indicators and predictors, NCLEX pass rates.

$\mathrm{I}$

$\mathrm{n}$ the United States, prelicensure nursing education programs are required to be approved by the BON in the state where the program is officially located.* This approval process begins with an initial application and extensive proposal to the BON, which performs an

extensive evaluation ensuring the program has the proper facilities, resources, administration and faculty, curriculum, clinical agreements, policies, and procedures, among many other requirements set forth in state regulations. Once the program is approved, the BON continually monitors the program. The monitoring process consists of overseeing NCLEX pass rates and may include other metrics such as student retention and/or graduation rates. Additionally, many BONs periodically conduct formal site visits to the program.

A common cause for conditional or loss of approval is a drop in the required NCLEX pass rate. Although the approval process is well recognized at the state level, there are questions regarding the prelicensure nursing program approval criteria, particularly using the NCLEX pass rates as the sole criteria for ongoing approval. Of the $57 \mathrm{BONs}$ that regulate nursing education programs surveyed in NCSBN's Member Board Profiles, 36 use first-time NCLEX pass rates; of those, $64 \%$ use the $80 \%$ pass rate as their standard. Six do not use pass rates as a performance measure, and another 15 use the national pass rate or a percentage thereof (NCSBN, 2019).

Questions by nurse educators remain as to whether first-time NCLEX pass rates are valid measures, when used alone, of nursing education program quality (Bernier et al., 2005; Giddens, 2009; Taylor et al., 2014). BONs also are asking whether other evidence-based metrics exist that should amend or replace the current regulatory standards set by each state. Therefore, in 2017, NCSBN embarked on a 3-year journey to identify the evidence needed to answer these questions.

This report presents a literature review that found there is currently little evidence with the rigor needed to support quality indicators of nursing education. Additionally, it details a three-part, mixed-methods national study that NCSBN conducted to identify quality indicators of nursing education programs, as well as warning signs when programs begin to fall below standards. From this large study, consisting of three national studies using very different research methodologies (Delphi, quantitative, and qualitative studies), nursing education approval guidelines were developed.

This groundbreaking work provides nursing regulators with evidence-based and legally defensible tools for approving programs. In their missions of public protection, regulators will be able to first identify warning signs when nursing programs are beginning to fall below standards. They can then use the quality indicators to guide programs before sanctions or program closures occur, thus continuing to graduate safe and competent nurses, in adequate numbers, to care for patients. Additionally, nurse educators will find this evidence valuable as they plan for and evaluate their programs.

Definitions of terms used in this study are provided in Appendix A.

\footnotetext{
* In Mississippi, the registered nurse programs are approved by the Mississippi Institutions of Higher Learning and the practical nurse programs are approved by the BON. In New York, the programs are approved by the New York Board of Regents. In Idaho, programs are approved as long as they are accredited by a national nursing accrediting agency recognized by the U.S. Department of Education, though the BON takes over if that accreditation is lost.
} 


\section{Literature Review}

The following three criteria relative to nursing program approval formed the basis of the literature review:

- Use of NCLEX pass rates as a performance measure of prelicensure nursing programs.

- Additional metrics used to measure performance of higher education programs and the supporting evidence.

- Warning signs indicating a nursing program is falling below standards and at risk of losing BON approval.

Medline, PsychInfo, ERIC (Education Resources Information Center), and CINAHL (Cumulative Index of Nursing and Allied Health Literature) Complete were queried using the following keywords: (a) nursing education outcomes (and higher education outcomes); (b) nursing education (and higher education) quality indicators; and (c) predictors of nursing education (and higher education) quality. Because of the lack of literature in these areas, we also searched gray literature, which included literature and publications related to nationally recognized expert reports from organizations, governmental agencies (eg, U.S. Department of Education [USDE]), international nursing regulatory bodies, national healthcare regulatory and accreditation bodies, and national education workshops. Additionally, literature reviews, case reports, and opinions of nationally recognized experts based on experiential evidence were included.

Our literature search also included U.S. and international databases from education and other related fields. Citations from 65 relevant articles and reports were retrieved and reviewed. These articles and reports are summarized citing the type of publication, its purpose, key findings (Appendix B2), using the level of evidence according to Johns Hopkins Levels of Evidence and Quality Guide (Dang \& Dearholt, 2017) (Appendix B1). For the levels of evidence, two researchers (one external to NCSBN) rated the evidence levels separately and then came to consensus on the final rating.

\section{Use of NCLEX Pass Rates as a Performance Measure of Prelicensure Nursing Programs}

Regulatory bodies in other professions use licensure or certification pass rates to assess program performance, though not as the sole measure (Association of Specialized and Professional Accreditors, 2016; Barrett et al., 2016; The National Academies of Sciences, Engineering, and Medicine [NASEM], 2018). Barrett et al. (2016) stated that the Fundamentals of Engineering licensing examination should not be used to determine program content because the examination is meant to measure competency for licensure and the criterion is too broad to be effective in program improvement. They instead assert that more specific measures are needed (Barrett et al., 2016). Often, too much attention on examination pass-rates leads to "teaching to the examination," which has been reported in nursing as well (Hickerson et al., 2016, p. 2). The Association of Specialized and Professional Accreditors (2016) surveyed 45 specialized and professional accreditors and found that not all professions use licensure or certification examinations to measure education outcomes. They reported that while $84 \%$ of the professions have certification or licensure examinations, $64 \%$ of those accreditors require education programs to use pass rates as part of their self-assessments.

In 2018, NASEM held a workshop on graduate medical education outcomes and metrics (NASEM, 2018). The workshop participants agreed that test results are being used as outcomes to assess graduate medical education. However, they also acknowledged that measuring outcomes in graduate medical programs is complex and encouraged institutions to pilot other criteria and innovative ways to provide feedback to the programs and trainees.

Similarly, how does program use of standardized examinations such as admission and course-related progression tests relate to pass rates? Odom-Maryon et al. (2018), in a large national study of 832 nursing programs, found that higher NCLEX pass rates were associated with programs that did not use standardized examinations for either admission or progression. The investigators caution that they did not assess overall performance of the programs and the standardized examinations may have been implemented by low-performing schools and thus had nothing to do with the influence of standardized tests on NCLEX pass rates. Similarly, Randolph's (2016) statewide study of 34 nursing programs found that when programs required a set score on an NCLEX predictor examination for graduation, NCLEX pass rates and on-time graduation rates were statistically significantly lower than those programs that did not have cut scores on predictor examinations. Randolph theorized that the low-performing programs use predictor examinations to eliminate students who would fail the NCLEX and lower their pass rates. She further concluded that if BONs use NCLEX pass rates as the only metric, nursing programs that use predictor examinations as exit examinations could be falsely elevating their NCLEX pass rates because they are preventing lower performing students from taking the examination.

Many questions from faculty exist regarding the use of first-time pass rates as the primary metric. Foreman (2017), in a study of NCLEX pass rates from 2010-2014 of 1,792 programs across the United States, found that 28\% of the programs that failed to meet states' 
pass rate standards were within the $95 \%$ confidence interval (CI), meaning that $28 \%$ of the programs that failed to meet their respective states' pass rates had a 95\% CI that included and at times surpassed the passing threshold. He concluded that it was perhaps by chance these programs fell below the pass rate standard. For this reason, most BONs take action after 2 or more years of below-standard pass rates.

The USDE recommends higher education use employment rates and graduation rates in addition to licensure or certification examination pass rates because these metrics are necessary for graduates to enter the workforce (The Secretary's Recognition of Accrediting Agencies, 2009). The national nursing accreditors (Accreditation Commission for Education in Nursing, 2017; Commission on Collegiate Nursing Education, 2018; National League for Nursing, 2016), and other U.S. healthcare accreditors use the USDE's requirements for their outcome metrics. While these outcomes have face validity, as new nurses must graduate, pass the NCLEX, and become employed in order to enter the workforce, there is little evidence these outcomes are indicators of program quality (Spector et al., 2018). Table 1 provides a comparison of standards from nursing and other healthcare accreditors.

\section{TABLE 1}

\section{Comparison of Healthcare Professions' Accreditation Standards by Accrediting Agency}

\begin{tabular}{|c|c|c|c|c|c|c|}
\hline $\begin{array}{l}\text { Accrediting } \\
\text { Agency }\end{array}$ & $\begin{array}{l}\text { Licensure } \\
\text { Examination } \\
\text { Outcomes } \\
\end{array}$ & $\begin{array}{l}\text { Completion/ } \\
\text { Graduation/ } \\
\text { Retention Rates }\end{array}$ & $\begin{array}{l}\text { Student } \\
\text { Feedback }\end{array}$ & $\begin{array}{l}\text { Job Placement } \\
\text { Rate }\end{array}$ & $\begin{array}{l}\text { Employer } \\
\text { Evaluation }\end{array}$ & Length \\
\hline $\begin{array}{l}\text { Accreditation } \\
\text { Commission for } \\
\text { Education in } \\
\text { Nursing (2019) }\end{array}$ & $\begin{array}{l}\geq 80 \% \text { first-time } \\
\text { pass rate on } \\
\text { NCLEX in } \\
12 \text {-month period }\end{array}$ & $\begin{array}{l}\text { Unique to } \\
\text { program; faculty } \\
\text { set target rates } \\
\text { based on } \\
\text { program } \\
\text { demographics }\end{array}$ & $\begin{array}{l}\text { Previously } \\
\text { required but } \\
\text { no longer } \\
\text { specified }\end{array}$ & $\begin{array}{l}\text { Unique to } \\
\text { program; faculty } \\
\text { set target rates } \\
\text { based on program } \\
\text { demographics }\end{array}$ & $\begin{array}{l}\text { No longer } \\
\text { required due to } \\
\text { difficulty in } \\
\text { collecting data }\end{array}$ & $\begin{array}{l}\text { Initial accreditation is } \\
5 \mathrm{y} \text {; continuing } \\
\text { accreditation is } 8 \mathrm{y} ; \\
\text { annual reports and } \\
\text { substantive change } \\
\text { reports must be filed }\end{array}$ \\
\hline $\begin{array}{l}\text { Commission on } \\
\text { Collegiate } \\
\text { Nursing } \\
\text { Education (2018) }\end{array}$ & $\begin{array}{l}\geq 80 \% \text { pass rate } \\
\text { on NCLEX }\end{array}$ & $\begin{array}{l}\geq 70 \% \\
\text { completion rate }\end{array}$ & $\begin{array}{l}\text { Student } \\
\text { satisfaction } \\
\text { data optional }\end{array}$ & $\begin{array}{l}\geq 70 \% \text { in } 12 \text {-month } \\
\text { period }\end{array}$ & $\begin{array}{l}\text { Employer } \\
\text { satisfaction data } \\
\text { optional }\end{array}$ & $\begin{array}{l}\text { Initial accreditation is } \\
\text { up to } 5 \mathrm{y} \text {; continuing } \\
\text { accreditation is up to } \\
10 \mathrm{y} \text {; annual reports } \\
\text { and substantive } \\
\text { change reports must } \\
\text { be filed }\end{array}$ \\
\hline $\begin{array}{l}\text { Liaison } \\
\text { Committee on } \\
\text { Medical } \\
\text { Education (2019) }\end{array}$ & $\begin{array}{l}\text { Performance on } \\
\text { USMLE compared } \\
\text { to national data } \\
\text { for all medical } \\
\text { schools and } \\
\text { medical students } \\
\end{array}$ & $\begin{array}{l}\text { Required but no } \\
\text { rate specified }\end{array}$ & $\begin{array}{l}\text { AAMC } \\
\text { Graduation } \\
\text { Questionnaire }\end{array}$ & $\begin{array}{l}\text { Residency } \\
\text { matching through } \\
\text { the NRMP }\end{array}$ & $\begin{array}{l}\text { Assessment of } \\
\text { graduates' } \\
\text { residency } \\
\text { performance }\end{array}$ & $\begin{array}{l}\text { 8-y cycle after second } \\
\text { full survey visit }\end{array}$ \\
\hline
\end{tabular}




\begin{tabular}{|c|c|c|c|c|c|c|}
\hline \multicolumn{7}{|c|}{ Comparison of Healthcare Professions' Accreditation Standards by Accrediting Agency (continued) } \\
\hline $\begin{array}{l}\text { Commission of } \\
\text { Accreditation in } \\
\text { PhysicalTherapy } \\
\text { Education (2017) }\end{array}$ & $\begin{array}{l}\geq 85 \% \text { pass rate on } \\
\text { NPTE averaged } \\
\text { over } 2 \mathrm{y}\end{array}$ & $\begin{array}{l}\geq 80 \% \text { graduation } \\
\text { rate averaged } \\
\text { over } 2 \mathrm{y}\end{array}$ & Not addressed & $\begin{array}{l}\geq 90 \% \text { employment } \\
\text { rate averaged over } \\
2 \text { y }\end{array}$ & Not addressed & $\begin{array}{l}\text { Initial approval is } 5 \text { y } \\
\text { followed by } 10-y \text { cycle }\end{array}$ \\
\hline
\end{tabular}

Note. USMLE = United States Medical Licensing Examination; AAMC = Association of American Medical Colleges; NRMP = National Resident Matching Program; NBCOT = National Board for Certification of Occupational Therapy; NPTE = National Physical Therapy Examination; NAPLEX = North American Pharmacist Licensure Examination; $\mathrm{AACP}=$ American Association of Colleges of Pharmacy.

\section{Additional Metrics Used to Measure Performance of Higher Education Programs}

Academia is changing what it considers performance metrics in undergraduate education. The NASEM workshop also explored the quality of undergraduate education and found student performance outcomes were the most appropriate set of indicators determining education quality over program inputs (i.e., student, faculty, and program characteristics) (NASEM, 2016, 2018). In the past, input measures such as faculty-student ratios, expenditures, or student test scores were used as metrics of education; however, many data elements measuring performance outcomes are not comparable across institutions due to different conceptual definitions and populations (NASEM, 2016, pp. 57-80). Institutional or program quality is multidimensional and subjective because both students and the public expect different results.

\section{Employment Rates}

Although widely used as measures of institutional quality, the validity of employment rates as a metric of education performance has been debated (Ferrante, 2017; NASEM, 2016, pp. 57-80; Spector et al., 2018; Taylor et al., 2014). Personal communications with representatives of national accreditors (February 28 and March 1, 2017) confirmed that employment rates are viewed as the least valid measure of quality, despite widespread use. While it may be presumed that a higher quality program produces a higher number of employed graduates, there is no sound method of using employment rates as a proxy for program performance without accounting for geographic differences in labor markets (NASEM, 2016, pp. 57-80). Additionally, a graduate can be newly employed only to be terminated after a few weeks for incompetence (Spector et al., 2018).

In a descriptive study of 5,182 engineering students in Italy, researchers measured both incoming quality and outgoing performance and determined that if employment rates are used to measure institutional quality, then assessors need to collect data on the average regional unemployment rate for the age group, in both the region of student residence and the region of the institution (Ferrante, 2017). Ferrante suggested that such data collection requires a significant investment of time and resources, one that yields little return because employment rates are mostly used with other quality measures.

Feeg and Mancino $(2016,2018)$ provided evidence that the changing job market, which nursing programs cannot control, reflected in various regions and the U.S. economy has a large impact on employment rates. For example, the U.S. economy negatively affected the job market from 2009 to 2012. The decreasing rates of new graduate employment from 2008 to 2010 (Feeg \& Mancino, 2016) reflected the economy and not the quality of the nursing program. Similarly, new graduate employment rates in the West and Northeast parts of the United States tend to be significantly lower than those in the South and Midwest parts of the United States (Feeg \& Mancino, 2016, 2018). These variables need to be accounted for if nursing relies on employment rates as a measure of quality.

Currently, only seven U.S. nursing regulatory bodies report using employment data for their approval processes (Nursing Education Outcomes and Metrics Committee, 2017). Given the difficulty obtaining the data and that employment rates reflect regional economics and job availability, using employment rates as a metric for BON approval is not recommended because it is burdensome and without evidence of validity as a measure of education performance (Spector \& Woods, 2013). 


\section{Graduation Rates}

Another common metric used to measure institutional quality is graduation rates, which is considered a more valid assessment tool than employment rates (Cohen \& Ibrahim, 2008; Giddens, 2009; NASEM, 2016, pp. 57-80; Randolph, 2013; Reyna, 2010; Wellman et al., 2012).

In nursing, the Commission on Collegiate Nursing Education (2018) requires a 70\% graduation (or completion) rate with some exceptions. The National League for Nursing Commission for Nursing Education Accreditation (2016) allows programs to set their own benchmarks and reach them for 3 averaged academic years. Similarly, the Accreditation Commission for Education in Nursing (2019) allows the faculty to establish an expected level of completion that reflects student demographics (Table 1). According to an NCSBN survey of the education consultants (Nursing Education Outcomes and Metrics Committee, 2017), 17 U.S. nursing regulatory bodies use graduation rates for their approval requirements.

How graduation rates are calculated is a point of debate. A common calculation is the Integrated Postsecondary Education Data System (IPEDS) calculation, which is also used to measure the quality of an institution. The IPEDS calculation counts only those students who enroll in an institution as full-time degree-seekers and finish a degree at the same institution within a prescribed period. IPEDS ignores certain students such as nontraditional (i.e., older) students, transfer students, part-time students, and students who enroll midyear (Cook \& Hartle, 2011; NASEM, 2016). This calculation gap risks incentivizing programs to implement more selective admissions policies, prioritizing students who are more likely to maintain the full-time, 6-year-or-less graduation track. Conversely, institutions that admit student populations not captured by the current calculation are at a disadvantage because the system does not count all graduates. Graduation rates should account for all students if they are going to be used as a metric of program performance.

Another method for calculating graduation rates proposed by Cohen and Ibrahim (2008) is the graduation efficiency metric. This metric emerged out of the perceived problems with the standard graduation rates and attempted to capture more of the student population, including part-time students and transfer students. To capture these students in the calculation, the graduation efficiency metric measures an institution's "production of graduates" in relation to the size of its full-time equivalent undergraduate student body adjusted for the balance of beginning and transfer students. Graduation rate calculations that account for different types of students (e.g., students who leave programs for maternity leave, illness, family issues, etc.) quickly become much more complex than the standard calculation. The graduation efficiency metric, however, is relatively straightforward and can be calculated from existing data that schools already collect. Moreover, this metric does not encourage institutions to turn away part-time students and transfer students in order to increase raw graduation rates in accordance with the traditional graduation rate calculation.

With a goal of holding institutions accountable for their graduation rates, DeAngelo et al. (2011) studied 210,056 students in 356 nonprofit, 4-year-degree institutions, merging data from the National Student Clearinghouse and freshman surveys. They found student characteristics, rather than the institution's characteristics, had an impact on student outcomes. Using multiple regression models, they could predict graduation rates based on student high school grades, SAT scores, race/ethnicity, and gender, as well as a variety of other indicators as obtained from the freshmen surveys (i.e., volunteer work in high school, student finances, parental background, working full-time, etc.). Students living off campus during their first year had 35\% lower odds of finishing their degree than students living in campus residence halls. Additionally, they found that the 4-year degree attainment for public universities would increase to $140 \%$ if they admitted students with the same characteristics as those admitted to private universities. They concluded that differences in graduation rates among higher education institutions are largely attributable to the profiles and characteristics of their incoming students. This study demonstrates that graduation rates may have little to do with the school's performance but rather are impacted by student characteristics.

\section{Retention}

Another way of measuring program performance is to shift the focus from raw rates of completion (using the number of degrees awarded to the population of first-time, full-time students who graduate from the institution that admitted them) to rates of student retention (Cohen \& Ibrahim, 2008). The rate of retention is defined by the National Governor's Association (Reyna, 2010) as the number and percentage of entering undergraduate students who enroll consecutively from fall to spring and fall to fall at an institution of higher education. Retention rates are also known as persistence rates (Papes \& Lopez, 2007).

As Papes and Lopez (2007) suggested, rates of retention should be approached by asking the general question, "What proportion of a university's nursing students graduate with a nursing degree within the typical time frame plus 50\%?” The additional $50 \%$ is added to account for students who take 6 years to graduate. The typical timeframe can be adjusted depending on the type of nursing program and track option (e.g., baccalaureate, accelerated). Furthermore, the timeframe can be set according to the date a given student took their first nursing course at the institution and the date the degree was awarded. Students who do not graduate should also be counted. How to measure the standard for each nursing program option requires discussion and modification among stakeholders until the data accurately report retention/persistence. Papes and Lopez also suggested that, from an assessment perspective, low persistence rates may be considered an aberration, but a declining rate should be taken seriously and considered a warning sign. 
In a study of 489 public and 820 private nonprofit universities, researchers investigated retention rates from 2003 to 2013 (EberleSudré et al., 2015) and found that universities with students of similar profiles had differing retention rates. The researchers concluded that what universities do above and beyond traditional teaching methods can influence retention rates. For example, San Diego State University employed several strategies to improve retention rates. They partnered with local junior high and high schools to connect students to college earlier, they pushed all students to carry a minimum of 15 credit hours, and they instituted proactive advising and degree planning, fostered communities for first year students, and used data to improve curricula. As a result, San Diego State University vastly improved retention of underrepresented students (Eberle-Sudre et al., 2015). These results add another perspective to DeAngelo et al.'s (2011) graduation rate findings previously discussed. Student profiles and characteristics, as well as strategies that supplement traditional teaching methods, influence retention and graduation rates.

Odom-Maryon et al. (2018) also found multiple factors not directly related to teaching that influenced graduate nurse outcomes on the NCLEX. They conducted a national study of 832 nursing programs in the United States and compared program, faculty, and curriculum characteristics to NCLEX pass rates. Using multilevel modeling and regression analyses and controlling for variables, they found a statistically significant increase in NCLEX first-time pass rates with public schools, semester schedules, larger admission cohorts, more students per didactic faculty, and a higher percentage of full-time faculty. There were no statistically significant findings associated with the use of simulation, integrated curricula (i.e., specialties are not offered as separate courses), online learning environments, individual course grades, minimal course grades, clinical evaluations, or allowing students to repeat courses (Odom-Maryon et al., 2018).

Studies and experts have examined program quality in terms of passage on the licensure examination, employment, graduation, and retention rates of students up to this point. However, the literature examining clinical experiences shifts the quality discussion to production of graduates that are prepared to safely care for patients.

\section{Quality Clinical Experiences}

There is consensus in the international literature that quality, direct-care clinical experiences with actual patients are the foundation of quality nursing education (Beauvais et al., 2017; Benner et al., 2010; Candela \& Bowles, 2008; El Haddad et al., 2017; Hungerford et al., 2019; Jamshidi et al., 2016; Kavanagh \& Szweda, 2017; Killam et al., 2011; NCSBN, 2005; Spector et al., 2018) and other professional programs (Luhanga et al., 2014). Similarly, nurse regulators recognize clinical experiences with actual patients are an integral part of the program approval process in the United States and Canada (Alexander, 2019; College of Nurses of Ontario, 2018; Hooper \& Ayars, 2017).

A suggested quality indicator for nursing education is the number of clinical hours required in a nursing curriculum, although this indicator has not been extensively studied. In an integrative literature review of 50 articles, Hickerson et al. (2016) reported that novice nurses believed nursing programs should devote more hours to clinical experiences. Hungerford et al. (2019) conducted a scoping review of four countries' clinical hours and found disparity among clinical hour requirements with little evidence to support any of them.* They suggest further research to determine the number of practice experience hours needed and how to ensure the practice hours experienced are of a high quality (Hungerford et al, 2019, p. 39).

Benner et al. (2010) recommends integrating clinical and classroom experiences. As part of a series of studies known as the Carnegie Foundation's Preparation for the Professions Program, Benner et al. used an ethnographic, interpretive, and evaluative design to study all aspects of nursing education. They researched nine programs they deemed to be excellent** at all prelicensure levels. The findings demonstrated that nursing programs that provided hands-on, interactive clinical experiences and integrated those experiences into the classroom had higher ratings of student satisfaction. A fragmented system where clinical and classroom learning are not linked may not provide for comprehensive understanding and does not allow for students to make astute clinical judgments (Benner et al., 2010; Kavanagh \& Szweda, 2017).

Researchers in a statewide survey of 352 nurses (12\% response rate) found the majority of respondents reported that they needed more clinical hours in the nursing program to enhance their readiness for practice (Candela \& Bowles, 2008). However, Kumm et al.'s (2016) study to evaluate student outcomes using two different models of clinical immersion with senior nursing students had different results. Kumm et al. evaluated the difference between the original 16-week clinical immersion experience and a revised 8-week experience in preparing senior nursing students for practice by using the New Graduate Nurse Performance Survey (later changed to the Nursing Practice Readiness Tool) developed by the Nursing Executive Center. The survey evaluates new graduates in six distinct competency areas (i.e., clinical knowledge, technical skills, critical thinking, communication, professionalism, and management of responsibilities) using 36 items. The researchers found no statistically significant differences in the new graduate nurses' performance between the two clinical immersion models, suggesting that it is the quality of experience that is important rather than the length of time. Similarly, El Haddad et al. (2017) cited literature from the 1970s (Sax, 1978) asserting hospital-trained graduates in Australia had too much practice

\footnotetext{
* Australia requires 800 hours at the baccalaureate level, not including simulation. New Zealand requires 1,100 hours of clinical experience, with 360 hours in the final semester. The United Kingdom requires 2,300 hours of clinical experience. The United States has no required hours nationally (although a few states have requirements), but the national median is 712 hours for baccalaureate programs; 683 for diploma programs; and 573 for ADN programs (Smiley, 2019).

** Excellence was defined as follows: (a) reputation for teaching and learning; (b) high NCLEX pass rates; (c) recommended by either the NRB or the accrediting body; and (d) additional consideration given to geographic sampling and accommodating the school's calendar (Benner et al., 2010).
} 
and not enough theory in the 1970s. Today, the argument related to the education-practice gap seems to be the opposite. This suggests the discourse should change from quantity of hours to quality of the direct care clinical experiences.

A number of studies in the United States (Beauvais et al., 2017; Berkow et al., 2008; Candela \& Bowles, 2008; Hayden et al., 2014; Kavanagh \& Szweda, 2017; Rusch et al., 2019; Spector et al., 2015), and other countries (Cantlay et al., 2017; El Haddad et al., 2017; Hsu \& Hsieh, 2013; Missen et al., 2016) have addressed preparation for practice by obtaining the input of practicing professionals and nursing graduates. The need for quality clinical hours, either with supervised clinical experiences with actual patients or with simulation, is a major research finding (Alexander et al., 2015; Beauvais et al., 2017; Candela \& Bowles, 2008; El Haddad et al., 2017; Hayden et al, 2014; Kavanagh \& Szweda, 2017). However, what are quality clinical hours, and how can BONs be sure that clinical experiences are providing the needed knowledge to prepare students for entry to practice? The following are cited in the literature as elements integral to a quality clinical experience:

- Clinical decision making and reasoning (Benner et al., 2010; Candela \& Bowles, 2008; Cantlay et al., 2017; Gonzalez, 2018; Kavanagh \& Szweda, 2017; Killam et al., 2011; 2012; Rusch et al., 2019)

- Effective delegation (Berkow et al., 2008; NCSBN, 2006)

- Electronic data and information management (Beauvais et al., 2017; Candela \& Bowles, 2008)

- Emergency procedures (Cantlay et al., 2017)

- Interprofessional communication (Beauvais et al., 2017; Killam et al., 2011; NCSBN, 2006)

- Pharmacology knowledge (Berkow et al., 2008; Candela \& Bowles, 2008; Jamshidi, et al., 2016; NCSBN, 2006; Rusch et al., 2019)

- Leadership (Beauvais et al., 2017; Candela \& Bowles, 2008; Cantlay et al., 2017)

- Time management and prioritization (Rusch et al., 2019)

- Understanding pathophysiology (Berkow et al., 2008; NCSBN, 2006; Rusch et al., 2019).

\section{Nursing Program Curriculum}

Rusch et al. (2019) conducted a descriptive exploratory study of 569 nursing student preceptors to determine student readiness for practice. Their results, along with those of Benner et al. (2010), suggest nursing programs need to place more emphasis on patient safety and integrating pharmacology more meaningfully throughout the program to have a truly high-quality program.

Developed by consensus of national nursing and healthcare experts, including input from nurse regulators, the Quality and Safety Education for Nurses (QSEN) competencies (Cronenwett et al., 2007) have been integrated into many U.S. nursing education programs as a foundation for professional competence and patient safety. No studies, however, have been conducted to determine whether these are quality indicators or whether programs that embed these competencies into their curriculum have better prepared students than schools that do not. Similarly, the provincial and territorial nurse regulators in Canada have developed the Jurisdictional Competency Process EntryLevel Registered Nurse Competencies (Canadian Council of Registered Nurse Regulators, 2018).* While the domains have different labels, the QSEN and the jurisdictional competency process for entry-level competencies are similar, including patient safety, professional responsibility, evidence-based practice, and knowledge-based care. This suggests there is some regulatory consistency for nursing program quality between the United States and Canada. Furthermore, the College of Nurses of Ontario finds these competencies so essential that they are incorporating them into their nursing education approval process.

\section{Faculty}

It is presumed that faculty play a leading role in the overall performance of a nursing education program, yet actual evidence for this assumption is limited. Libner and Kubala (2017) recommended strategies for Illinois programs to improve their NCLEX pass rates based on their observations as regulation board members who conducted site visits to prelicensure programs. Their suggestions included focusing on the appropriate ratio of full-time versus part-time faculty (no recommendation given) and whether faculty professional development needs were being met. Additionally, they suggested evaluating the program's administrative support, including leadership of the program and financing, to support ongoing program improvement. Other areas they found important to assess included evaluation tools, teaching/ learning methodologies, admission policies, faculty-student ratios, and academic support.

Odom-Maryon et al. (2018) examined faculty qualifications such as whether a higher percentage of doctoral faculty teaching didactic courses and certification in specialty fields or in nursing education resulted in higher NCLEX pass rates. Data were not statistically significant. Only one study (an unpublished master's thesis) of 92 nursing programs in Kansas and Missouri found a positive trend between NCLEX pass rates and faculty with doctoral degrees (Longabach, 2012), and even this finding was not statistically significant. Odom-Maryon et al. (2018) did find a statistically significant difference in NCLEX pass rates when a program had a higher percentage of full-time faculty versus part-time or adjunct faculty.

\footnotetext{
* Professional responsibility and accountability, knowledge-based practice, ethical practice, service to the public and self-regulation.
} 


\section{Systematic Program Evaluation}

The need for a program evaluation system has been cited as a crucial element for assessing a program by regulators, accreditors, and educators (Hooper \& Ayars, 2017; Oermann, 2017; Spector et al., 2018). Oermann (2017, p. 1) defines program evaluation as a systematic process for collecting data for making decisions about the nursing program and assessing its value. This process is also foundational to the national nursing accreditors as they evaluate programs for accreditation (Accreditation Commission for Education in Nursing, 2017; Commission on Collegiate Nursing Education, 2018; National League for Nursing, 2016). No actual studies have been conducted or data collected as to the most important elements of a program evaluation.

\section{Institution Type}

Although there is no specific explanation as to why, there is evidence that the type of institution (i.e., public, nonprofit, for profit) affects program and student outcomes. As cited previously, DeAngelo et al. (2011) found that public schools would outperform private schools in terms of graduation rates if the schools had similar characteristics. For-profit institutions were not included in DeAngelo's sample. Pittman et al. (2019) studied 5 years' worth of data from 13,745 nursing programs in 41 states and the District of Columbia using multivariable linear and regression models and controlling for variables. Public schools outperformed (using NCLEX first-time pass rates as the measure) the nonprofit and for-profit schools, though the margin of effect was much higher for the for-profit schools. Similarly, Odom-Maryon et al. (2018) found public schools outperformed private nonprofit and for-profit schools. Both Pittman et al. (2019) and Odom-Maryon et al. (2018) reported that private nonprofit institutions outperformed private for-profit institutions.

\section{National Accreditation}

Odom-Maryon et al. (2018) did not find a statistically significant difference between accredited schools versus unaccredited schools; however, only 43 (6\%) of the programs they studied were not accredited*. Spector et al. (2018) studied all RN nursing programs in 2016, comparing first-time NCLEX pass rates with accreditation status (i.e., Yes/No), and found a statistically significant difference in NCLEX pass rates between accredited programs versus unaccredited programs. Specifically, 741 programs (ADN and BSN) were not accredited and had pass rates of $72 \%$, whereas 1,531 programs (ADN and BSN) were accredited and had pass rates of $87 \%$. More research is needed on the relationship between national nursing accreditation and program outcomes.

In summary, during a national workshop, higher education experts reviewed the literature and found that there are no magical solutions to the long-standing issue of performance measurement in higher education institutions (NASEM, 2016), which is similar to the findings of this literature review of higher education outcomes and metrics. In fact, none of these components alone may be indicative of a quality program. It may require a combination of factors that lead to producing competent graduates.

\section{Warning Signs Indicating a Nursing Program Is Falling Below Standards and At Risk of Losing BON Approval}

While the literature does not address warning signs, per se, it does address observations when nursing programs begin to experience difficulties.

Failing to address unsafe students in the clinical area could be a warning sign for a nursing program. Docherty and Dieckmann (2015) surveyed 84 faculty in one Western state and found that faculty frequently do not fail nursing students, neither in didactic nor clinical areas, who demonstrate unsatisfactory progression in the program. This poses safety issues for patients and challenges for the practice setting and nurse regulators, especially when the school does not have a remediation process. Furthermore, Luhanga et al. (2014) conducted a qualitative descriptive design with nursing, education, and social work students to learn why faculty have difficulty failing students in clinical experiences. They suggest student failure is a difficult experience for the student and faculty and there are consequences for the program as well.

Hooper and Ayars (2017), nurse regulators from Texas, documented some of the weaknesses they encounter when they evaluate nursing programs and provided ideas for early interventions. Areas of weakness include (a) lack of early recognition of at-risk students, (b) inconsistent use of grading policies, (c) insufficient numbers of faculty, (d) lack of faculty development, (e) lack of rigor across the curriculum, (f) inadequacies with the testing processes, (g) difficulty in locating clinical placements, and (h) an ineffective program evaluation plan. Alexander (2019) editorialized about what nurse regulators observe when a program abruptly shuts its doors. The warning signs that nursing regulatory bodies observe when programs experience difficulties include:

- Rapid growth in admissions

- High faculty turnover

- Unclear workload policies

* It should be noted that while almost $89 \%$ of BSN nursing programs are accredited, only about $53 \%$ of associate degree programs and $11 \%$ of practical nursing programs are accredited (Silvestre, 2020).

Volume 11/Issue 2 Supplement July 2020

www.journalofnursingregulation.com 
- High administrator turnover

- High rate of complaints

- Weak admissions policies

- Old-fashioned skills lab with high student ratios

- Poor clinical placements.

\section{Conclusion}

There is an overall lack of evidence regarding the existence of validated metrics that could be used to evaluate a nursing education program, although the number of articles suggest there is a growing body of evidence that is defining what constitutes a quality education in nursing. We did not critique the quality of the research studies within the text of this report since our goal was to determine the state of the science so we could answer our research questions. However, we did rate the level and quality of the research and reports using Johns Hopkins evidence levels and quality ratings, which can be found in Appendix B1 and B2.

While many studies examined different components of nursing education, there is not one quality indicator or one warning sign that indicates a program's quality. Rather, this literature review points to several factors that in combination may serve as metrics for evaluating a program. These vary from components a program may have little to no control over, such as the type of institutional ownership, to the selected clinical experiences the school is able to obtain and afford to students. The evidence is insufficient to lead us to any conclusion. More research is needed in this area. To this end, NCSBN embarked upon a three-part national study to further examine the three topics studied within this review. Those data, along with the work herein, may provide evidence into the development of a guidance document for program approval. 


\section{A National Mixed-Methods Study to Identify Quality Indicators and Warning Signs of Nursing Education Program Performance}

NCSBN conducted a groundbreaking, national, mixed-methods study to identify evidence-based quality indicators and warning signs of nursing program performance. This comprehensive study comprises three national studies using different methodologies: (1) a national Delphi study, (2) a quantitative 5-year annual report study, and (3) a qualitative 5-year site visit study.

\section{A National Delphi Study to Determine Quality Indicators and Warning Signs of Nursing Education Program Performance}

The objective of this Delphi study was to provide data on consensus from experts in nursing education, regulation, and practice regarding nursing education quality indicators, warning signs when programs are beginning to fall below standards, and performance of nursing education programs. Specifically, we aimed to answer the following research questions:

- What are characteristics/quality indicators of nursing education programs that graduate safe and competent nurses?

- What are warning signs that indicate a nursing program is falling below the standard of graduating safe and competent nurses?

- What outcome measures could BONs use to determine whether nursing programs are graduating safe and competent nurses?

Institutional review board approval was obtained from the Western Institutional Review Board.

\section{Methods}

The Delphi method assumes group opinion is more valid than individual opinion (Keeney et al., 2011). In this method, generally there are two to four rounds of surveys, with the goal being that the group comes to consensus on issues. Round one is a qualitative round where the participants are asked to provide their views on issues. It is imperative that the questions are clear and understandable by the participants. To this end, it is recommended to pilot the questions with a small group of experts first (Benton et al., 2013; Keeney et al., 2011). In round two, the participants rate the factors identified in round one. If there are areas of disagreement, rounds three and four will allow participants to change their minds based on the findings of the group.

Benton et al. (2013) indicated that the advantages of this method are (a) gathering expert opinion while providing anonymity to the participants, (b) providing for a controlled and structured process, and (c) allowing for relatively simple statistics to interpret the results. The Delphi method has been used successfully for answering policy questions (Benton et al., 2013; Linstone \& Turoff, 2002; McGeouch et al., 2014; Meskell et al., 2014; Rayens \& Hahn, 2000) and in education (Barton et al., 2009; van Houwelingen et al., 2016). For policy questions, Delphi uses a heterogeneous group of experts so that diverse views of the issues can be sought (Benton et al., 2013; Linstone \& Turoff, 2002).

\section{Defining Consensus}

The literature supports using a 67\% threshold for agreement (Benton et al., 2013; Keeney et al., 2011). Benton (2013) explains that particularly with policy Delphi studies, a 67\% agreement is in concert with the threshold vote for Robert's Rules Online (n.d., Art. VII. Debate.) when the vote addresses an important policy issue. Therefore, for this study, a 67\% agreement was set for the threshold. Additionally, the interquartile range, which measures the dispersion of the data and, therefore, the collective judgments of the respondents, was set at 1.0 or below, which is also supported in the literature (Benton et al., 2013; Keeney et al., 2011).

\section{Study Sample Selection}

The research team used NCLEX program code data to obtain a list of email addresses for nurse educators of RN-MSN, RN-BSN, RNADN, RN-diploma and licensed practical nurse/licensed vocational nurse (LPN/LVN) programs in the United States. A list of email addresses for clinical nurse educators was purchased from the Association for Nursing Professional Development. The list of experts in 
nursing regulation was obtained by using the education consultant distribution list from the NCSBN membership email address list. Inclusion criteria for educators were as follows:

- Taught master's entry, BSN, ADN, diploma, or LPN/LVN for at least 2 years

- If an LPN/LVN educator, must have at least a BSN

- If an RN educator, must have at least a master's degree.

Clinical educators were required to have worked with new graduate LPN/LVNs or RNs for at least 2 years. Education consultants were required to have been hired by the $\mathrm{BON}$ to regulate nursing programs. In addition, all participants were required to be willing to complete three rounds of surveys about nursing education programs that graduate students who are competent and safe to practice.

By including regulators, educators, and those who supervise new graduates in practice, we were able to include diverse perspectives in this Delphi study. Additionally, with practice readiness being addressed in the literature related to performance outcomes, we wanted the practice perspective. Thus clinical nurse educators who work with new graduates in hospitals were included.

The demographics of the Delphi study participants are presented in Table 2. The demographics were balanced across the sample, except for the highest level of education attained. Whereas $51 \%$ of educators and $50 \%$ of the regulators had doctorates, only $19 \%$ of the clinical nurse educators who work in hospitals did.

\section{TABLE 2}

\section{Demographics of Survey Participants in the Delphi Study}

\begin{tabular}{|c|c|c|}
\hline Participant Type & $n$ & $\%^{a}$ \\
\hline Educators & 174 & \\
\hline \multicolumn{3}{|l|}{ Sex } \\
\hline Female & 162 & 93 \\
\hline Male & 10 & 6 \\
\hline Prefer not to say & 2 & 1 \\
\hline \multicolumn{3}{|l|}{ Age Range } \\
\hline $18-24$ & 0 & 0 \\
\hline $25-34$ & 4 & 2 \\
\hline $35-44$ & 10 & 6 \\
\hline $45-54$ & 33 & 19 \\
\hline $55-65$ & 89 & 51 \\
\hline$>65$ & 38 & 22 \\
\hline \multicolumn{3}{|c|}{ Highest Level of Education Attained } \\
\hline Diploma & 0 & 0 \\
\hline ADN & 0 & 0 \\
\hline BSN & 7 & 4 \\
\hline MS/MSN & 68 & 39 \\
\hline DNP & 20 & 11 \\
\hline $\mathrm{PhD}$ & 79 & 45 \\
\hline \multicolumn{3}{|c|}{ Years of Experience in Nursing Education ${ }^{b}$} \\
\hline 2 & 0 & 0 \\
\hline $3-5$ & 8 & 5 \\
\hline $6-10$ & 19 & 11 \\
\hline$>10$ & 147 & 84 \\
\hline \multicolumn{3}{|l|}{ Types of Students Taught } \\
\hline LPN/LVN only & 24 & 14 \\
\hline Diploma only & 3 & 2 \\
\hline ADN only & 27 & 16 \\
\hline BSN only & 61 & 35 \\
\hline Master's entry only & 3 & 2 \\
\hline LPN/LVN and ADN & 26 & 15 \\
\hline LPN/LVN and BSN & 1 & 1 \\
\hline ADN and BSN & 6 & 3 \\
\hline LPN/LVN, diploma, BSN & 1 & 1 \\
\hline
\end{tabular}

\begin{tabular}{|c|c|c|}
\hline Participant Type & $n$ & $\%^{\mathrm{a}}$ \\
\hline Educators & 174 & \\
\hline LPN/LVN, ADN, BSN & 3 & 2 \\
\hline LPN/LVN, BSN, master's entry & 1 & 1 \\
\hline LPN/LVN, ADN, BSN, master's entry & 1 & 1 \\
\hline ADN, BSN, master's entry & 4 & 2 \\
\hline ADN, diploma, BSN, master's entry & 1 & 1 \\
\hline BSN and master's entry & 12 & 7 \\
\hline Participant Type & $n$ & $\%^{\mathrm{a}}$ \\
\hline Education Consultants & 50 & \\
\hline \multicolumn{3}{|l|}{ Sex } \\
\hline Female & 48 & 96 \\
\hline Male & 2 & 4 \\
\hline Prefer not to say & 0 & 0 \\
\hline \multicolumn{3}{|l|}{ Age Range } \\
\hline $18-24$ & 0 & 0 \\
\hline $25-34$ & 0 & 0 \\
\hline $35-44$ & 4 & 8 \\
\hline $45-54$ & 10 & 20 \\
\hline $55-65$ & 24 & 48 \\
\hline$>65$ & 12 & 24 \\
\hline \multicolumn{3}{|l|}{ Highest Level of Education Attained } \\
\hline No response & 2 & 4 \\
\hline Diploma & 0 & 0 \\
\hline ADN & 0 & 0 \\
\hline BSN & 2 & 4 \\
\hline MS/MSN & 21 & 42 \\
\hline DNP & 8 & 16 \\
\hline $\mathrm{PhD}$ & 17 & 34 \\
\hline \multicolumn{3}{|c|}{$\begin{array}{l}\text { Years of Experience in Regulation of Nursing Education } \\
\text { Programs }\end{array}$} \\
\hline $0-2$ & 9 & 18 \\
\hline $3-5$ & 14 & 28 \\
\hline $6-10$ & 14 & 28 \\
\hline$>10$ & 13 & 26 \\
\hline
\end{tabular}




\section{Demographics of Survey Participants in the Delphi Study (continued)}

\begin{tabular}{|c|c|c|c|c|c|}
\hline Participant Type & $n$ & $\%^{\mathrm{a}}$ & Participant Type & $n$ & $\%^{\mathrm{a}}$ \\
\hline Education Consultants & 50 & & Clinical Nurse Educators & 71 & \\
\hline Types of Programs Regulated & & & Prefer not to say & 0 & 0 \\
\hline LPN/LVN only & 1 & 2 & Age Range & & \\
\hline LPN/LVN and BSN & 1 & 2 & $18-24$ & 0 & 0 \\
\hline ADN and BSN entry & 3 & 6 & $25-34$ & 6 & 8 \\
\hline BSN and BSN entry & 1 & 2 & $35-44$ & 12 & 17 \\
\hline ADN, BSN, BSN entry & 1 & 2 & $45-54$ & 19 & 27 \\
\hline ADN, Diploma, BSN entry & 1 & 2 & $55-65$ & 32 & 45 \\
\hline ADN, Diploma, BSN, BSN entry & 1 & 2 & $>65$ & 2 & 3 \\
\hline LPN/LVN, ADN, BSN entry & 4 & 8 & Highest Level of Educatic & & \\
\hline LPN/LVN, ADN, BSN, BSN entry & 6 & 12 & Diploma & 0 & 0 \\
\hline LPN/LVN, ADN, diploma & 1 & 2 & ADN & 0 & 0 \\
\hline LPN/LVN, ADN, diploma, BSN & 8 & 16 & BSN & 5 & 7 \\
\hline LPN/LVN, ADN, diploma, BSN entry & 4 & 8 & MS/MSN & 53 & 75 \\
\hline \multirow[t]{2}{*}{ LPN/LVN, ADN, diploma, BSN, BSN entry } & 18 & 36 & DNP & 9 & 13 \\
\hline & & & $\mathrm{PhD}$ & 4 & 6 \\
\hline Participant Type & $n$ & $\%^{\mathrm{a}}$ & Years of Experience Work & ate $\Lambda$ & \\
\hline Clinical Nurse Educators & 71 & & $0-2$ & 3 & 4 \\
\hline Sex & & & $3-5$ & 16 & 23 \\
\hline Female & 68 & 96 & $6-10$ & 12 & 17 \\
\hline Male & 3 & 4 & $>10$ & 40 & 56 \\
\hline
\end{tabular}

Note. ADN = associate degree in nursing; BSN = bachelor of science in nursing; $M S$ = master of science; $M S N=$ master of science in nursing;

DNP = doctor of nursing practice; LPN = licensed practical nurse; LVN = licensed vocational nurse.

a Percentages may not total 100 due to rounding.

${ }^{b}$ Educators with less than 2 years' experience were excluded and skipped to the end of the survey.

\section{Procedure}

Ten experts in regulation, education, and clinical education (in hospitals) piloted the surveys for clarity, and revisions were made based on their feedback. For example, we originally used the phrase "regulatory quality indicators," and although the educators and education consultants understood the term, the clinical educators did not. Therefore, we changed it to "characteristics of nursing programs that graduate safe and competent nurses," which was universally understood.

An introductory email describing the Delphi study was sent to the entire list of clinical nurse educators, educators in nursing programs, and education consultants inviting them to participate. If they met the inclusion criteria and were interested in participating, they were directed via hyperlink to the Qualtrics (Utah) online survey platform asking for demographics and related experience.

The educators in nursing programs $(\mathrm{n}=293)$, clinical nurse educators $(\mathrm{n}=125)$, and education consultants $(\mathrm{n}=62)$ who agreed to participate and completed the demographic survey were sent the first round of Delphi surveys (round one).

In round one, the participants were asked a series of open-ended questions. These included asking the participants to list up to 15 variables they would consider for each of the following:

- Characteristics/quality indicators of nursing education programs that graduate safe and competent nurses

- Warning signs that indicate a nursing program is falling below the standard of graduating safe and competent nurses

- Outcome measures BONs could use to determine whether nursing programs are graduating safe and competent nurses.

All participants had the opportunity to provide qualitative feedback during this round and were allowed 15 responses for each question (Keeney et al., 2011). Participants were allowed 2 weeks to respond to the survey. Reminder emails were sent at specific intervals to those who had not completed the surveys.

Major recurring themes from the first round were initially identified using NVivo 12 Plus software (QRS International). Text search and word frequency queries were run within each of the quality indicators, warning signs, and outcomes categories, and then across all three categories to determine possible themes. Text searches were directed by using the top word frequencies and the predominant themes that came out of the published literature. The possible themes were further content-analyzed by the research team.

$\mathrm{R}$ software ( $\mathrm{R}$ Foundation for Statistical Computing) was used to help validate the themes obtained manually by the research team and by using NVivo. Latent Dirichlet allocation with R (Grün \& Hornik, 2011) was used to categorize comments into naturally occur- 
ring themes by examining word frequency. Latent Dirichlet allocation is a statistical unsupervised learning technique that categorizes comments by assigning them to topics where the comments within a topic share more words in common than those in other topics.

A set of major themes emerged from round one (Table 3) for use in round two. In round two, each participant from round one was administered another survey that included the major themes identified. The participants were asked to rate the importance of each theme or variable using a 4-point Likert scale ( 1 = unimportant, 2 = not too important, $3=$ important, and $4=$ very important). The 4-point scale is particularly suited to a policy Delphi because it forces the respondents to take a position (Benton et al., 2013). Participants were again allowed 2 weeks to respond to the survey and reminder emails were sent at specific intervals to those who had not completed the surveys.

\section{TABLE 3}

\section{Major Themes Emerging From Delphi Round One}

\section{Quality Indicators}

1. Evidence-based curriculum that emphasizes quality and safety standards for patient care

2. Evidence-based curriculum that emphasizes critical thinking and clinical reasoning skills

3. Faculty are able to role model professional behaviors

4. Clinical experiences with actual patients that prepare students for the reality of clinical practice

5. Systematic process is in place to address and remediate student practice errors

6. Faculty teaching clinical courses demonstrate current clinical competence

7. Consistent administrative leadership in the nursing program

8. Collaboration between education and practice to enhance readiness for practice

9. Ongoing systematic evaluation of the nursing program

10. Institutional administrative support of the nursing program

11. Consistently has a pattern of NCLEX pass rates that meet set standards

12. Administrative support for ongoing faculty development

13. Significant opportunities for a variety of clinical experiences with diverse populations

14. Consistent full-time faculty, as opposed to reliance on adjunct faculty

15. Quality simulation is used to augment clinical experiences

16. Comprehensive student support services

17. National nursing accreditation

18. Admission criteria emphasize a background in the sciences

Warning Signs

1. Lack of consistent and prepared clinical faculty

2. Limited clinical experiences that do not prepare the students for practice

3. Poor leadership in the nursing program

4. Trend of NCLEX pass rates is inconsistent or decreasing

5. Complaints to the nursing program or board of nursing from employers, students, or faculty

6. Pattern of faculty attrition

7. Pattern of nursing program administrator attrition

8. Unwillingness of health care institutions to host clinical experiences for the nursing program's students

9. Pattern of student attrition

10. Curriculum is based on "teaching to the NCLEX"

11. Over-reliance on simulation to replace clinical experiences with actual patients

\section{Program Outcome Measures}

1. NCLEX pass rates of the nursing program

2. Relationship of the nursing program with its clinical partners

3. Employer satisfaction with the graduates' readiness for practice

4. Graduate preparedness to practice for an interprofessional environment

5. Graduates' satisfaction with the nursing program

6. Graduation rates of students in the nursing program

7. Consistency of graduate employment rates with regional data on nurse employment rates

8. History of board of nursing discipline with the graduates of the nursing program

A third round of Delphi surveys was planned but round two yielded such high agreement (see Results) across all groups for all variables that it was deemed unnecessary. 


\section{Statistical Analysis}

Statistical analysis was conducted using SPSS version 22.0. Simple descriptive statistics were estimated for each item and agreement was estimated by looking at the percentage of respondents who agreed that an item was either important or very important (a Likert rating of 3 or 4). Group differences were examined using a one-way analysis of variance, where post hoc comparisons were used to determine which group or groups differed on rating the item.

\section{Results}

Of the 293 educators, 125 clinical educators, and 62 education consultants, 174 educators ( $59 \%$ response rate); 71 clinical nurse educators who work with new graduates ( $57 \%$ response rate); and 50 education consultants, who are hired by BONs and approve nursing programs ( $81 \%$ response rate), completed both rounds of the study.

Results from the second round of the Delphi analysis found excellent agreement, and relatively little dispersion of ratings of importance (Table 4). Percent agreement ranged from $78 \%$ to $100 \%$. None of the items had a median rating below 3.00 (important). All of the interquartile ranges (IQRs) were either zero or one. These results met the criteria established for adequate agreement with percent agreement above $67 \%$ and all IQR's at one or below.

\section{TABLE 4}

\section{Agreement With Regulatory Quality Indicators Among Participants in the Second Round of the Delphi Analysis ${ }^{a}$}

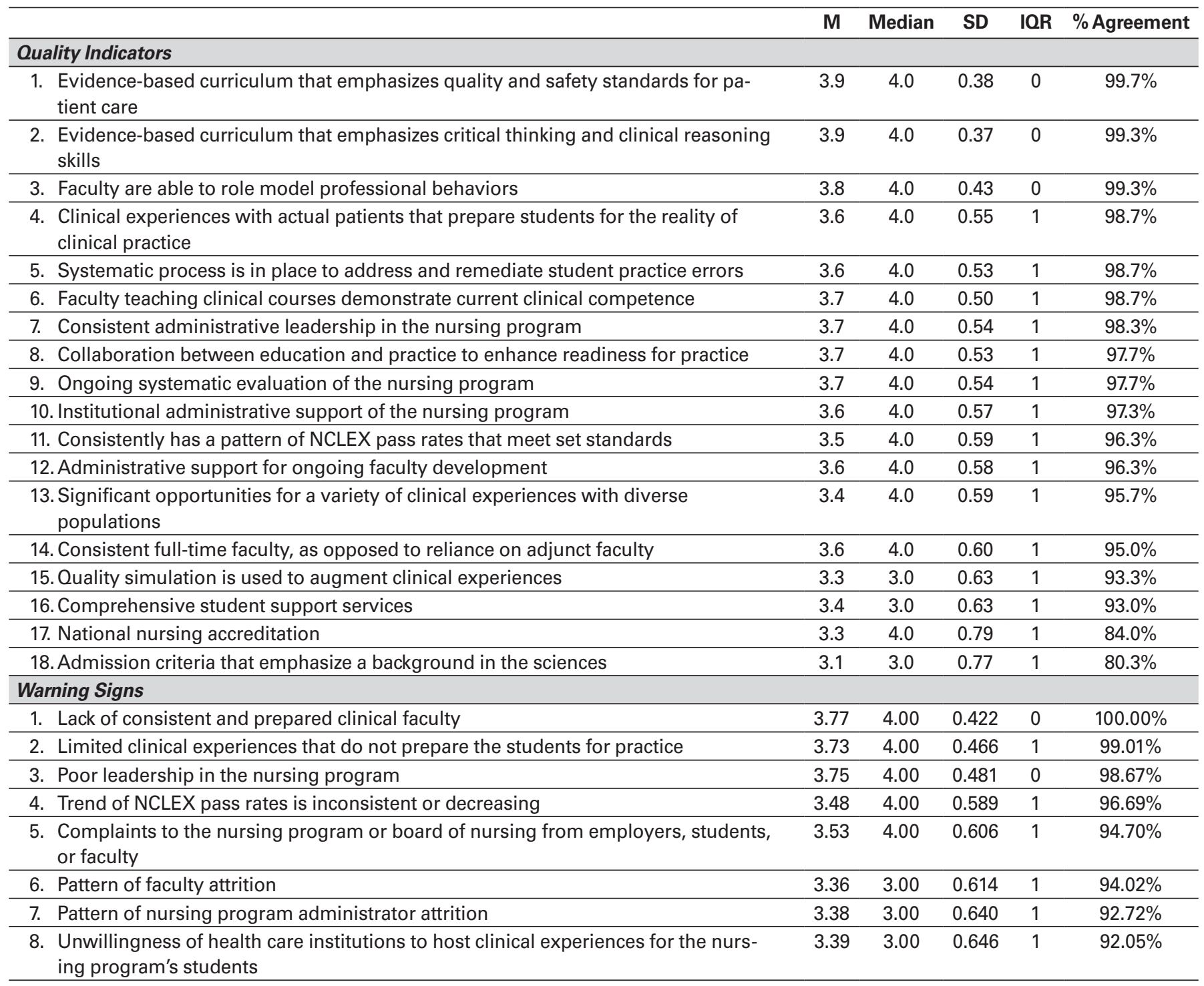




\section{Agreement With Regulatory Quality Indicators Among Participants in the Second Round of the Delphi Analysisa (continued)}

\begin{tabular}{|c|c|c|c|c|c|}
\hline & M & Median & SD & IQR & $\%$ Agreement \\
\hline 9. Pattern of student attrition & 3.11 & 3.00 & 0.645 & 1 & $85.05 \%$ \\
\hline 10. Curriculum is based on "teaching to the NCLEX" & 3.19 & 3.00 & 0.740 & 1 & $81.73 \%$ \\
\hline 11. Over-reliance on simulation to replace clinical experiences with actual patients & 3.08 & 3.00 & 0.766 & 1 & $80.13 \%$ \\
\hline \multicolumn{6}{|l|}{ Performance Outcome Measures } \\
\hline 1. NCLEX pass rates of the nursing program & 3.46 & 3.00 & 0.558 & 1 & $97.67 \%$ \\
\hline 2. Relationship the nursing program has with its clinical partners & 3.50 & 4.00 & 0.559 & 1 & $97.00 \%$ \\
\hline 5. Graduates' satisfaction with the nursing program & 3.04 & 3.00 & 0.611 & 0 & $85.38 \%$ \\
\hline 6. Graduation rates of students in the nursing program & 3.04 & 3.00 & 0.671 & 0 & $80.40 \%$ \\
\hline $\begin{array}{l}\text { 7. Consistency of graduate employment rates with regional data on nurse employ- } \\
\text { ment rates }\end{array}$ & 3.04 & 3.00 & 0.681 & 1 & $79.33 \%$ \\
\hline 8. History of board of nursing discipline with the graduates of the nursing program & 3.08 & 3.00 & 0.816 & 1 & $78.00 \%$ \\
\hline
\end{tabular}

There were some statistical differences between the clinical nurse educators, academic nurse educators, and educational consultants on mean importance for 15 of the 37 characteristics. Most of these findings were because the clinical nurse educators rated items as more or less important than the other two groups. For only one item was the mean score for the differing group below 2.90. This was for the item stating, "Admission criteria that emphasize a background in the sciences," and even in this case, the clinical nurse educators rated the item as 2.83 in importance, which was still in the "important" range (from 2.5 to 3.5 ) of the Likert scale.

\section{Discussion}

This Delphi study identified 18 quality indicators (characteristics of nursing programs that graduate safe and competent students), 11 warning signs when nursing programs begin to fall below standards, and eight performance outcomes nursing regulatory bodies could measure. The quality indicators fall into the following categories: (a) school leadership and faculty support, (b) consistent and competent faculty, (c) providing quality, hands-on clinical experiences with meaningful collaboration with clinical partners, and (d) having an evidence-based curriculum emphasizing quality and safety and critical thinking/clinical reasoning. While the warning signs are similar to the quality indicators (only the opposite), there are some additional intriguing ones. There were few surprises with the performance outcomes (i.e, NCLEX pass rates, graduation rates, employment rates, etc.), although there were a few that are new.

\section{Quality Indicators}

While many of the quality indicators identified are supported by the literature, this national Delphi study lends further credence to the previous findings. Additionally, under each category are some possible indicators that could be used by regulators and educators when evaluating nursing programs. The general category of leadership and faculty support was identified (Table 4, quality indicators 3, 6, 7, 10, and 12). Hooper \& Ayars (2017), in their observations when approving nursing programs in Texas, found faculty development is an important factor for quality programs. Nurse regulators in Illinois (Libner \& Kubala, 2017) found administrative support to be an essential quality indicator. Alexander (2019) reports on U.S. nursing regulatory bodies' observations related to program approval with consistency in program directors being paramount.

There is also support in the literature for admission criteria emphasizing the sciences (Benner et al., 2010) and for more rigorous admission policies (Alexander, 2019); ongoing systematic evaluation plan (Hooper \& Ayars, 2017; Oermann, 2017); requiring national nursing accreditation (Hooper \& Thomas, 2014; Jones et al., 2012; Spector et al., 2018); consistent pattern of licensure pass rates (College of Nurses of Ontario, 2018; Hooper \& Ayars, 2017; Libner \& Kubala, 2017); and that the program has a systematic process in place to address and remediate student practice errors (College of Nurses of Ontario, 2018). However, it should be noted that much of this evidence is observational.

There is a higher order of evidence for faculty ratios and qualifications* (Table 4, quality indicators 3,6, and 14). Odom-Maryon et al. (2018) found a statistically significant relationship between full-time faculty ratio and NCLEX pass rates. Libner \& Kubala (2017),

\footnotetext{
* The highest level of evidence is a randomized controlled trial, followed by a quasi-experimental study, a nonexperimental study, expert opinion, and lastly experiential and nonresearch evidence (Dang \& Dearholt, 2017).
} 
based on their observations regulating nursing programs, found that a focus on appropriate full-time faculty ratios was important when remediating nursing programs that were falling below state standards.

Related to the curriculum, the Delphi participants strongly agreed on an evidence-based curriculum that emphasizes critical thinking and clinical reasoning skills, as well as one that emphasizes quality and safety standards for patient care (Table 4, quality indicators 1 and 2). Odom-Maryon et al. (2018) did not find any curricular factors to be related to NCLEX pass rates. The evidence supporting clinical reasoning as a quality indicator is strong. Benner et al. (2010) in their mixed-methods study of nine prelicensure RN nursing programs (all levels) with excellent reputations for teaching and learning, concluded that to shift to integrating clinical experience into the classroom, faculty should place more emphasis on clinical reasoning. Others have provided evidence to support clinical reasoning as a quality indicator (Candela \& Bowles, 2008; Cantlay et al., 2017; Gonzalez, 2018; Kavanagh \& Szweda, 2017; Killam et al., 2011; Pitt et al., 2012; Rusch et al., 2019). The evidence supporting quality and safety education as a quality indicator is supported by the national initiative QSEN (Cronenwett et al., 2007; QSEN, 2019), which is being integrated in undergraduate nursing education.

The Delphi participants identified four indicators for quality clinical experiences in the nursing program (Table 4, quality indicators 4, 8, 13, and 15). Benner et al. (2010), in their national study of nursing education, highlighted the importance of quality, hands-on clinical experiences as being a strength of the nursing programs in their study. Candela and Bowles (2008) and El Haddad et al. (2017) both called for more hours in clinical experiences, although there have been no studies linking increased numbers of clinical hours to improved educational outcomes. The evidence does, however, support clinical experiences with actual patients that mirror the reality of practice and opportunities for a variety of clinical experiences (Beauvais et al., 2017; Benner et al., 2010; Berkow et al., 2008; Kavanagh \& Swezda, 2017; NCSBN, 2006; Rusch et al., 2019), as well as the quality of simulation (Hayden et al., 2014). Similarly, there is much support in the literature for a more meaningful collaboration between practice and education (Beauvais et al., 2017; Boston-Fleischhauer, 2019; Granger et al., 2012; El Haddad et al., 2017; Kavanagh \& Swezda, 2017; Rusch et al., 2019). Specifically, Boston-Fleischhauer (2019) calls for practice to become more innovative in clinical experience, planning for more opportunities in primary and ambulatory care settings, and thus preparing new graduates for cross-continuum practice of the future.

\section{Warning Signs}

Some of the warning signs the participants identified were the opposite of the quality indicators (Table 4, warning signs 1, 2, 6, 7, 9, and 10). However, participants identified specific ones, such as an unwillingness for the healthcare institutions to host clinical experiences. If an institution hosts other programs, but refuses one program, it likely is a problem with that program. The literature only alludes to this problem (Hooper \& Ayars, 2017), where regulators observe programs are beginning to fall below standards when they are unable to acquire settings for clinical experiences.

Complaints to the nursing regulatory bodies were also identified as a warning sign, which is supported by Alexander (2019) in an editorial reporting on observations from U.S. nursing regulatory bodies when nursing programs are beginning to fall below standards. The Delphi participants identified the curriculum being heavily based on the NCLEX as a warning sign, which also has been addressed in the nursing literature as a problem (Candela \& Bowles, 2008; Kavanagh \& Swzeda, 2017), as well as in non-nursing literature where licensure examinations are used (Barrett et al., 2016).

Additionally, an interesting warning sign was identified that has not been reported in the literature: over-reliance on simulation to replace clinical experiences with actual patients. This item could be affected by a number of intervening variables, such as the program has a lack of sufficient hands-on clinical experiences or it is increasing its simulation percentage without adhering to accepted simulation guidelines (Alexander et al., 2015).

\section{Performance metrics}

The participants were asked to identify outcomes that nursing regulatory bodies could measure. There were a few new ideas, although some of the items addressed those metrics that are already being used and have little evidence to support their being related to the quality of the nursing programs, such as NCLEX pass rates (Bernier et al., 2005; Foreman, 2017; Giddens, 2009; O'Lynn, 2017; Taylor et al., 2014), employment rates (Ferrante, 2017; NASEM, 2016, pp. 57-80), and graduation rates (Cook \& Hartle, 2011; NASEM, 2016). History of the U.S. nursing regulatory body's discipline with the graduates was another metric cited by the participants; however, there would be many intervening variables, such as the practice environment.

Two other metrics identified were the graduate's satisfaction with the nursing program and employer satisfaction with the graduate. Although some healthcare accreditors evaluate these metrics, nursing accreditors report that these data are often incomplete and difficult for programs to obtain. Two outcomes were reported that have not been reported in the literature: (1) the relationship the nursing program has with its clinical partners, and (2) the graduates' preparedness to practice for an interprofessional environment. These outcomes relate to the quality of clinical experiences, which was identified as an important quality indicator. 


\section{Achieving Consensus}

We reached consensus on two rounds with this Delphi study. The piloting of the questions was very important for ensuring the questions were understood uniformly across our sample. We piloted the survey to all three groups in our sample and made many revisions based on the feedback.

Some of the educators and education consultants may have resorted to metrics they commonly use related to either the accreditation or regulatory standards. We particularly saw that with the outcomes that were identified. This likely was not a major factor because the clinical nurse educators, who work with new graduates in practice, are not tied to the national accreditation standards or to state requirements. Therefore, they were more apt to come up with innovative factors that have not been used when assessing programs. Some ideas, not previously cited, did come from the practice educators, and those were then selected as important or very important by the educators and regulators.

\section{Limitations}

While these quality indicators, warning signs, and outcomes were identified by experts, it should be noted the metrics are the opinions of experts in the field, which is the lowest level of evidence. Additionally, while our response rate across the two rounds was good (61\% overall), a 70\% response rate is recommended by some researchers (Keeney et al., 2011). Currently, however, no specific guidelines exist for acceptable response rates for Delphi studies (Keeney et al., 2011), and reported response rates range from 8\% to $100 \%$ in Delphi studies. The larger the number of participants, the lower the expected response rate (Keeney et al., 2011). Our response rate, therefore, was acceptable given our large sample, and it probably benefitted by our sending out reminders every 2 days.

\section{Conclusions}

NCSBN conducted this Delphi study to learn about expert consensus of quality indicators, warning signs, and performance outcomes. The diverse group of educators, regulators, and clinical educators who work with new graduates agreed on 18 quality indicators, 11 warning signs, and eight outcome measures. While this study lends more support to those metrics that have already been studied, some newer ones have also been identified (such as collecting evidence on the relationship the nursing program has with the facilities they use for clinical experiences or the graduates' preparedness to work in an interprofessional environment).

Some highlights of this study are that we used three separate methods of qualitative analysis (content analysis done by hand as well as verifying the findings with NVivo and R [Latent Dirichlet Allocation] software), thereby providing a comprehensive and reliable list of quality indicators, warning signs, and performance outcomes. Additionally, by including regulators (education consultants), educators, and those who work with new graduates in practice, our experts provided diverse perspectives and therefore enhanced the breadth of findings.

\section{Acknowledgment}

The researchers would like to acknowledge Lou Fogg, PhD, Associate Professor in the Department of Community, Systems and Mental Health Nursing, at Rush College of Nursing in Chicago, for his direction and mentorship in conducting this study and his expertise in statistically analyzing the results. 


\section{A Quantitative Analysis of 5 years of BONs Annual Report Documents}

This second national study to identify evidence-based quality indicators, warning signs, and performance outcomes is a quantitative analysis examining 5 years' worth of data from BON annual reports. Specifically, we aimed to answer the following research questions:

- What nursing education program performance indicators are associated with full approval of a prelicensure nursing education program?

- What additional factors exist that are associated with prelicensure nursing programs that have lost full program approval?

In a post hoc analysis, in order to uncover all the possible evidence, we asked the same questions, using $80 \%$ or higher NCLEX pass rates as the outcome.

\section{Methods}

This is a quantitative retrospective cohort study examining 5 years' worth of data (2012-2017) from U.S. BONs' annual reports to identify QIs and thereby systematically evaluate nursing education program performance. All 55 U.S. BONs that approve nursing programs, as well as the Board of Regents in New York and the Mississippi Institutions of Higher Learning, were invited to participate. In total, 43 U.S. BONs, including one U.S. territory and geographically diverse states of all sizes and demographics (Figure 1), provided 11,378 annual report documents for inclusion in the study. Institutional review board approval was obtained from the American Institutes for Research (AIR) because they assisted with collecting the data.

\section{FIGURE 1}

\section{Geographic Representation of U.S. Boards of Nursing That Participated in the Study}

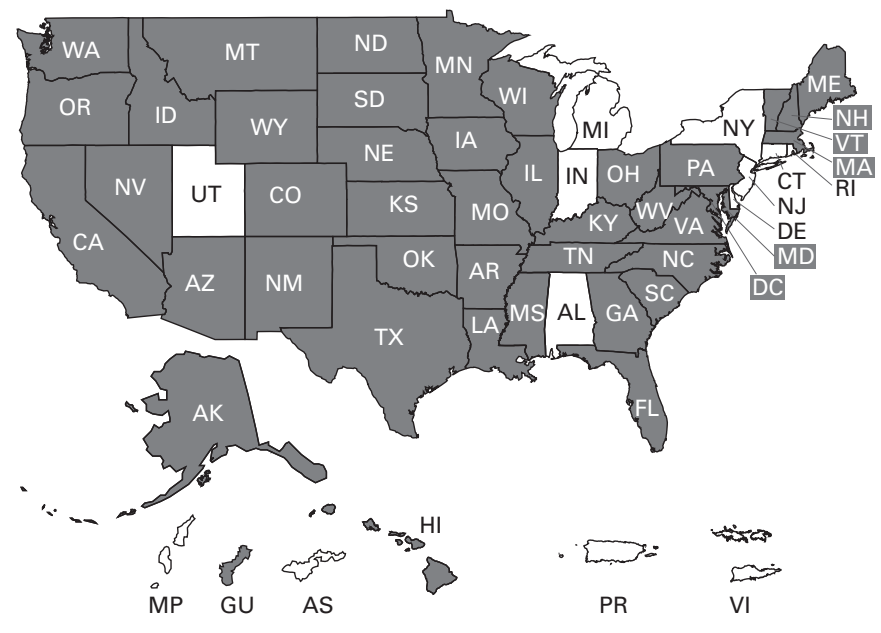

Data submitted for analysis

\section{Data Collection}

NCSBN staff sent a detailed request to the U.S. BONs that approve nursing programs in February 2018, and a webinar for the BONs was held on February 20, 2018, to answer any questions and provide more information. Annual report and site visit data were requested for the academic years of 2012-2013, 2013-2014, 2014-2015, 2015-2016, and 2016-2017 from all BONs. Data submissions began after the webinar with an April 15, 2018 deadline for data collection. Many BONs needed permission from other entities or their attorneys before submitting their data. Some BONs requested NCSBN send a request to their state agencies. As a result, many BONs could not meet the April 15 deadline, so it was extended to September 24, 2018.

Because of the large quantity of submitted data, an outside vendor, AIR, collected it on a secure database. Each state and territory had its own password-protected link for sending the data. In a few cases, the BONs sent in boxes of their documents for NCSBN or AIR to scan and enter into the database. When all the data were collected, AIR transferred the information to a secure database at NCSBN for data analysis and storage.

\section{Variables}

More than 40 variables were reviewed to determine initial eligibility for analysis. Of the more than 40 variables, 25 factors had sufficient sample size for inclusion (a priori threshold of $\geq 1,000$ records). Upon further review, 17 variables were selected for the study based on a range of criteria, including valid response values, sufficiently common or similar tracking procedures across boards, etc. Still, these variables presented in varying levels of completeness (some factors had only $\leq 5 \%$ missing data, others had as much as $\geq 50 \%$ ). Valid $N$ totals 
provide important context when interpreting the results presented in the accompanying descriptive table. Thus, each median estimate and proportion is reported only out of the total number of program entries for which the information could be verified.

Extensive recoding was also applied to a majority of the 17 variables given the disparate means of data collection and coding across all participating BONs. Several quality assurance measures were implemented to ensure accuracy, including redundant coding procedures and substantial peer review. All variable transformations and recode parameters are specified below.

\section{Student Age}

Student age was initially tracked as a multi-level ordinal variable. The proportion of enrolled students was reported for each of the following age categories, in years: (a) 17-20, (b) 21-25, (c) 26-30, (d) 31-40, (e) 41-50, (f) 51-60, and (g) $\geq 61$. Initial steps were taken to validate the original tracking by ensuring that no single cell value fell outside a predetermined maximum acceptable range, 0.99-1.01, to account for rounding error. Any record that did not meet this eligibility criterion was reviewed and, if it could not be reconciled, was omitted. In addition, to facilitate further modeling, a single response for each program record was selected. The age category that a majority or plurality (if no majority existed) of students fell was chosen for analysis. Still, due to low observed cell counts, each band was further collapsed for analysis until only two age categories remained with sufficient numbers for modeling (17-25 and $\geq 26$ ).

\section{Student Race}

Student race was initially tracked as a multi-level categorical variable. The proportion of enrolled students was reported or each of the following categories: (a) Asian, Black, (b) Caucasian, (c) Hispanic, (d) Native American, and (e) Native Hawaiian-Pacific Islander. Initial steps were taken to validate the original tracking by ensuring that no single cell value fell outside a predetermined maximum acceptable range, 0.99-1.01, to account for rounding error. Any record that did not meet this eligibility criterion was reviewed and, if it could not be reconciled, was omitted. In addition, to facilitate further modeling, a single response for each program record was selected to indicate a plurality of Caucasian students $(\geq 40 \%)$.

\section{Program Director Credentials}

Program director credentials were initially tracked as a multi-level categorical variable, which included BA, BS, MSN, DNP, PhD, and various other fields (master of education [MEd], doctorate of education [EdD], "non-nursing master's", etc.). To facilitate the analysis, broader "baccalaureate" and "other graduate" fields were created to further collapse otherwise related fields with low observed cell counts. The bulk of the other graduate field included MEd and EdD recipients.

\section{Faculty Qualifications}

Faculty qualifications were initially tracked as a multi-level categorical variable. For each of the following categories, the proportion of faculty members holding these education credentials was reported: (a) associate degree, (b) baccalaureate nursing, (c) baccalaureate nonnursing, (d) master's nursing, (e) master's non-nursing, (f) DNP, (g) PhD nursing, and (h) PhD non-nursing. Initial steps were taken to validate the original tracking by ensuring that no single row fell outside a predetermined maximum acceptable range, 0.99-1.01, to account for rounding error. Any record that did not meet this eligibility criterion was reviewed and, if it could not be reconciled, was omitted. In addition, to facilitate further modeling, a single response for each program record was selected. The binned category in which a majority or plurality (if no majority) of faculty members fell was chosen for analysis. Due to low observed cell counts, each band was further collapsed for analysis until only two categories remained: "baccalaureate or lower" and "master's or higher".

\section{Proportion of Full-Time Faculty}

The proportion of full-time faculty was originally scored on both a $0-1$ and $0-100$ scale. When possible, valid cell values were rescaled (e.g., 34 to 0.34 ) to a $0-1$ scale. Steps were then taken to validate the original tracking by ensuring that no single cell value fell outside a predetermined acceptable range, 0 to 0.99-1.01 (accounting for rounding error). Non-possible values (e.g., > 101) were reviewed and, if they could not be reconciled, were recoded as missing. Given how skewed the raw scores remained, the variable was further collapsed into quartiles.

\section{Student-to-Clinical Faculty Ratio}

Raw scores were highly skewed and grouped around a single common value (8); thus, the variable was collapsed into a binary predictor (e.g. $\leq 8$ vs. $\geq 9$ ).

\section{Program Age}

Raw scores were highly skewed; thus, the variable was further collapsed into quartiles. 
Separate variables were present for total student enrollment and maximum program capacity. Most of the programs did not have data for both variables. The 28 programs with data for both variables were analyzed, and it was determined that the data were sufficiently comparable and could be combined into a single variable. For the 28 programs containing both values, the data on total enrollment was used. Any record containing a zero-cell value for both criteria was recoded as missing. Given how skewed the raw scores were, the data were then binned into quartiles.

\section{Estimated Graduation Rate}

Raw scores were highly skewed; thus, the variable was collapsed into quartiles.

\section{NCLEX Pass Rates}

NCLEX pass rates were originally tracked separately from all other data elements. As a result, this information was matched to program data for analysis using unique program codes as the primary key. As $\geq 80 \%$ is currently the passing standard used by the majority of U.S. BONs, as well as by the national nursing accreditors, that cut point was selected for analysis purposes.

\section{Number of Program Sites}

Given low observed cell counts for higher raw values and the truncated nature of the range, this variable was further collapsed into a binary predictor (e.g., 1 vs. $\geq 2$ ).

\section{Program Status}

This variable was not originally embedded in the supporting program documentation. Supplementary secondary searches were conducted to ascertain if the programs under review were either public, private nonprofit, or private for-profit.

\section{Statistical Methods}

A descriptive summary of the data included frequencies and proportions for all categorical characteristics, whereas continuous variables were reported using median and IQR estimates (Table 5). Generalized linear mixed-effects models were used to estimate the odds of full approval as a function of univariable faculty demographic and program characteristics. Post-hoc analyses assessing NCLEX pass rates at or above $80 \%$ were also investigated. In both instances, full multivariable modeling was pursued only if two criteria were met: (1) specific evidence-driven hypotheses guiding the inquiry and (2) sufficiently robust model samples. In all models, a binomial distribution was specified for the outcome, and logit links were used to estimate the odds ratio for each predictor. To account for the longitudinal structure of the data, random intercepts were allowed for each program and state to account for within-program correlation and the possible influence of common state-level regulations. An alpha error rate of $p \leq .05$ was considered statistically significant and all analyses were conducted using SAS 9.4 .

\section{Results}

A total of 11,378 annual reports from the 43 BONs that participated in the study were analyzed by researchers at NCSBN.

\section{Program Demographics Characteristics}

The median program age in the sample was 23 years (IQR $=7-33$ years) with a median enrollment capacity of approximately 66 students $(I Q R=32-123)$. Summary outcome measures were strong, with a median graduation rate of 70\% (IQR = 51-85) and NCLEX pass rate of $87 \%$ (IQR $=77-94)$. Approximately $90 \%$ of all programs $(n=9,168)$ received full program approval during the study period.

A majority of the programs included in the analysis reported more traditional (17-25 years old; $n=497,61.7 \%)$ and largely Caucasian ( $\geq 40 \%$ Caucasian; $n=1,621,87.3 \%$ ) student populations. Approximately $90 \%$ of programs had directors with evidence of graduate training in place, led by $\operatorname{MSN}(n=1,128,46.2 \%)$ and $\mathrm{PhD}(n=495,20.3 \%)$ degrees. Similarly, nearly three-quarters of programs $(n=1,115,72.8 \%)$ also reported a majority or, at minimum, a plurality of faculty with an academic credential of MSN or higher.

The median rate of full-time faculty across all programs was 50\% (IQR $=34-75 \%$ ). Between $30 \%$ and $40 \%$ of all programs reported a student-to-clinical faculty ratio of 8 , so data were binned accordingly, resulting in a near even split between those programs with a ratio $\leq 8(n=682,46.8 \%)$ and those with $\geq 9(n=776,53.2 \%)$. A majority of the programs were accredited $(n=4,738,68.4 \%)$.

Overall, there were fairly even distributions of programs by learning modality (in-person $n=1,004,43.9 \%$; hybrid $n=750$, $32.8 \%$; online $n=534,23.3 \%$ ), as well as degree type (LPN/LVN $n=2,556,42.7 \%$; ADN $n=2,077,34.7 \%$; BSN $n=1,354,22.6 \%$ ). Most programs in the sample were public institutions $(n=5,878,61.7 \%)$, and the median number of program directors was one, with a range of one to seven. 


\section{TABLE 5}

\section{Program Characteristics and Student Demographics as Provided in Annual Report Documents}

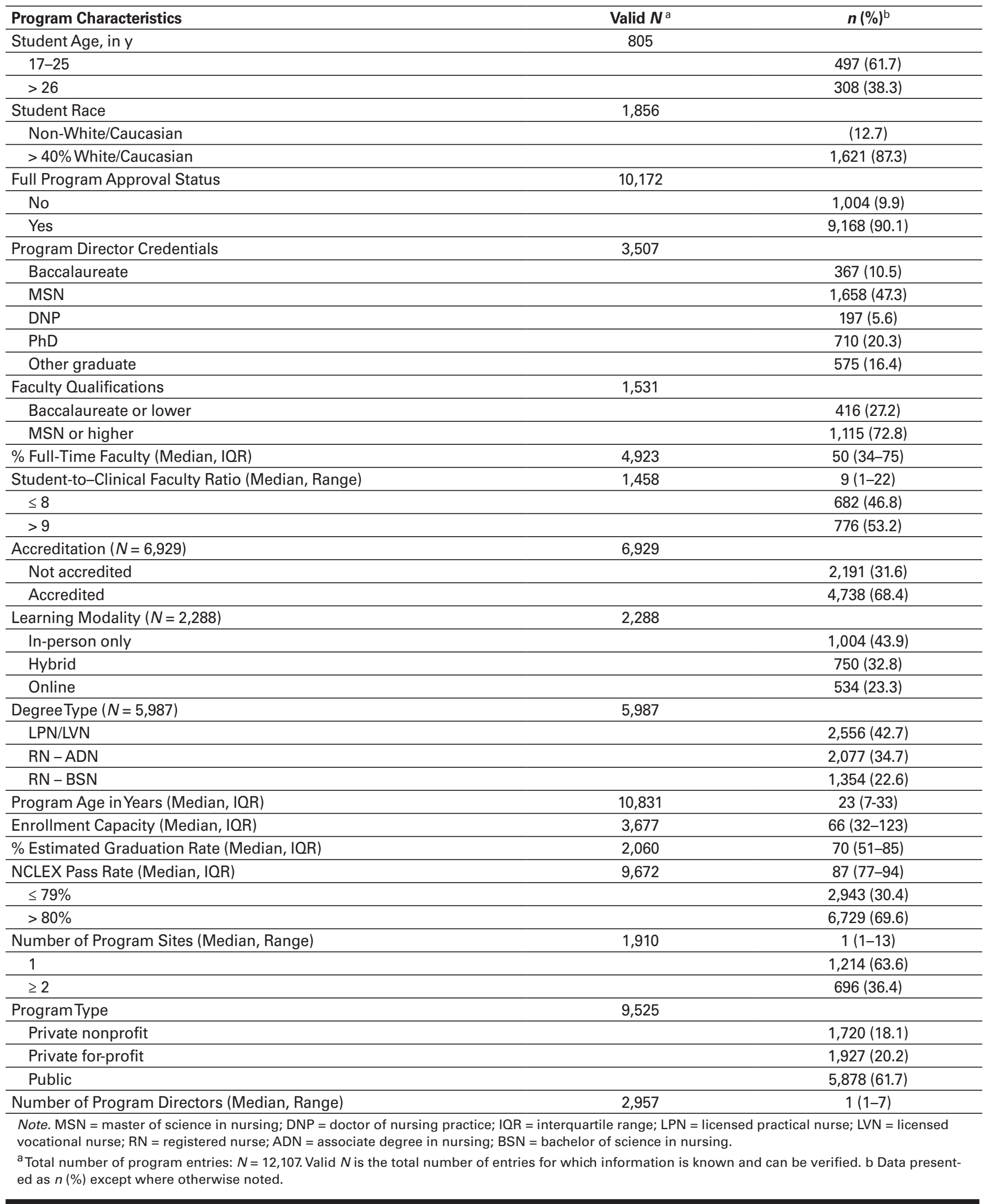




\section{Faculty Characteristics Related to Full Approval}

Programs with a majority of graduate-educated faculty were marginally more likely (odds ratio $[\mathrm{OR}]=1.82,95 \% \mathrm{CI}=0.89-3.73$, $p=.10)$ to receive full approval compared to programs with a majority of faculty with a bachelor's or lower degree. Similarly, programs with a larger proportion of full-time faculty were marginally more likely to receive full approval $(p=.08)($ Table 6$)$.

After adjusting for degree type, programs with a majority graduate educated faculty were found to be 2.80 times more likely (95\% $\mathrm{CI}=1.22-6.39, p=.003$ ) to receive full approval compared to programs with a majority of bachelor's or lower educated faculty (Table 6).

\section{TABLE 6}

\section{Univariable Binary Logistic Regression Results Examining Faculty Characteristics Related to Program Full Approval Status}

\begin{tabular}{|c|c|c|c|}
\hline Faculty Characteristics & $n$ & OR $(95 \% \mathrm{Cl})$ & $p$ \\
\hline Program Director Credentials & 3,353 & & .39 \\
\hline Baccalaureate & & $1.63(0.89-2.99)$ & .11 \\
\hline MSN (Ref) & & - & \\
\hline $\mathrm{PhD}$ & & $1.19(0.78-1.83)$ & .42 \\
\hline Other graduate & & $0.88(0.56-1.37)$ & .56 \\
\hline MSN or higher & & $1.82(0.89-3.73)$ & .10 \\
\hline \% Full-Time Faculty & 4,353 & & .08 \\
\hline$\leq 34$ (Ref) & & - & \\
\hline $35-50$ & & $1.46(1.06-2.01)$ & .02 \\
\hline $51-75$ & & $1.46(1.03-2.06)$ & .03 \\
\hline$>9$ & & $1.51(0.76-2.99)$ & .24 \\
\hline
\end{tabular}

\section{Program Characteristics Related to Full Approval}

Programs that are accredited by a national nursing accreditation body were 2.03 times $(95 \% \mathrm{CI}=1.44-2.87)$ more likely to receive full approval compared to non-accredited programs $(p<.001)$ (Table 7).

Online programs were also $55 \%(\mathrm{OR}=0.45,95 \% \mathrm{CI}=0.27-0.73, p=.001)$ and $51 \%(\mathrm{OR}=0.49,95 \% \mathrm{CI}=0.27-0.73, p=.001)$ less likely to receive full approval compared to in-person and hybrid programs, respectively.

Longer standing and larger enrollment/capacity programs were both more likely to receive full approval ( $\mathrm{p}<.001)$ compared to new programs (both $\mathrm{p}<.001)$. Similarly, programs with more than one site were $70 \%$ more likely $(\mathrm{OR}=1.70,95 \% \mathrm{CI}=1.04-2.77)$ to receive full approval compared to programs with only a single site $(p=.03)$.

Private for-profit programs were $71 \%(\mathrm{OR}=0.29,95 \% \mathrm{CI}=0.22-0.38, p<.001)$ less likely to receive full approval compared to public programs and $60 \%(\mathrm{OR}=0.40,95 \% \mathrm{CI}=0.28-0.56, \mathrm{p}<.001)$ less likely to receive full approval compared to private nonprofit programs. Private nonprofit programs were also $27 \%(\mathrm{OR}=0.73,95 \% \mathrm{CI}=0.55-0.96, p=.03)$ less likely to receive full approval compared to public programs. Programs with NCLEX pass rates at or above $80 \%$ were 5.34 times more likely $(95 \% \mathrm{CI}=4.36-6.54)$ to receive full approval compared to programs that fell below that passing threshold $(p<.001)$.

While less pronounced, we also observed several other noteworthy trends. Those included an inverse relationship between higher rates of program director attrition and full program approval $(\mathrm{OR}=0.86,95 \% \mathrm{CI}=0.69-1.07, p=.17)$. Similarly, there was an observed trend of BSN programs receiving full program approval at higher rates than both $\mathrm{LPN} / \mathrm{LVN}(\mathrm{OR}=0.69,95 \% \mathrm{CI}=0.46-1.04, p=0.08)$ and $\mathrm{ADN}(\mathrm{OR}=0.67,95 \% \mathrm{CI}=0.44-1.01, p=.06)$ programs. These relationships by degree type (LPN/LVN vs. BSN - adjusted OR $[\mathrm{AOR}]=0.83,95 \% \mathrm{CI}=0.54-1.29, p=.40$ and $\mathrm{ADN}$ vs. $\mathrm{BSN}-\mathrm{AOR}=0.71,95 \% \mathrm{CI}=0.48-1.07, p=.10)$ held even after controlling for national accreditation. 


\section{TABLE 7}

\section{Univariable Binary Logistic Regression Results Examining Program Characteristics Related to Program Full Approval Status}

\begin{tabular}{|c|c|c|c|}
\hline Program Characteristics & $n$ & OR $(95 \% \mathrm{Cl})$ & $p$ \\
\hline Accreditation & 5,913 & & \\
\hline Not accredited (Ref) & & - & \\
\hline Accredited & & $2.03(1.44-2.87)$ & $<.001$ \\
\hline Learning Modality & 2,156 & & .01 \\
\hline In-person only (Ref) & & - & \\
\hline Hybrid & & $0.92(0.62-1.35)$ & .66 \\
\hline LPN/LVN & & $0.69(0.46-1.04)$ & .08 \\
\hline $\mathrm{RN}-\mathrm{ADN}$ & & $0.67(0.44-1.01)$ & .06 \\
\hline $\mathrm{RN}-\mathrm{BSN}$ (Ref) & & - & \\
\hline Program Age, in y & 9,224 & & $<.001$ \\
\hline$\leq 7$ (Ref) & & - & \\
\hline Enrollment Capacity & 3,371 & & .01 \\
\hline $1-32$ & & $0.39(0.22-0.68)$ & $<.001$ \\
\hline $33-66$ & & $0.66(0.38-1.14)$ & .14 \\
\hline $67-123$ & & $0.58(0.34-0.99)$ & .04 \\
\hline$>123($ Ref) & & - & \\
\hline Estimated Graduation Rate & 1,466 & & .62 \\
\hline$\leq 50 \%(\operatorname{Ref})$ & & - & \\
\hline $51 \%-70 \%$ & & $0.84(0.48-1.46)$ & .54 \\
\hline $71 \%-85 \%$ & & $1.06(0.58-1.93)$ & .86 \\
\hline$>85 \%+$ & & $1.23(0.67-2.28)$ & .51 \\
\hline Private nonprofit & & $0.73(0.55-0.96)$ & .03 \\
\hline Private for-profit & & $0.29(0.22-0.38)$ & $<.001$ \\
\hline Public (Ref) & & - & \\
\hline Number of Program Directors & 2,879 & $0.86(0.69-1.07)$ & .17 \\
\hline
\end{tabular}

\section{Relationship Between NCLEX Pass Rates and Faculty Characteristics}

The relationship between $\geq 80 \%$ NCLEX pass rates and faculty characteristics is illustrated in Table 8 . This was a post hoc analysis carried out to uncover all possible faculty characteristics related to program outcomes.

Programs whose director had a PhD were marginally more likely to have NCLEX pass rates $\geq 80 \%(p=.08)$. In addition, there was a trend toward programs with a greater proportion of full-time faculty having NCLEX pass rates $\geq 80 \%$ compared to programs with a smaller proportion full-time faculty $(p=.11)$. 
TABLE 8

\section{Univariable Binary Logistic Regression Results Examining Faculty Characteristics Related to NCLEX Pass Rates}

\begin{tabular}{|c|c|c|c|}
\hline Faculty Characteristics & $n$ & OR $(95 \% \mathrm{Cl})$ & $p$ \\
\hline Program Director Credentials & 2,864 & & .08 \\
\hline Baccalaureate & & $1.12(0.75-1.68)$ & .57 \\
\hline MSN (Ref) & & - & \\
\hline DNP & & $1.35(0.82-2.22)$ & .24 \\
\hline $\mathrm{PhD}$ & & $1.56(1.14-2.13)$ & .01 \\
\hline Other graduate & & $1.21(0.86-1.70)$ & .27 \\
\hline MSN or higher & & $1.26(0.72-2.20)$ & .41 \\
\hline$\%$ Full-Time Faculty & 3,287 & & .11 \\
\hline$\leq 34$ (Ref) & & - & \\
\hline $35-50$ & & $1.24(0.93-1.66)$ & .14 \\
\hline$>9$ & & $0.96(0.60-1.52)$ & .85 \\
\hline
\end{tabular}

\section{Program Characteristics Related to NCLEX Pass Rates}

Hybrid programs were $51 \%(\mathrm{OR}=1.51,95 \% \mathrm{CI}=1.09-2.10, p=.01)$ and $64 \%(\mathrm{OR}=1.64,95 \% \mathrm{CI}=1.03-2.56, p=.03) \mathrm{more}$ likely to have a NCLEX pass rate $\geq 80 \%$ compared to in-person and online programs, respectively (Table 9). ADN programs were $45 \%$ less likely $(\mathrm{OR}=0.55,95 \% \mathrm{CI}=0.39-0.78, p<.001)$ to have an NCLEX pass rate $\geq 80 \%$ of $80 \%$ or above compared to BSN programs. When the outcome was full approval, the BSN programs trended toward (though it was not statistically significant) being more likely to have full approval than ADN or LPN/LVN programs.

As when the outcome was full approval, longer-standing programs were more likely to have a NCLEX pass rate $\geq 80 \%$ of $80 \%$ or above $(p<.001)$ compared to new programs ( $\leq 7$ years).

Also, similar to the outcome of full approval, programs with more than one site were also $50 \%$ more likely $(\mathrm{OR}=1.50,95 \%$ $\mathrm{CI}=1.04-2.16)$ to have a NCLEX pass rate of $\geq 80 \%$ compared to programs with only a single site $(p=.03)$.

Private for-profit programs were $82 \%(\mathrm{OR}=0.18,95 \% \mathrm{CI}=0.15-0.23, p<.001)$ and $73 \%(\mathrm{OR}=0.27,95 \% \mathrm{CI}=0.21-0.36$, $p<.001)$ less likely to have a NCLEX pass rate $\geq 80 \%$ compared to public and private nonprofit programs, respectively. Private nonprofit programs were also $33 \%(\mathrm{OR}=0.67,95 \% \mathrm{CI}=0.54-0.84, p<.001)$ less likely to have a NCLEX pass rate $\geq 80 \%$ compared to public programs. As director attrition increases, programs were $23 \%$ less likely $(\mathrm{OR}=0.77,95 \% \mathrm{CI}=0.66-0.91)$ to have a NCLEX pass rate $\geq 80 \%(p=.002)$.

\section{TABLE 9}

\section{Univariable Binary Logistic Regression Results Examining Program Characteristics Related to NCLEX Pass Rates}

\begin{tabular}{|c|c|c|c|}
\hline Program Characteristics & $n$ & OR $(95 \% \mathrm{Cl})$ & $p$ \\
\hline Accreditation & 5,148 & & \\
\hline Not accredited (Ref) & & - & \\
\hline Accredited & & $1.12(0.89-1.41)$ & .32 \\
\hline Learning Modality & 1,808 & & .01 \\
\hline In-person only (Ref) & & - & \\
\hline Hybrid & & $1.51(1.09-2.10)$ & .01 \\
\hline
\end{tabular}




\section{Univariable Binary Logistic Regression Results Examining Program Characteristics Related \\ to NCLEX Pass Rates (continued)}

\begin{tabular}{|c|c|c|c|}
\hline Program Characteristics & $n$ & OR $(95 \% \mathrm{Cl})$ & $p$ \\
\hline LPN/LVN & & $0.75(0.53-1.06)$ & .11 \\
\hline $\mathrm{RN}-\mathrm{ADN}$ & & $0.55(0.39-0.78)$ & $<.001$ \\
\hline $\mathrm{RN}-\mathrm{BSN}(\operatorname{Ref})$ & & - & \\
\hline$\leq 7$ (Ref) & & - & \\
\hline $8-23$ & & $1.83(1.51-2.21)$ & $<.001$ \\
\hline Enrollment Capacity & 2,221 & & .20 \\
\hline $1-32$ & & $0.97(0.61-1.55)$ & .90 \\
\hline $33-66$ & & $0.73(0.47-1.12)$ & .15 \\
\hline $67-123$ & & $0.69(0.45-1.07)$ & .10 \\
\hline$>123$ (Ref) & & - & \\
\hline $71-85 \%$ & & $1.01(0.67-1.53)$ & .97 \\
\hline$>85 \%$ & & $1.16(0.76-1.77)$ & .50 \\
\hline Number of Program Sites & 1,758 & & \\
\hline 1 (Ref) & & - & \\
\hline$>2$ & & $1.50(1.04-2.16)$ & .03 \\
\hline Program Type & 8,762 & & $<.001$ \\
\hline Private nonprofit & & $0.67(0.54-0.84)$ & $<.001$ \\
\hline Private for-profit & & $0.18(0.15-0.23)$ & $<.001$ \\
\hline Public (Ref) & & - & \\
\hline Number of Program Directors & 2,198 & $0.77(0.66-0.91)$ & .002 \\
\hline
\end{tabular}

\section{Discussion}

A profile of the nursing programs most likely to secure full approval status emerged in the analysis. Specifically, shared characteristics of approved programs included (a) national accreditation, (b) traditional or hybrid modalities, (c) longer-standing programs, (d) higher enrollment capacity, (e) $\geq 80 \%$ or above first-time NCLEX pass rates, (f) multiple program sites, and (g) private nonprofit or public institutions. While not statistically significant, there were some observed trends that may also prove noteworthy for BONs. Related to faculty, programs with a majority of graduate-educated faculty were marginally more likely to receive full approval $(p=.10)$, as were those with a greater proportion of full-time faculty $(p=.08)$. Importantly, adjusting for degree type, programs with a majority graduateeducated faculty were ultimately found to more likely to receive full approval $(p=.003)$. There was also a marginal, inverse relationship between program director turnover and full program approval $(p=.17)$, which underscores the potentially important role of administrative stability. Finally, there was evidence that BSN programs received full approval more frequently than either $\operatorname{LPN} / \operatorname{LVN}(p=0.08)$ or $\operatorname{ADN}$ programs $(p=.06)$.

When using first-time NCLEX pass rates of $\geq 80 \%$ as the outcome, many of the findings associated with full program approval were replicated, though there were a few notable differences. For example, in the post-hoc NCLEX analysis, programs were marginally $(p=.08)$ more likely to have NCLEX pass rates $\geq 80 \%$ when the program director was $\mathrm{PhD}$ educated, as compared to program directors with other graduate and undergraduate credentials. Online programs were significantly less likely to be approved than programs using traditional or hybrid modalities, whereas programs incorporating hybrid learning strategies were significantly more likely to have higher NCLEX pass rates. ADN programs were also significantly less likely to have higher NCLEX pass rates compared to BSN and LPN/LVN programs, as were all programs that experienced greater director attrition ( $>3$ directors in 5 years). In both instances, degree type and program director attrition were only marginally associated with full program approval. By contrast, enrollment capacity was a significant 
finding when examining approval status, but not NCLEX pass rates $(p=.20)$. For both full approval and NCLEX pass rates, the percent of full-time faculty ( $>35 \%)$ was a marginal finding $(p=.08 ; p=.11)$.

This quantitative study found that programs using hybrid-learning modalities were significantly more likely to have $\geq 80 \%$ firsttime NCLEX pass rates. Similarly, a seminal, multi-year USDE meta-analysis of more than 1,000 studies with measured student outcomes found that hybrid (or blended) approaches had significantly better outcomes (Means et al., 2010). A rigorous national study of nursing education characteristics as compared to NCLEX outcomes found the percentage of full-time faculty was a predictor of NCLEX success. Our quantitative study found that trend with both the full approval and NCLEX pass rates outcomes as well (Odom-Maryon et al., 2018).

An interesting finding in two large national studies on NCLEX outcomes related to nursing program characteristics (Odom-Maryon et al., 2018; Pittman et al., 2019), as well as our quantitative study, was that public nursing programs have significantly better outcomes than private nonprofit or private for-profit programs. Both in the Pittman et al. (2019) study and our study, the private for-profit programs had significantly poorer outcomes. What is it about the for-profit programs that puts their students at risk? This finding needs to be studied with more depth in the future. Somewhat related, our study found that long-standing programs with more than one site and with higher capacities have significantly better outcomes.

The evidence for quality clinical experiences and simulation was strong in the Delphi study and literature. Benner et al. (2010), in a seminal mixed-methods, longitudinal study, found that highly performing programs provided quality clinical experiences, emphasizing clinical judgment and reasoning. Similarly, Kavanagh and Szweda (2017), in their national study of more than 5,000 new graduates, found that high-performing nursing programs had competent clinical faculty who focused on the development of clinical judgment. However, these factors were not assessed in our quantitative study as those data are not consistently collected in annual reports and therefore are not available for analysis.

\section{Limitations}

While a high number of annual and site reports were obtained from diverse U.S. BONs, the data collected were not consistent across all BONs. For example, many BONs did not report estimated graduation rates, numbers of hours for clinical experiences, simulation percentages, use of simulation guidelines, etc. Similarly, there were missing or incomplete data for those characteristics the BONs did track. This gap in data significantly limited the extent of the multivariable modeling possible. Guided by specific hypotheses, targeted multivariable models were generated when sufficiently robust model samples could be confirmed. However, full models assessing all potential factors simultaneously were not possible given the current sample limitations.

\section{Conclusion}

This quantitative study of 5-years of BON annual reports provides us with a profile of those nursing programs that meet state approval requirements. Statistically significant characteristics of approved programs and those with $\geq 80 \%$ NCLEX pass rates included (a) national accreditation, (b) traditional or hybrid modalities, (c) long-standing programs, (d) higher enrollment capacity, (e) multiple program sites, (f) private nonprofit or public institutions, (g) program director with a $\mathrm{PhD}$, (h) LPN/LVN and BSN programs (as opposed to ADN programs), and (i) no more than three program directors in 5 years. A marginally significant finding was that programs with more than $35 \%$ full-time faculty had $\geq 80 \%$ first-time NCLEX pass rates and full approval. 


\section{A Qualitative Analysis of 5 years of BONs Site Visit Documents}

A qualitative study of 5 years' worth of BONs' site visit documents was conducted to better understand the qualifiable descriptors of why programs become at risk for failing or do fail. Specifically, we aimed to answer the following research question:

What are the warning signs when programs become at risk for failing or do fail?

\section{Methods}

This qualitative descriptive design blended directed-content analysis techniques to generate the findings for this report. Qualitative descriptive designs are the most basic of all approaches to data analysis and seek to identify and describe a phenomenon that is not well understood (Sandelowski, 2000, 2009). Considering that what leads to program failures in nursing is not well defined, a descriptive approach was the best methodological match. NCSBN and AIR researchers collected the data while external experts in qualitative research analyzed the data.

\section{Document Sample Inclusion and Exclusion Criteria}

The analytical sample provided to the team included 2,853 eligible documents from 40 states (Table 10). For each state, first the number of documents per state was counted. Next, the researchers checked whether files were "readable" (in a compatible file format) according to the MaxQDA software. Documents were then reviewed and sorted according to the inclusion and exclusion criteria, adhering to the principles of best practices of systematic reviews. Documents were included for analysis if they were classified as "site" or "survey" visits.

Exclusion criteria were as follows:

- Self-study reports/plans

- Letters (e.g., letters of intent, approval letters, etc.)

- Addenda

- Current board status at full approval

- State level summaries of any kind

- Action plans and responses

- Duplicate files

- Accreditation documents

- Spreadsheets

- Signature pages

- State BON annual reports.

\section{TABLE 10}

\section{Total Site Visit Documents by State}

\begin{tabular}{lcccc}
\hline State/Board & Total Received & Incompatible File Format & Excluded $^{\text {a }}$ & Total Reviewed $^{\text {In }}$ \\
\hline AK & 3 & 0 & 3 & 0 \\
\hline AR & 207 & 34 & 101 & 72 \\
\hline AZ & 35 & 4 & 20 & 11 \\
\hline CA-RN & 409 & 23 & 44 & 342 \\
\hline CA-VN $^{b}$ & 53 & 2 & 7 & 44 \\
\hline CO & 16 & 0 & 6 & 10 \\
\hline DC & 40 & 0 & 40 & 0 \\
\hline GA & 4 & 0 & 2 & 2 \\
\hline IA & 7 & 0 & 0 & 7 \\
\hline ID & 8 & 3 & 8 & 0 \\
\hline IL & 13 & 2 & 0 & 11 \\
\hline KS & 66 & 10 & 52 & 4 \\
\hline KY & 8 & 0 & 8 & 0 \\
\hline LA-RN & 225 & 13 & 197 & 15 \\
\hline MA & 92 & 0 & 92 & 0 \\
\hline MN & 63 & 9 & 18 & 36 \\
\hline MO & 4 & 3 & 0 & 1 \\
\hline MS & 4 & 0 & 4 & 0 \\
\hline
\end{tabular}




\section{Total Site Visit Documents by State (continued)}

\begin{tabular}{|c|c|c|c|c|}
\hline State/Board & Total Received & Incompatible File Format & Excluded $^{a}$ & Total Reviewed \\
\hline MT & 21 & 0 & 21 & 0 \\
\hline NC & 1 & 0 & 1 & 0 \\
\hline ND & 18 & 3 & 0 & 15 \\
\hline NE & 15 & 2 & 0 & 13 \\
\hline $\mathrm{NH}$ & 14 & 0 & 10 & 4 \\
\hline NM & 22 & 3 & 3 & 16 \\
\hline $\mathrm{OH}$ & 299 & 0 & 0 & 299 \\
\hline OK & 39 & 0 & 0 & 39 \\
\hline OR & 32 & 0 & 4 & 28 \\
\hline SC & 4 & 0 & 4 & 0 \\
\hline SD & 2 & 0 & 0 & 2 \\
\hline TN & 52 & 18 & 0 & 34 \\
\hline$T X$ & 129 & 0 & 2 & 127 \\
\hline$\overline{V A}$ & 69 & 0 & 7 & 62 \\
\hline VT & 15 & 0 & 12 & 3 \\
\hline WA & 354 & 47 & 236 & 71 \\
\hline $\mathrm{Wl}$ & 7 & 0 & 7 & 0 \\
\hline $\mathrm{WV}^{\mathrm{R} N^{\mathrm{d}}}$ & 485 & 13 & 460 & 12 \\
\hline WY & 18 & 5 & 12 & 1 \\
\hline TOTAL & 2,853 & 194 & 1,381 & 1,278 \\
\hline
\end{tabular}

a Documents were not site visit or survey reports.

${ }^{b}$ California has two nursing boards: California Board of Registered Nursing (CA-RN) and California Board of Vocational Nursing and Psychiatric Technicians (CA-VN). Both boards submitted documents.

${ }^{\mathrm{C}}$ Please provide explanation for LA-RN

d Please provide explanation for WV-RN

Of the documentation from 40 states in the sample, nine states had no documents that met the inclusion criteria; therefore, this analysis represents data from 31 states. After the inclusion/exclusion criteria were applied, there were 1,278 site visit reports for all RN and LPN/LVN programs eligible for the analysis. The final step in the process was to determine which reports were for programs that were on probation, under review, or did not have full approval. Only these reports would form the dataset for analysis.

\section{Data Analysis}

Two researchers used MaxQDA qualitative data analysis software to analyze the documents. Coding occurred through content analysis and context analysis. Content analysis is an iterative coding process whereby codes emerge naturally from the data using a specific intent to guide the process (Miller \& Alvarado, 2005). In this case, the intent was issues contributing to low performing schools (poor NCLEX pass rates and approval downgrades). All documents from fully approved programs were randomly reviewed to be sure they didn't have the same issues, and these issues were unique to the low performing schools.

Researchers also used context analysis that considered the geographic location of the school, the state regulatory context (as specified through websites), and whether the school was classified as urban, suburban, rural, or virtual (Miller \& Alvarado, 2005). The team developed a codebook to harmonize their coding (Appendix C). RN and LPN/LVN programs were analyzed separately, and then coding was harmonized and tracked for similarities and distinctions based on entry-level program type.

Figure 2 illustrates how codes emerged during the data analysis process. Researchers tracked the number of codes generated with each document to determine when coding saturation would occur, according to the methods recommended by Hennink et al. (2017). Our process results were similar to those of the study by Hennink et al, which demonstrated that coding saturation occurs between interviews/ data sources nine to 11 and minimal codes generated after interview 16. Ours differed only slightly, with saturation occurring later in the coding process, which may reflect the different reporting formats of the states. Themes and categories emerged iteratively from the coding process, and finalized themes and categories represent consensus agreement by the analysts. 


\section{FIGURE 2}

\section{Number of New Codes Generated by Site Visit Documents}

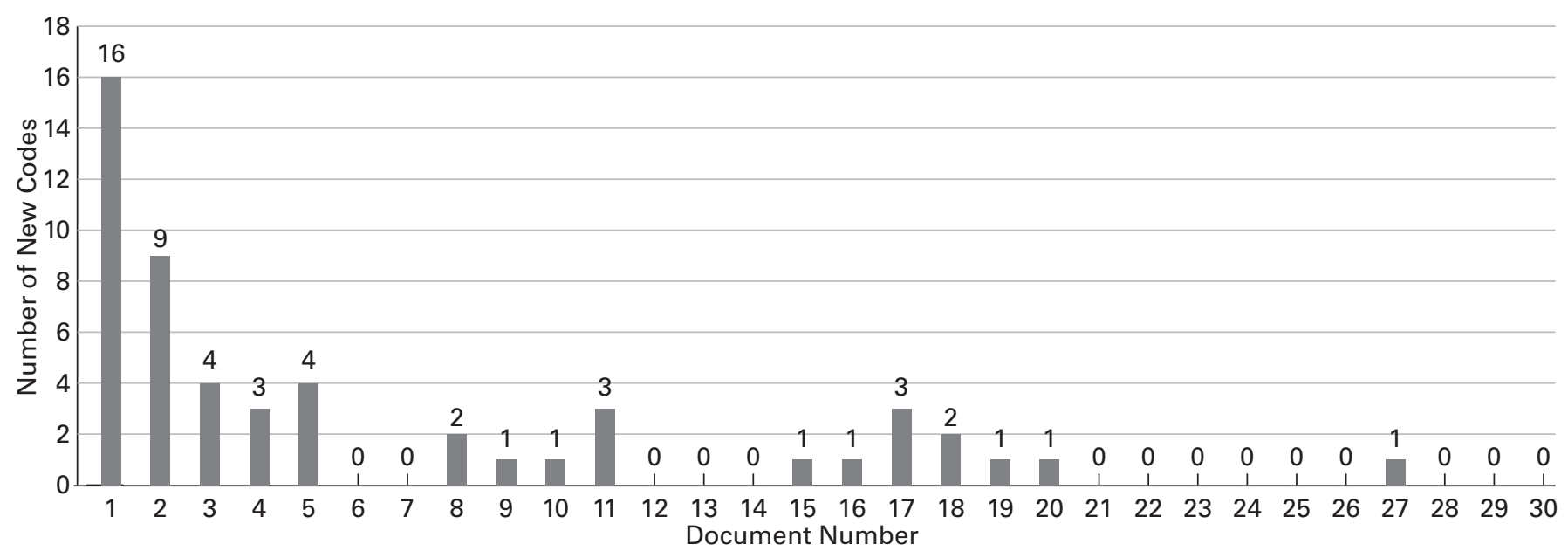

\section{Results}

The findings here represent data from 139 survey or site visit reports that formed the final sample for analysis, with 52 reports from RN programs and 87 from LPN/LVN programs. Eighteen states had both RN and LPN/LVN programs represented, and 15 states had only RN programs.

There were several notable observations in the analysis. First, a large number of for-profit programs received citations. This may merit further exploration. Second, "younger" programs ( $<10$ years in operation) appeared to be at higher risk for failure. Third, more LPN/LVN programs received citations compared to RN programs.

The data comprising the sample allowed us to achieve a level of data saturation that generated themes and categories. Through a summative content analysis, which examined the frequency with which codes were used to analyze the data (Hsieh \& Shannon, 2005), all codes appeared in the documents with a frequency of $50 \%$ or greater. The themes and categories aligned well with Bronfenbrenner's socioecological model as an organizing framework for why programs become at risk or fail (Darling, 2007; Christenson, 2010).

In the case of nursing education, the student is the center of development as they are socialized and educated to become nurses within a specific context. Their responses to the environment where they are shaped affect their developmental processes and outcomes. With NCLEX as the final quantitative developmental indicator of an entry-level educational program in nursing, a series of failures on the NCLEX suggests there may be contextual issues affecting students' performance. The right educational context should be able to ameliorate individual level issues with students who would otherwise confound the outcomes. Effective educational environments are "person centered" with teaching strategies, student services and support, and faculty qualifications aligned to optimize student success. As such, themes and associated categories are presented in alignment with this model in Figure 3. All schools had at least two of these areas where problems had occurred, with faculty and leadership issues being the most common. Failing programs usually had problems at every level, with the state regulatory context dictating the severity of those issues based on local laws.. 


\section{FIGURE 3}

\section{A Socioecological Perspective on Factors Contributing to At-Risk Status of Nursing Education Programs}

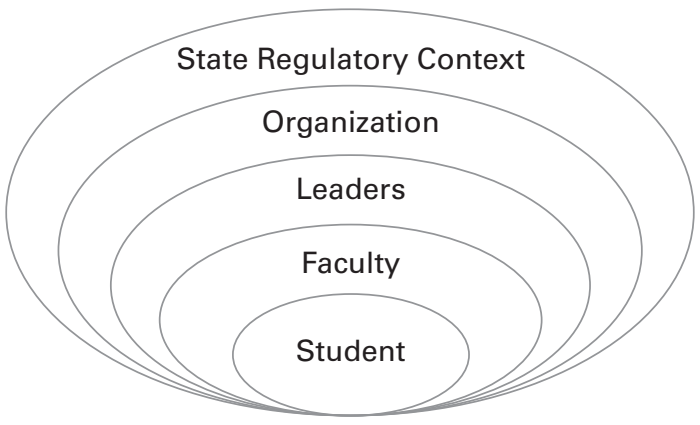

The findings are presented by the three overarching themes that emerged from the analysis followed by the categorical presentation of findings associated with the theoretical framework.

\section{Emerging Themes}

\section{Theme 1: Site Visit Triggers}

Site visit triggers are defined as the issue or issues that triggered a review of the program via a site or survey visit. The main signal for a "site visit trigger" was NCLEX pass rates $\leq 80 \%$ for 4 or more quarters. The length of time it took to trigger a site visit related to NCLEX performance concerns varied by state regulations. Other site visit triggers were associated with student complaints about the program, clinical site complaints about the program or students, and/or public formal complaints about a program or its graduates.

What triggered the site visit appeared to set the tone of the visit for the surveyor. Reports that involved student or public complaints were more detailed, and assessments appeared more thorough than with only a trend in NCLEX failures.

\section{Theme 2: Administrative Processes Are a Primary Source of Program Vulnerability}

Administrative processes are defined as the necessary operational procedures, policies, and resources needed to ensure adequate record keeping for students and faculty, support faculty productivity, and facilitate program leadership. When programs had failing NCLEX rates for more than a year, it was clear that administrative processes had either (a) never existed, (b) not been revised in more than 5 years,

(c) were ignored altogether, or (d) had been cut during a reorganization or as part of "efficiency" measures.

Notable hallmarks of poor administrative processes leading to citations by the state include:

- Poor record keeping of faculty credentials, course evaluations, and student records

- A general lack of policies and procedures

- A lack of quality improvement processes around program and curricular evaluations

- A lack of faculty and student input into policies, procedures, and processes

- Students failing to receive educational materials (e.g., books, uniforms, software, internet access, syllabi, etc.) at the beginning of the semester.

Most failing programs had at least two of these factors involved when receiving a violation.

\section{Theme 3: Use of Data}

Programs that failed to use data to set admission, progression, and student performance standards appeared to have consistent problems. These issues were also persistent over time when programs received a citation for a deficiency and data were not used to address it. It was also a persistent issue when programs failed to conduct adequate self-evaluations. The potential reasons for a lack of use of data include:

- Lack of administrative competence with interpreting and using data to guide decision making (e.g., statistical process control)

- Lack of faculty competence with interpreting and using data to set standards

- No internal statistical support to conduct predictive analyses about what factors influence student performance and may predict NCLEX first-time pass success

- No resources to contract out data for analysis to inform decision making.

Key areas where data need to be used to facilitate student success include:

- Student demographics

○ Socioeconomic status 
- English

- First language

- Other languages

- Presence of children younger than 18 years in the home

- Need to work while attending the program

- Program admission

- High school or previous coursework cumulative grade point average

- SAT or ACT scores (when applicable)

- Secondary education in the United States

- Presence of a remediation program prior to start of coursework

- Program progression

- Minimum grade point average standard

- Minimum passing grade in specific courses

- No pass/fail grades

- Predictive examination scores (e.g., HESI examinations)

These were all indicated in survey reports captured by the surveyor as factors that were influencing the risk for program success or failure.

\section{Categorical Findings Associated With the Theoretical Framework}

\section{Student Feedback}

Student feedback reported in the summaries provided useful perspectives on sources of problems from a non-faculty viewpoint. From the student perspective, they were readily able to:

- Differentiate between well-managed versus poorly managed schools

- Identify lack of program director support

- Verbalize fear of retaliation from faculty for discussing program concerns

- Identify a lack of student input into program decision making

- Highlight school-student communication issues.

Student demographics may also be factors. The most consistent faculty-reported student issues associated with NCLEX performance problems included status of English as a first or other languages speaker and undiagnosed learning disabilities. Poverty and family issues were the next most attributed factors affecting students' academic performance and NCLEX pass rates. The faculty-cited student issues were reported almost entirely in LPN/LVN program reports.

\section{Faculty Feedback}

A persistent theme throughout all reports and the most consistent characteristic of programs becoming at risk or failing was that faculty do not have training in basic pedagogical methods. Reasons why faculty lacked training included (a) lack of bachelor's or master's degree-prepared faculty who had undergone any kind of teaching training; (b) faculty who transitioned directly from clinical practice roles and who had little to no experience with precepting; (c) heavy workloads; (d) a lack of ongoing faculty development of substance; and (e) limited new faculty mentorship. Regarding the lack of ongoing faculty development, such development opportunities focused on what leadership deemed important rather than preparing faculty to become teachers or improve skills.

Another persistent faculty theme was "a lack of recent clinical practice experience." Schools with faculty who had not completed direct patient care within the past 5 years appeared to have outdated teaching approaches, were not in tune with the latest in clinical practice, and often relied less on the use of evidence in their curricula. Given the increased use of technology in the workplace and the increased use of electronic health records that have fundamentally changed the implementation of the hospital nursing role, faculty without recent clinical experience appear to be a liability that places programs at risk.

Curriculum development skills by faculty were also lacking in many programs and appears associated with the level of curricular control faculty were perceived to have by the surveyor. Many failing schools had no overarching philosophy that tied the curriculum together. This resulted in curricular plans that were task centered, often in ways that masked themselves as being competency based.

High faculty turnover or an inability to recruit qualified personnel was also a factor in many schools. An extensive reliance on adjunct faculty to teach all classes is a known issue in higher education quality and nursing programs. Programs that lacked full-time faculty saw problems with NCLEX performance as their quality indicator. Poor compensation (in comparison to full- time clinical nursing positions) and a lack of incentives were both contributors to turnover and recruitment issues. Faculty in for-profit schools often observed that while administrators often had incentives like stock options in the parent company who owned the program, faculty were rarely offered such incentives. 


\section{Teaching and Learning Resources}

Teaching and learning resources were a critical subtheme for faculty. Even qualified faculty would have trouble doing their jobs if teaching and learning resources were not available or poorly managed. Teaching and learning resources were also tied directly to the leader's ability to procure them resources for faculty and the organization's management.

Key teaching and learning resources that appear tied to a program's risk for failure fell into three categories: (a) teaching resources, (b) physical instructional resources, and (c) quality of materials. Using NCLEX test preparation materials and online supplemental instructional resources with classroom and clinical instruction appeared linked to satisfactory NCLEX pass rates. The brand of these materials did not matter. A survey of programs may produce insights as to which brands are most effective, but it also may be linked to student demographic data.

\section{Physical Instructional Resources}

Physical resources include the quality of materials in the simulation laboratory, the quality of other physical instructional resources for teaching and learning, and whether full- or part-time faculty had private office space for student meetings or their own work. Office space for adjunct faculty did not appear significant, but the ability to reserve a conference room to meet with students was important for them. Programs that lacked simulation laboratory accreditation appeared at higher risk for failure. Broken mannequins or equipment, out-of-date materials, and a lack of equipment for medication administration were common issues cited.

The quality of materials is defined as whether teaching materials were prepared and managed according to the course outcomes in the syllabi and were consistent in their design with internal policies. It was not uncommon for site visitors to find that the content of a class did not match the approved course description or outcomes. The more classes with issues, the more likely the program was to have prolonged performance issues on NCLEX. However, it was not always possible to follow up on NCLEX performance at a school level after a probationary citation because of variations in state transparency around problem program reporting.

\section{Leadership of the Nursing Program}

Nursing program leadership had three dimensions that appeared to affect the risk of a program failing or falling under review. The first was when the director of the nursing program, through organizational consolidation, was placed in charge of other allied health and/or vocational programs. These added responsibilities often came without the addition of an assistant director who could manage the day- today operations of the nursing program. The additional responsibilities detracted from program quality, a factor that was also reflected in student feedback. It is another "symptom" of potentially problematic program management practices.

The second leadership dimension appears to be tied to the degree qualifications of a director. Doctoral-level education appeared to mitigate against a lack of academic administrative experience, though the exact effect of why this level of education appeared to be protective against program failure is not yet clear and would merit further exploration. It may be that individuals with doctorates have more diversity of work experience in general and that the training provided additional skills that facilitated program management. It was clear that directors in charge of programs that did not have a college or university affiliation and whose leaders were only prepared at the master's level were at greater risk for failure. Because demographic data about these individuals were not available, it was difficult to determine why this finding occurred in the reports; however, it was consistently observed.

The final nursing program leadership issue that arose frequently was when a nurse was not in charge of the program. This could be either due to the position being vacant for a long period or higher administration not thinking a nurse needed to oversee the program despite the regulatory context dictating otherwise. Both factors were more common in for- profit programs than other types.

\section{Educational Organizations}

Educational organizations had other specific issues that emerged as distinct categories in the analysis-namely, organizational changes and resources, which could influence program success or failure.

Organizational changes are changes in schools with other degree-granting programs where administration decided to make changes based on economic efficiencies. Sometimes, these changes masked broader financial problems for the parent institution overall. Also, changes could add or decrease responsibilities for nursing faculty. From the reports, it appears that 1 to 3 years after these changes, programs are at risk for changes in NCLEX performance, which increase the risk of probation. The longer performance issues persist after these changes, the more likely the program would transition from probation to failing. These trends likely reflected the nursing program leadership's ability to navigate existing faculty through the changes or how they managed higher faculty turnover rates that are often associated with organizational change of any kind.

Resources provided by organizations to facilitate nursing education were another factor that was often missing. While often monetary in nature, resources include (but are not limited to) student affairs support, administrative support, libraries, and information technology. How resources were allocated toward clinical learning experiences and clinical sites, including simulation and laboratory supplies, were also important. Problematic programs usually lacked in at least one but sometimes all of these areas. 
It is important to note that we observed that for-profit schools appeared to trigger more site visits than nonprofit or state schools. This was especially true for LPN/LVN programs.

\section{State Regulatory Context}

It was clear the regulatory context of the program approval of nursing education had a positive effect in terms of holding the programs accountable for standards. This was particularly true related to the minimum requirements for faculty. It held whether or not the program was accredited by a national accrediting agency.

Probationary and failure consequences varied in the length of time schools had to address their deficiencies. Unsurprisingly, shorter periods usually meant increased chance of failure. A shorter period also meant that schools had to rely on obtaining resources to hire consultants to help them address deficiencies.

Without a standardized chart to compare regulatory contexts for nursing education, our ability to compare between states to determine the associations with geographic, socioeconomic, and other factors was limited.

\section{Limitations}

Despite the volume of documents that served as the initial sample size, there were a number of problems with file management that may have precluded a larger sample size or fully complete analysis of all site or survey visits. These include:

- An inconsistent and unstructured file naming and management system

- Incompatible file types with qualitative data analysis software

- Improper file format for analysis or optical character recognition

- Files that were not able to be downloaded for analysis

- Missing reports for RN or LPN/LVN programs from 10 states.

While every effort was made to ensure that all site visit or survey report documents were included, some may have not been included due to how files were named or classified.

Nonetheless, because of the number of documents included, the researchers are confident of the results because of coder consensus, because only one new code appeared after the 20th document, and because both coders believed they had achieved saturation around 40 to 45 coded interviews.

\section{Conclusion}

Considerable and specific data on what happens when nursing programs begin to fail or do fail were found in the site visit documents. Three overarching themes (site visit triggers, administration processes, and the nursing school's use of data in continuous improvement) were found. Specific findings in the areas of student, faculty, leadership, organization, and state regulatory context were also presented. The issues coalesce nicely with the data found in the literature and our Delphi study.

The site visit study was the first to find that BON approval of nursing education programs is an essential process for protecting the public and maintaining nursing education program standards. This was true regardless of whether the programs were accredited by a national nursing accreditation agency. 


\section{SUMMARY}

This comprehensive literature review and three-part national study provides substantial evidence-based criteria for identifying quality indicators of successful and high-risk nursing education programs to effectively recommend guidelines for nursing education approval. These criteria include quality indicators and warning signs related to: (a) organizational requirements and processes, (b) program leadership, (c) faculty quality and requirements, and (d) curriculum and clinical program components.

\section{Organizational Requirements, Policies, and Processes}

Administrative processes, such as a lack of policies and procedures, were found in both the site visit study and the literature review as being problematic for nursing programs. The literature review, Delphi study, and site visit study all emphasized the importance of collecting data to establish policies and procedures and to evaluate the nursing program based on the data collected. A major theme identified in the site visit study was that programs that fail to collect data to set admission, progression, and student performance standards received downgraded approval statuses.

The site visit study cited key areas where these data could facilitate student success: (a) student demographics, (b) program admission standards, (c) remediation program, and (d) program progression. The literature review and Delphi study supported this finding as well. BONs should expect these data to be collected and acted upon. For example, if the program has a high rate of students with English as a foreign language, they should have resources in place to assist these students. Likewise, if the socioeconomic status of the students means they come from disadvantaged homes where the school systems are not up to par, there should be remediation programs in place. Additionally, the site visit study found that students in underperforming schools often verbalized communication issues and lack of input into program decision making. These findings illustrate the importance of regulators meeting with the students when making a site visit.

The failure of nursing programs to collect data also meant that they were unable to evaluate their programs. The literature review, Delphi study, and site visit study all emphasized the importance of a systematic evaluation of the nursing program based on data collection. Yet, one problem identified in the site visit study was that in underperforming programs, even when data were collected, faculty often are not able to interpret or use data for setting standards. Likewise, faculty may not have access to statistical support when analyzing the data.

In the site visit study, researchers found that in programs that lost approval, policies and procedures had not been revised in more than 5 years or they had been ignored (because of "efficiency" measures). Furthermore, there was no faculty or student input into the policies and procedures.

In programs that lose full board approval, organizational changes made for "economic efficiencies" sometimes mask larger financial problems. BONs will want to find out more about what is behind organizational changes because they can affect faculty workload and responsibilities. As noted in the site visit study, when organizations begin to make organizational changes because of financial problems, they often lose board approval within 1 to 3 years. This is an important consideration for BONs when evaluating programs. Similarly, when the parent organization does not provide the program with sufficient resources, such as student services, libraries, information technology, and adequate clinical facilities and simulation, the programs and students struggle.

In the site visit study, another issue that often triggered further review by a BON was associated with student, clinical site, or formal public complaints. This finding was further substantiated by the Delphi study, which cited complaints to the BON as a warning sign for the program. Given the issues that were uncovered in these site visits, BONs should continue the practice of site visits to programs with a substantial number of complaints.

The annual report and site visit studies and some of the literature demonstrated that nursing program ownership may impact outcomes. Negative outcomes can range from low NCLEX pass rates to the program unexpectedly shutting down while students are enrolled. Data indicate that for-profit schools are at the greatest risk. Public schools and those that are well-established ( $\geq 10$ years) are the most likely to maintain educational standards set forth by the state. Therefore, new programs require more oversight, as do online programs.

\section{Leadership}

Consistent leadership in a nursing program was found to be crucial. The literature review and Delphi study cited program director attrition as a warning sign, whereas the annual report study found frequent director turnover resulted in significant statistical differences in the NCLEX pass rates and differences in program approval status.

Both the site visit study and the annual report study found that when the program director was doctorally prepared, the programs had higher NCLEX pass rates and were more likely to have full approval. In the site visit study, it appears as though the doctoral degree may make up for a lack of academic administrative experience due to the other valuable experiences the individual may bring to the role.

The site visit study was able to delve deeper into leadership of the nursing program and found that when a director is placed in charge of other allied health and/or vocational programs, usually for financial reasons, the program is more at risk due to having the director's attention diverted by multiple programs. Additionally, the site visit study discovered that program issues arose when a nurse was not in charge of the program. This often happened when the position had been vacant for some time or when administration did not think it necessary. These situations happened more often in for-profit institutions. 


\section{Faculty Quality and Requirements}

The quality of faculty is at the core of a successful nursing program. Having consistent, full-time faculty (at least 35\% full-time faculty, as opposed to adjunct or part-time faculty) in a nursing program predicts full approval and higher NCLEX pass rates according to the annual report study. The literature review also found that the full-time faculty percentage was linked to higher NCLEX pass rates, and the Delphi study reported consistent, full-time faculty as an essential element in a nursing program. The site visit study found high faculty turnover and the inability to recruit qualified faculty were linked to poor NCLEX performance.

Both the annual report and site visit studies demonstrated that a lack of a graduate degree for faculty was linked to less than full approval status. Additionally, as seen in the site visit study, faculty with little training in basic pedagogies was a persistent theme in failing programs. Faculty in programs that were failing often had no training in teaching, having transitioned directly from clinical practice to education. Likewise, they had heavy workloads and limited new faculty mentorship opportunities. The site visit study cited the lack of substantive and ongoing faculty development opportunities as an important element of failing nursing programs. The literature review and Delphi study also cited faculty development as important factors in successful nursing programs.

The literature review, Delphi study, and site visit study all identified current clinical experiences as a critical element of successful nursing programs. The site visit study found that schools where faculty had not provided direct patient care in the past 5 years appeared to have outdated teaching experiences and were not teaching the latest technological advances. There are many ways a program could provide their students with faculty who are clinically competent. They might, for example, develop partnerships with practice, such as dedicated education units, in which the faculty lead the clinical experiences but experienced nurses work directly with their students.

The site visit study also found that in programs that lost approval, faculty did not have the resources needed to teach. For example, faculty lacked the ability to reserve a conference room to meet with students or equipment in their learning and simulation laboratories was missing or broken. Likewise, the quality of the syllabi was often questionable in underperforming programs; for example, it was typical that the content of the classes did not match the course descriptions or outcomes.

\section{Curriculum and Clinical Experiences}

The annual report study found hybrid education was a predictor of $80 \%$ or higher NCLEX pass rates and that online education predicted the program was less likely to be approved.

Quality and safety concepts, such as the QSEN competencies, were identified in the literature review and Delphi study as important elements of nursing curricula. However, more research on whether integrating QSEN into the curriculum is associated with better outcomes is needed.

According to the site visit study, many failing schools had no overarching philosophy and curricular framework that tied the curriculum together. This resulted in curricula that were task-oriented, masking themselves as being "competency-based." The literature review and Delphi study highlighted that clinical judgment is critical to thread throughout the curricula but provided little detail on specifically how to do that, though that literature is growing.

The literature review, Delphi study, and site visit study all found quality clinical experiences and simulation to be critical for successful nursing programs. Clinical experiences with actual patients in a variety of clinical settings were found to be important. BONs should evaluate the relationship the program has with its clinical partners, looking for collaboration between the nursing program and practice sites. Programs that lost BON approval often had a limited number of clinical sites, and their parent organizations did not allocate enough resources (such as clinical faculty) toward clinical learning experiences according to the site visit study. Likewise, in weaker programs, supplemental instructional resources (such as videos and online modules) were lacking. The literature review found the following to be important areas to include in clinical experiences: (a) clinical reasoning, (b) delegation, (c) electronic data management, (d) emergency procedures, (e) interprofessional communication, (f) knowledge of pharmacology, (g) leadership, (h) time management, and (i) understanding pathophysiology.

As documented in the literature review, Delphi study, and site visit study, quality simulation is an important element of a successful nursing program and is an important curricular component for BONs to evaluate. The site visit study found the quality of the materials in the simulation laboratory was poor with broken or out-of-date materials in failing programs. Often there was a lack of equipment for teaching medication administration, a critical curricular element. Simulation laboratory accreditation should be mandated for all programs substituting simulation for direct care clinical experiences.

National nursing accreditation of the nursing program is associated with higher NCLEX pass rates, as seen in the literature review, Delphi study, and annual report study, although we are not sure why. It may be that the more seasoned and successful programs seek national nursing accreditation. More research should be conducted to clarify the reasons. While most BSN programs are nationally accredited, only about $53 \%$ of ADN programs and $11 \%$ of LPN/LVN programs are accredited (Silvestre, 2020). Currently, about half the BONs require programs to be nationally nursing accredited. 


\section{Conclusion}

In their missions of public protection, the BONs have called for nursing education quality indicators and warning signs as they approve nursing programs. This literature review and three-part mixed-methods study have provided robust and specific data for developing evidence-based and legally-defensible approval guidelines. From this evidence, a site visit template (Appendix D) was developed for BONs to use when making site visits, and an annual report template (Appendix E) was developed for collecting core data on an annual basis. The annual report template will enable the collection of core, consistent data across the BONs, thus allowing for continuing data analysis and making the guidelines a living document that will change based on new data. Part III presents the approval guidelines. 


\section{NCSBN Guidelines for Nursing Education Program Approval}

\section{Introduction}

Considering the literature and study evidence presented, NCSBN invited a group of research, education, regulatory, and legal experts (Table 11) to analyze the data together and make recommendations for evidence-based, legally defensible guidelines for nursing regulatory bodies (NRBs) and nursing education programs (Figure 4). It is hoped that these guidelines will increase collaboration between regulators and educators, allow for transparency in the approval process, help NRBs avoid antitrust issues, and provide criteria that allow NRBs to intervene prior to programs falling below standards.

\section{FIGURE 4}

\section{Evidence-Based Model for Nursing Education Program Approval}

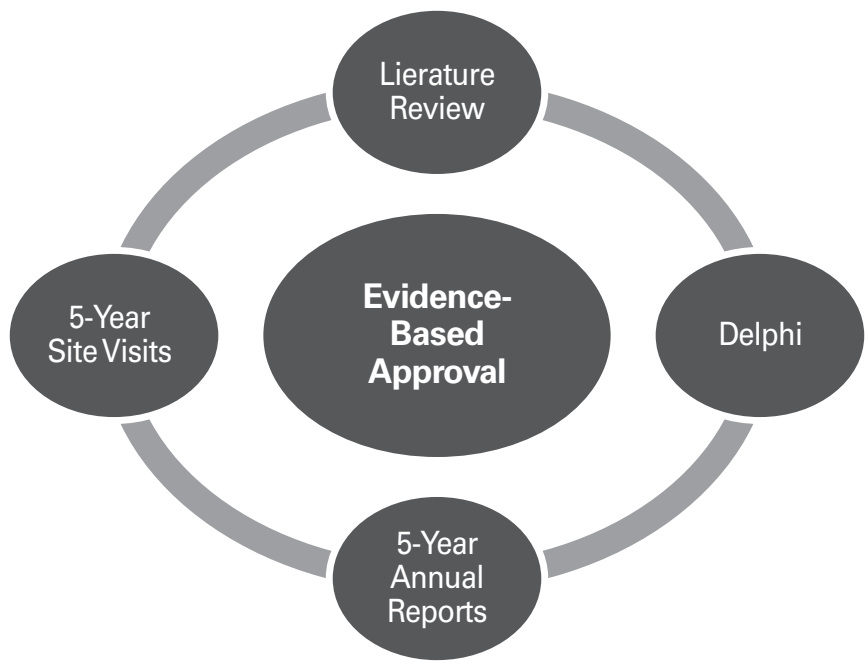

The guidelines allow NRBs to use the evidence-based quality indicators to provide guidance on where the nursing program needs to act. NRBs will also be able to identify warning signs and high-risk programs, from either site visits (Appendix D) or annual reports (Appendix E), and to take action before a program falls below standards. This will enable the BONs to be proactive rather than reactive. The evidence for the quality indicators and warning signs can be found in Table 12. The site visit template (Appendix D) was developed from the evidence and can be used by NRBs during site visits. Additionally, the annual report core data template (Appendix E) was devised from the quantitative data and can be used by BONs to collect critical nursing education data. 
TABLE 11

\section{Expert Panel}

\begin{tabular}{|c|c|}
\hline $\begin{array}{c}\text { Maryann Alexander, PhD, FAAN } \\
\text { Chief Officer, Nursing Regulation } \\
\text { NCSBN }\end{array}$ & $\begin{array}{l}\text { Donna Meyer, MSN, ANEF, FAADN, FAAN } \\
\text { CEO, Organization of Associate Degree Nursing }\end{array}$ \\
\hline $\begin{array}{c}\text { Janice Brewington, PhD, RN, FAAN } \\
\text { Director, Center forTransformational Leadership } \\
\text { Chief Program Officer } \\
\text { National League for Nursing }\end{array}$ & $\begin{array}{l}\text { Bibi Schultz, MSN, RN, CNE } \\
\text { Director of Education } \\
\text { Missouri State Board of Nursing }\end{array}$ \\
\hline $\begin{array}{c}\text { Rebecca Fotsch, JD } \\
\text { Director, State Advocacy and Legislative Affairs } \\
\text { NCSBN }\end{array}$ & $\begin{array}{c}\text { Anne Marie Shin, RN, MN, MSc (QIPS) } \\
\text { Manager, Education Program } \\
\text { College of Nurses of Ontario }\end{array}$ \\
\hline $\begin{array}{c}\text { Janice I. Hooper, PhD, RN, FRE, CNE, FAAN, ANEF } \\
\text { Nursing Consultant for Education } \\
\text { Texas Board of Nursing }\end{array}$ & $\begin{array}{c}\text { Josephine Silvestre, MSN, RN } \\
\text { Senior Associate, Regulatory Innovations } \\
\text { NCSBN }\end{array}$ \\
\hline $\begin{array}{c}\text { Nicole Livanos, JD } \\
\text { Senior Associate, State Advocacy and Legislative Affairs } \\
\text { NCSBN }\end{array}$ & $\begin{array}{c}\text { Nancy Spector, PhD, RN, FAAN } \\
\text { Director, Regulatory Innovations } \\
\text { NCSBN }\end{array}$ \\
\hline $\begin{array}{c}\text { Brendan Martin, PhD } \\
\text { Associate Director, Research } \\
\text { NCSBN }\end{array}$ & $\begin{array}{c}\text { CrystalTillman, DNP, RN, CPNP, PMHNP-BC, FRE } \\
\text { Director of Education and Practice } \\
\text { North Carolina Board of Nursing }\end{array}$ \\
\hline
\end{tabular}

\section{Quality Indicators}

The quality indicators are categorized into administrative requirements, program director, faculty, students, curriculum and clinical experiences, and teaching and learning resources. They were developed by the expert panel based on the literature review and the Delphi, annual report, and site visit studies (Table 12).

\section{Administrative Requirements}

1. The program has criteria for admission, progression, and student performance.

2. Written policies and procedures are in place and have been vetted by faculty and students.

\section{Program Director}

1. The program director of an $\mathrm{RN}$ program is doctorally prepared and has a degree in nursing.

2. The program director of an LPN/LVN program has a graduate degree and a degree in nursing.

\section{Faculty}

1. At a minimum, $35 \%$ of the total faculty (including all clinical adjunct, part-time, or other faculty) are employed at the institution as full-time faculty.

2. In $\mathrm{RN}$ programs, faculty hold a graduate degree.

3. In LPN/LVN programs, faculty hold a BSN degree.

4. Faculty can demonstrate they have been educated in basic instruction of teaching and adult learning principles and curriculum development. This may include the following:

5. Methods of instruction

a. Teaching in clinical practice settings

b. Teaching in simulation settings

c. How to conduct assessments, including test item writing

d. Managing "difficult" students.

6. Faculty can demonstrate participation in continuing education related to nursing education and adult learning pedagogies.

7. The school provides substantive and periodic workshops and presentations devoted to faculty development. 
8. Formal mentoring of new full-time and part-time faculty takes place by established peers.

9. Formal orientation of adjunct clinical faculty occurs.

10. Clinical faculty have up-to-date clinical skills and have had experience in direct patient care in the past 5 years.

11. Simulation faculty are certified.

\section{Students}

1. The nursing program should ensure the following are in place to assist students:

a. English as a second language assistance is provided.

b. Assistance is available for students with learning disabilities.

c. All students have books and resources necessary throughout the program and strategies are in place to help students who can't afford books and resources.

d. Remediation strategies are in place at the beginning of each course and students are aware of how to seek help. This should include processes to remediate errors and near misses in the clinical setting.

\section{Curriculum and Clinical Experiences}

1. At least $50 \%$ or more of clinical experience in each clinical course is direct care with patients.

2. Variety of clinical settings with diverse patients.

3. Opportunities for quality and safety education integrated into the curriculum, including delegating effectively, emergency procedures, interprofessional communication, and time management.

4. Systematic evaluation plan of the curriculum is in place.

\section{Teaching and Learning Resources}

1. The simulation laboratory is accredited.

2. Students have access to a library, technology, and other resources.

3. Programs are able to assess students with learning disabilities and tailor the curriculum to meet their needs.

\section{Warning Signs}

NRBs should intervene early when programs experience the following warning signs. The evidence indicates these programs could be identified either from site visits or annual reports (Table 12). The warning signs include:

1. Complaints to BONs or other NRBs from students, faculty, clinical sites, or the public.

2. Turnover of program directors (more than three directors in a 5 -year period).

3. Frequent faculty turnover/cuts in numbers of faculty.

4. Trend of decreasing NCLEX pass rates.

\section{High-Risk Programs That May Need Additional Oversight}

If a program has been in operation for 7 years or fewer, it may need additional oversight because the NRB does not have a history with that program. This recommendation is supported by the literature review, the annual report study, and the site visit study. Additional oversight may include more frequent progress reports related to the number of students, faculty qualifications, stability of the program director, and NCLEX pass rates, in addition to the regularly collected annual reports. If there is concern, the BON may make a focused visit to the program to further assess and possibly make recommendations. 


\section{Supportive Evidence for the Approval Guidelines}

Evidence supporting how each warning sign and quality indicator is linked to the evidence is presented in Table 12.

\section{TABLE 12}

\section{Evidence Supporting Guidelines for Quality Indicators and Warning Signs}

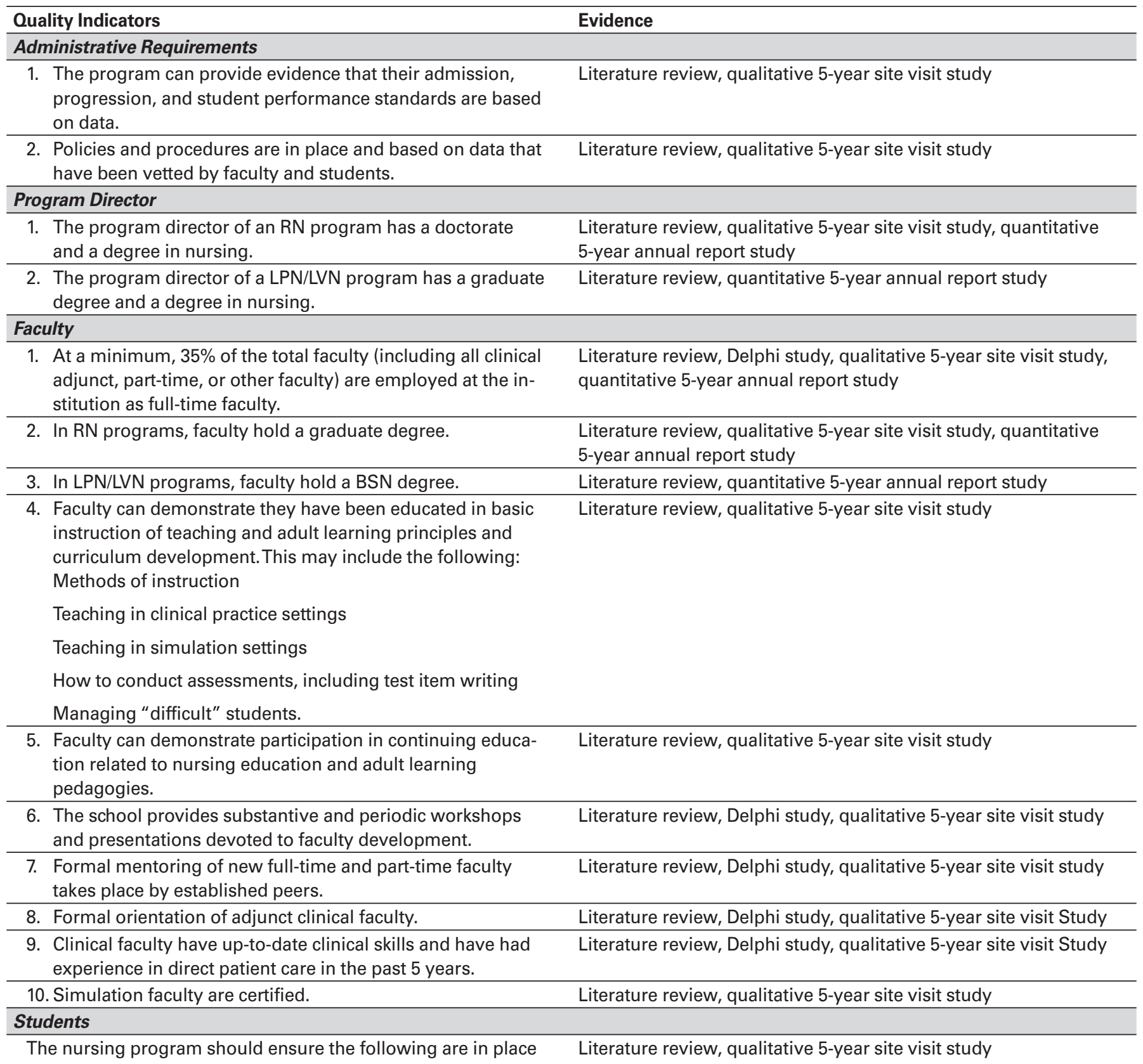

to assist students:

English as a second language assistance

Assistance for students with learning disabilities

Necessary books and resources available throughout the program, as well as strategies to help students who cannot afford books and resources

Remediation strategies are in place at the beginning of each course and students are aware of how to seek help. This should include processes to remediate errors and near misses in the clinical setting.

(continued) 


\section{Evidence Supporting Guidelines for Quality Indicators and Warning Signs (continued)}

Quality Indicators Evidence

Curriculum and Clinical Experiences

1. $50 \%$ or more of clinical experience in each clinical course is Literature review, Delphi study direct care with patients.

2. Variety of clinical settings with diverse patients. Literature review, Delphi study, qualitative 5-year site visit study

3. Opportunities for quality and safety education integrated into the curriculum, including delegating effectively, emergency procedures, interprofessional communication, and time management.

4. Systematic evaluation plan of the curriculum is in place. Teaching and Learning Resources

1. The simulation laboratory is accredited. Literature review, Delphi study, qualitative 5-year site visit study Literature review, qualitative 5-year site visit study

2. Students have access to a library, technology, and other Literature review, qualitative 5-year site visit study resources.

3. Programs are able to assess students with learning disabili- Literature review, qualitative 5-year site visit study ties and tailor the curriculum to meet their needs.

\section{Warning Signs}

1. Complaints to boards of nursing or other nursing regulatory boards from students, faculty, clinical sites, or the public.

2. Turnover of program directors; more than three directors in a 5-year period.

3. Frequent faculty turnover or cuts in number of faculty members.

4. Trend of decreasing NCLEX pass rates.

5. High-Risk Programs needing additional oversight, such as Prelicensure programs younger than 7 years.

\section{Evidence}

Literature review, Delphi study, qualitative 5-year site visit study

Literature review, Delphi study, qualitative 5-year site visit study, quantitative 5-year annual report study

Literature review, Delphi study, qualitative 5-year site visit study, quantitative 5-year annual report study Delphi, qualitative 5-year site visit study, quantitative 5-year annual report study

Literature review, qualitative 5-year site visit study, quantitative 5-year annual report study 


\section{References}

Accreditation Commission for Education in Nursing. (2019). ACEN accreditation manual: 2017 standards and criteria. https://www. acenursing.org/for-programs/general-resources/resources-acenaccreditation-manual/

Accreditation Council for Occupational Therapy Education. (2019). 2018 Accreditation Council for Occupational Therapy Education (ACOTE) standards and interpretive guide. https://acoteonline.org/accreditationexplained/standards/

Accreditation Council for Pharmacy Education. (2015). Accreditation standards and key elements for the professional program in pharmacy leading to the doctor of pharmacy degree. https://www.acpe-accredit.org/pdf/ Standards2016FINAL.pdf

Alexander, M. (2019). How can we best evaluate nursing education programs [Editorial]? Journal of Nursing Regulation, 9(4), 3. https://doi. org/10.1016/S2155-8256(19)30010-9

Alexander, M., Durham, C. F., Hooper, J. I., Jeffries, P. R., Goldman, N., Kardong-Edgren, S., Kesten, K. S., Spector, N., Tagliareni, E., Radtke, B., \& Tillman, C. (2015). NCSBN simulation guidelines for prelicensure nursing programs. Journal of Nursing Regulation, 6(3), 39-42. https://doi.org/10.1016/S2155-8256(15)30783-3

Association of Specialized and Professional Accreditors. (2016). Outcomes: Getting to the core of programmatic education and accreditation. https:// www.aspa-usa.org//wp-content/uploads/2016/06/Outcomes-ReportJune-2016.pdf

Barrett, S. F., Steadman, J. W., \& Whitman, D. L. (2016). Using the fundamentals of engineering $(F E)$ examination as an outcomes assessment tool. National Council of Examiners for Engineering and Surveying. https://ncees.org/wp-content/uploads/FEOAT-booklet-2018.pdf.

Barton, A. J., Armstrong, G., Prehelm, G., Gelmon, S. B., \& Andrus, L. C. (2009). A national Delphi to determine progression of quality and safety competencies in nursing education. Nursing Outlook, 57(6), 313-322. https://doi.org/10.1016/j.outlook.2009.08.003

Beauvais, A. M., Kazer, M. W., Aronson, B., Conlon, S. E., Forte, P., Fries, K. S., Hahn, J. M., Hullstrung, R., Levvis, M., McCauley, P., Morgan, P. P., Perfetto, L., Reveschi, L. M., Solernou, S. B., Span, P., \& Sundean, L. J. (2017). After the gap analysis: Education and practice changes to prepare nurses of the future. Nursing Education Perspectives, 38(5), 250-254. https://doi.org/ 10.1097/01. NEP.0000000000000196

Benner, P., Sutphen, M., Leonard, V., \& Day, L. (2010). Educating nurses: A call for radical transformation. Jossey-Bass.

Benton, D. C., González-Jurado, M. A., \& Beneit-Montesinos, J. V. (2013). Defining nurse regulation and regulatory body performance: A policy Delphi study. International Nursing Review, 60(3), 303-312.

Berkow, S., Virkstis, K., Stewart, J., \& Conway, L. (2008). Assessing new graduate nurse performance. The Journal of Nursing Administration, 38(11), 468-474. https://doi.org/ 10.1097/01. NNA.0000339477.50219.06

Bernier, S. L., Helfert, K., Teich, C. R., \& Viterito, A. (2005). Are we using the right "gold" standard? Community College Journal, 76(1), 36.

Boston-Fleischhauer, C. (2019). Confronting clinical rotations. The Journal of Nursing Administration, 49(1), 6-8. https://doi.org/ 10.1097/ NNA.0000000000000699

Canadian Council of Registered Nurse Regulators. (2018). Entry to practice competencies for the practice of registered nurses. http://www.ccrnr.ca/assets/ draft-rn-elc-competencies-july-24-2018_en.pdf

Candela, L., \& Bowles, C. (2008). Recent RN graduate perceptions of educational preparation. Nursing Education Perspectives, 29(5), 266-271.

Cantlay, A., Salamanca, J., Golaw, C., Wolf, D., Maas, C., \& Nicholson, P. (2017). Self-perception of readiness for clinical practice: A survey of accelerated master's program graduate nurses. Nursing Education in Practice, 24, 34-42.
Christensen, J. (2010). Proposed enhancement of Bronfenbrenner's Development Ecology Model. Education Inquiry, 1(2), 117-126. https:// doi.org/10.3402/edui.v1i2.21936

Cohen, H., \& Ibrahim, N. (2008). A new accountability metric for a new time: A proposed graduation efficiency measure. Change: The Magazine for Higher Learning, 40(3), 47-52.

College of Nurses of Ontario. (2018). Nursing education program approval guide: Overview of the program approval process. http://www.cno.org/ globalassets/3-becomeanurse/educators/nursing-education-programapproval-guide-vfinal2.pdf

Commission of Accreditation in Physical Therapy Education. (2017). Standards and required elements for accreditation of physical therapist education programs. http://www.capteonline.org/ AccreditationHandbook/

Commission on Collegiate Nursing Education. (2018). Standards for accreditation of baccalaureate and graduate nursing programs. https://www. aacnnursing.org/Portals/42/CCNE/PDF/Standards-Amended-2018. pdf

Cook, T., \& Hartle, T. W. (2011). Why graduation rates matter - and why they don't. American Council on Education. https://www.acenet.edu/ Documents/College-Graduation-Rates-Behind-the-Numbers.pdf

Cronenwett, L., Sherwood, G., Barnsteiner, J., Disch, J., Johnson, J., Mitchell, P., Sullivan, D. T., \& Warren, J. (2007). Quality and safety education for nurses. Nursing Outlook, 55(3), 122-131. https://doi. org/10.1016/j.outlook.2007.02.006

Dang, D., \& Dearholt, S. (2017). Johns Hopkins nursing evidence-based practice: Model and guidelines (3rd ed.). Sigma Theta Tau International.

Darling, N. (2007). Ecological systems theory: The person in the center of the circles. Research in Human Development, 4(3-4), 203-217. https:// doi.org/10.1080/15427600701663023

DeAngelo, L., Franke, R., Hurtado, S., Pryor, J. H., \& Tran, S. (2011). Completing college: Assessing graduation rates at four-year institutions. Higher Education Research Institute at UCLA. https://www. researchgate.net/profile/Ray_Franke/publication/249644731_ Completing_College_Assessing_Graduation_Rates_at_Four-Year_ Institutions/links/0046351e5bb5279e3a000000.pdf

Docherty, A., \& Dieckmann, N. (2015). Is there evidence of failing to fail in our schools of nursing? Nursing Education Perspectives, 36(4), 226231. https://doi.org 10.5480/14-1485

Eberle-Sudré, K., Welch, M., \& Nichols, A. H. (2015). Rising tide: Do college grad rate gains benefit all students? The Education Trust. https:// edtrust.org/wp-content/uploads/2014/09/TheRisingTide-DoCollege-Grad-Rate-Gains-Benefit-All-Students-3.7-16.pdf

El Haddad, M., Moxham, L., \& Broadbent, M. (2017). Graduate nurse practice readiness: A conceptual understanding of an age old debate. Collegian, 24(4), 391-396. https://doi.org/10.1016/j. colegn.2016.08.004

Feeg, V., \& Mancino, D. J. (2016). Trends upward and trends downward reflecting a changing job market for new nursing graduates. Dean's Notes, 37(4-5), 1-5. https://www.ajj.com/sites/default/files/services/ publishing/deansnotes/summer16.pdf

Feeg, V., \& Mancino, D. J. (2018). New graduates' first jobs and future plans: Debt, employers and education prospects. Dean's Notes, 40(1), $1-5$.

Ferrante, F. (2017). Assessing quality in higher education: some caveats. Social Indicators Research, 131, 727-743.

Foreman, S. (2017). The accuracy of state NCLEX-RN passing standards for nursing programs. Nurse Education Today, 52, 81-86. http://doi. org/ 10.1016/j.nedt.2017.02.019

Gaberson, K. B., Oermann, M. H., \& Shellenbarger, T. (2015). Clinical teaching strategies in nursing (4th ed.). Springer Publishing Company. 
Giddens, J. F. (2009). Changing paradigms and challenging assumptions: Redefining quality and NCLEX-RN pass rates. Journal of Nursing Education, 48(3), 123-124. https://doi.org/ 10.3928/0148483420090301-04

Gonzalez, L. (2018). Teaching clinical reasoning piece by piece: A clinical reasoning concept-based learning method. Journal of Nursing Education, 57(12), 727-735. https://doi.org/ 10.3928/0148483420181119-05

Granger, B. B., Prvu-Bettger, J., Aucoin, J., Fuchs, M. A., Mitchell, P. H., Holditch-Davis, D., Roth, D., Califf, R. M., \& Gillis, C. L. (2012). An academic-health service partnership in nursing: Lessons from the field. Journal of Nursing Scholarship, 44(1), 71-79. https://doi. org/10.1111/j.1547-5069.2011.01432.x

Grant, A. R. (2015). NCLEX-RN predictor test scores and NCLEX-RN success [Doctoral dissertation, Walden University]. ScholarWorks. https:// scholarworks. waldenu.edu/cgi/viewcontent. cgi?article $=2621 \&$ contex $\mathrm{t}=$ dissertations

Grün B., \& Hornik, K. (2011). Topicmodels: An R package for fitting topic models. Journal of Statistical Software, 40(13), 1-30.

Hayden, J., Smiley, R. A., Alexander, M., Kardong-Edgren, S., \& Jeffries, P. R. (2014). The NCSBN national simulation study: A longitudinal, randomized, controlled study replacing clinical hours with simulation in prelicensure nursing education. Journal of Nursing Regulation, 5(2), S1-S40. https://doi.org/10.1016/S21558256(15)30062-4

Hennink, M. M., Kaiser, B. N. \& Marconi, V. C. (2017). Code saturation versus meaning saturation: How many interviews are enough? Qualitative Health Research, 27(4), 591-608. https://doi.org/ $10.1177 / 1049732316665344$

Hickerson, K. A., Taylor, L. A., \& Terhaar, M. F. (2016). The preparationpractice gap: An integrative literature review. The Journal of Continuing Education in Nursing, 47(1), 17-23. https://doi. org/10.3928/00220124-20151230-06

Hooper, J. I., \& Ayars, V. D. (2017). How Texas nursing education programs increased NCLEX pass rates and improved programming. Journal of Nursing Education, 8(3), 53-58. https://doi.org/10.1016/ S2155-8256(17)30160-6

Hooper, J. I., \& Thomas, M. B. (2014). National Accreditation as a criterion for ongoing approval of education programs. Journal of Nursing Regulation, 4(4), 48-50. https://doi.org/10.1016/S21558256(15)30110-1

Hsieh H.-F. \& Shannon, S. E. (2005). Three approaches to qualitative content analysis. Qualitative Health Research, 15(9), 1277-1288. https:// doi.org/10.1177/1049732305276687

Hsu, L.-L., \& Hsieh, S.-I. (2013). Development and psychometric evaluation of the competency inventory for nursing students: A learning outcome perspective. Nursing Education Today, 33(5), 492-497. https://doi.org/10.1016/j.nedt.2012.05.028

Hungerford, C., Blanchard, D., Bragg, S., Coates, A., \& Kim, T. (2019). An international scoping exercise examining practice experience hours completed by nursing students. Journal of Nursing Education, 58(1), 33-41. https://doi.org/10.3928/01484834-20190103-06

Jamshidi, N., Molazem, Z., Sharif, F., Torabizadeh, C., \& Kalyani, M. N. (2016). The challenges of nursing students in the clinical learning environment: A qualitative study. The Scientific World Journal, 2016, 1846178. https://doi.org/10.1155/2016/1846178

Jones, A., Foote, J., \& Ridgeway, S. (2012). Program approval: Minnesota's case for accreditation requirement. Journal of Nursing Regulation, $2(4), 40-42$.

Kavanagh, J. M., \& Szweda, C. (2017). A crisis in competency: The strategic and ethical imperative to assessing new graduate nurses' clinical reasoning. Nursing Education Perspectives, 38(2), 57-62. https://doi. org/10.1097/01.NEP.0000000000000112
Keeney, S., Hasson, F., \& McKenna, H. (2011). The Delphi technique in nursing and health research. Wiley-Blackwell.

Killam, L. A., Luhanga, F., \& Bakker, D. (2011). Characteristics of unsafe undergraduate nursing students in clinical practice: An integrative literature review. Journal of Nursing Education, 50(8), 437-446. https://doi.org/10.3928/01484834-20110517-05

Kumm, S., Godfrey, N., Richards, V., Hulen, J., \& Ray, K. (2016). Senior student nurse proficiency: A comparative study of two clinical immersion models. Nurse Education Today, 44, 146-150. https://doi. org/10.1016/j.nedt.2016.05.023

Liaison Committee on Medical Education. (2019). Functions and structure of a medical school: Standards for accreditation of medical education programs leading to the MD degree. https://lcme.org/ publications/\#Standards

Libner, J., \& Kubala, S. (2017). Improving program NCLEX pass rates: Strategies from one state board of nursing. Nursing Education Perspectives, 38(6), 325-329.

Linaker, K. L. (2015). Student evaluations, outcomes, and national licensure examinations in radiology education: A narrative review of the literature. Journal of Chiropractic Humanities, 22(1), 17-21. https:// doi.org/10.1016/j.echu.2015.09.002

Linstone, H. A., \& Turoff, M. (Eds.). (2002). The Delphi method: Techniques and applications. Authors. https://web.njit.edu/ turoff/pubs/ delphibook/delphibook.pdf

Longabach, T. (2012). Number of clinical hours in the nursing programs and National Council Licensure Examination for Registered Nurses (NCLEX$R N)$ passing rate [Unpublished master's thesis]. University of Kansas.

Loversidge, J. M. (2016). An evidence-informed health policy model: Adapting evidence-based practice for nursing education and regulation. Journal of Nursing Regulation, 7(2), 27-33. https://doi. org/10.1016/S2155-8256(16)31075-4

Luhanga, F. L., Larocque, S., MacEwan, L., Gwekwerere, Y. N., \& Danyluk, P. (2014). Exploring the issue of failure to fail in professional education programs: A multidisciplinary study. Journal of University Teaching E Learning Practice, 11(2), 3.

McGeoch, M., Brunetto, Y., \& Brown, K. (2014). The policy Delphi method: Contribution to policy and strategy within energy organisations: A 2013 Malaysian case study with global implications. Quality and Quantity, 48, 3195-3208.

Means, B., Yoyama, Y., Murphy, R., Bakia, M., \& Jones, K. (2010). Evaluation of evidence-based practices in online learning: A meta-analysis and review of online learning studies. U.S. Department of Education. https:// www2.ed.gov/rschstat/eval/tech/evidence-based-practices/finalreport. pdf

Meskell, P., Murphy, K. Shaw, D. G., \& Casey, D. (2014). Insights into the use and complexities of the Policy Delphi technique. Nurse Researcher, 21(3), 32-39. https://doi.org/10.7748/nr2014.01.21.3.32.e342

Miller F. A., \& Alvarado K. (2005). Incorporating documents into qualitative nursing research. Journal of Nursing Scholarship, 37(4), 348-353. https://doi.org/10.1111/j.1547-5069.2005.00060.x

Missen, K., McKenna, L., Beauchamp, A., \& Larkins, J. (2016). Qualified nurses' perceptions of nursing graduates' abilities vary according to specific demographic and clinical characteristics: A descriptive quantitative study. Nurse Education Today, 45, 108-113. https://doi.org/ 10.1016/j.nedt.2016.07.001

The National Academies of Sciences, Engineering, and Medicine. (2016). Quality in the undergraduate experience: What is it? How is it measured? Who decides? The National Academies Press.

The National Academies of Sciences, Engineering, and Medicine. (2018). Graduate medical education outcomes and metrics: Proceedings of a workshop. The National Academies Press. 
National Council of State Boards of Nursing. (2005). Clinical instruction in prelicensure nursing programs. https://www.ncsbn.org/Final_Clinical_ Instr_Pre_Nsg_programs.pdf

National Council of State Boards of Nursing. (2006). A national survey of elements of nursing education [Research brief]. https://www.ncsbn.org/ Vol_24_web.pdf

National Council of State Boards of Nursing. (2019). Member board profiles. https://www.ncsbn.org/2019Education.pdf

National League for Nursing Commission for Nursing Education Accreditation. (2016). Accreditation standards for nursing education programs. http://www.nln.org/docs/default-source/accreditation-services/cneastandards-final-february-201613f2bf5 c78366c709642ff00005f0421. pdf? sfvrsn $=12$

Nursing Education Outcomes and Metrics Committee. (2017). Report on BON Approval Survey - 2017. https://www.ncsbn.org/670.htm

Odom-Maryon, T., Bailey, L. A., \& Amiri, S. (2018). The influences of nursing school characteristics on NCLEX-RN pass rates: A national study. Journal of Nursing Regulation, 9(3), 59-69. https://doi. org/10.1016/S2155-8256(18)30154-6

Oermann, M. (Ed.). (2017). A systematic approach to assessment and evaluation of nursing programs. Wolters Kluwer.

O'Lynn, C. (2017). Rethinking indicators of academic quality in nursing programs. Journal of Nursing Education, 56(4), 195-196. https://doi. org/10.3928/01484834-20170323-01

Papes, K., \& Lopez, R. (2007). Establishing a method for tracking persistence rates of nursing students: One school's experience. Journal of Professional Nursing, 23(4), 241-246. https://doi.org/10.1016/j. profnurs.2007.01.004

Pitt, V., Powis, D., Levett-Jones, T., \& Hunter, S. (2012). Factors influencing nursing students' academic and clinical performance and attrition: An integrative review. Nurse Education Today, 32(8), 903-913. https://doi.org/10.1016/j.nedt.2012.04.011

Pittman, P., Bass, E., Han, X., \& Kurtzman, E. (2019). The growth and performance of nursing programs by ownership status. Journal of Nursing Regulation, 9(4), 5-21. https://doi.org/10.1016/S21558256(19)30011-0

Quality and Safety Education for Nurses. (2019). QSEN Competencies. http://qsen.org/competencies/pre-licensure-ksas/

Randolph, P. (2013). Program Outcome Index: A measure of program effectiveness. Leader to Leader. https://www.ncsbn.org/L2L_Fall2013_ v5.pdf

Randolph, P. K. (2016). Standardized testing practices: Effect on graduation and NCLEX pass rates. Journal of Professional Nursing, 33(3), 224-228. https://doi.org/10.1016/j.profnurs.2016.09.002

Rayens, M. K., \& Hahn, E. J. (2000). Building consensus using the Policy Delphi method. Policy, Politics, E Nursing Practice, 1(4), 308-315. https://doi.org/10.1177/152715440000100409

Reyna, R. (2010). Complete to compete: Common college completion metrics. National Governors Association.

Robert's Rules Online. (n.d.). Roberts' Rules of Order Revised (4th ed.). http:// www.rulesonline.com/rror-07.htm.

Rusch, L., Manz, J. A., Hercinger, M., Oertwich, A., \& McCafferty, K. (2019). Nurse preceptor perceptions of nursing student progress toward readiness for practice. Nurse Educator, 44(1), 34-37. https:// doi.org/10.1097/NNE.0000000000000546

Sandelowski, M. (2000). Whatever happened to qualitative description? Research in Nursing and Health, 23(4), 334-340.

Sandelowski, M. (2009). What's in a name? Qualitative description revisited. Research in Nursing and Health, 33(1), 77-84. https://doi. org/10.1002/nur.20362
Sax, S. (1978). Nurse education and training: Report of the Committee of Inquiry Into Nurse Education and Training to the Tertiary Education Commission. Tertiary Education Commission. https://www.voced.edu.au/content/ ngv\%3A35641.

The Secretary's Recognition of Accrediting Agencies, 34 C.F.R. $\$ 602.16$ (2009). https://www2.ed.gov/policy/highered/reg/hearulemaking/ hea08/34cfr602.pdf

Silvestre, J. H. (2020). Percentages of programs that are accredited: An update. Leader to Leader. https://www.ncsbn.org/LTL_Spring2020.pdf

Smiley, R. A. (2019). Survey of simulation use in prelicensure nursing programs: Changes and advancements, 2010-2017. Journal of Nursing Regulation, 9(4), 48-61. https://doi.org/10.1016/S21558256(19)30016-X

Spector, N., Blegen, M. A., Silvestre, J., Barnsteiner, J., Lynn, M. R., Ulrich, B., Fogg, L., \& Alexander, M. (2015). Transition to practice study in hospital settings. Journal of Nursing Regulation, 5(4), 24-38. https://doi.org/10.1016/S2155-8256(15)30031-4

Spector, N., Hooper, J. I., Silvestre, J., \& Qian, H. (2018). Board of nursing approval of registered nurse education programs. Journal of Nursing Regulation, 8(4), 22-29. https://doi.org/10.1016/ S2155-8256(17)30178-3

Spector, N., \& Woods, S. L. (2013). A collaborative model for approval of prelicensure nursing programs. Journal of Nursing Regulation, 3(4), 47-52. https://doi.org/10.1016/S2155-8256(15)30186-1

Taylor, H., Loftin, C., \& Reyes, H. (2014). First-time NCLEX-RN pass rate: Measure of program quality or something else? Journal of Nursing Education, 53(6), 336-341. https://doi.org/ 10.3928/0148483420140520-02

van Houwelingen, C.T., Moerman, A.H., Ettema, R.G.A., Kort, H.S., \& Ten Cate, O. (2016). Competencies required for telehealth activities: A Delphi-study. Nurse Education Today, 39, 50-62. https://doi. org/10.1016/j.nedt.2015.12.025

Wellman, J., Johnson, N., \& Steele, P. (2012). Measuring (and managing) the invisible costs of postsecondary attrition [Policy brief]. American Institutes for Research. 


\section{APPENDIX A}

\section{Definition of Terms}

\begin{tabular}{|c|c|}
\hline Annual Report & $\begin{array}{l}\text { Contains data the NRBs require from the nursing programs on a yearly basis. These data are not con- } \\
\text { sistent among the NRBs but often consist of faculty, student, and program demographic data; pro- } \\
\text { gram resources; student outcomes; clinical experiences; curriculum; etc. }\end{array}$ \\
\hline $\begin{array}{l}\text { Approval of nursing education } \\
\text { programs }\end{array}$ & $\begin{array}{l}\text { Official recognition of nursing education programs that go through a systematic approval process } \\
\text { implemented by U.S. BONs, thus meeting regulatory standards and being able to make their stu- } \\
\text { dents eligible to take the nursing licensure examination. In most states, the approval process will be } \\
\text { designated as full approval when all requirements are met; conditional or probationary or other des- } \\
\text { ignations when some of the requirements are met; or approval removal when programs fail to cor- } \\
\text { rect cited deficiencies (adapted from Spector et al., 2018). }\end{array}$ \\
\hline Graduation rates & Number and percentage of degree-seeking students who graduate within the normal program time. \\
\hline Hybrid learning modality & Blended elements of face-to-face and online instruction. \\
\hline Metrics & $\begin{array}{l}\text { For the purposes of this report, those measures that are used when evaluating the outcomes, quality, } \\
\text { and warning signs of nursing programs. }\end{array}$ \\
\hline $\begin{array}{l}\text { NCLEX-RN predictor } \\
\text { examinations }\end{array}$ & $\begin{array}{l}\text { Examinations developed by proprietary companies external (not related) to NCSBN. The examina- } \\
\text { tions are intended to measure the readiness of a graduating nursing student to take the NCLEX-RN. } \\
\text { They are also termed exit examinations. }\end{array}$ \\
\hline $\begin{array}{l}\text { Practice readiness of graduat- } \\
\text { ing students }\end{array}$ & $\begin{array}{l}\text { Newly licensed nurses being able to deliver consistent, competent, and safe care in predictable situa- } \\
\text { tions, with some guidance in more complex situations (adapted from Cantlay et al., 2017; Kavanagh } \\
\text { \& Szweda, 2017). }\end{array}$ \\
\hline Quality clinical experiences & $\begin{array}{l}\text { Either in face-to-face clinical experiences or in simulation, under the oversight of an experienced clin- } \\
\text { ical instructor, the intentional integration of knowledge, clinical reasoning, skilled know-how, and eth- } \\
\text { ical comportment across the lifespan (adapted from Benner et al., 2010). }\end{array}$ \\
\hline Quality indicators & $\begin{array}{l}\text { As adapted from the Agency for Healthcare Research and Quality (https://www.qualityindicators. } \\
\text { ahrq.gov/), quality indicators are evidence-based measures of nursing education outcomes that are } \\
\text { readily available data to track program performance. }\end{array}$ \\
\hline
\end{tabular}

Note. $\mathrm{NRB}=$ nursing regulatory board; $\mathrm{BON}=$ board of nursing; $\mathrm{NCSBN}=$ National Council of State Boards of Nursing. 


\section{APPENDIX B1}

\section{The Johns Hopkins Evidence Levels and Quality Ratings}

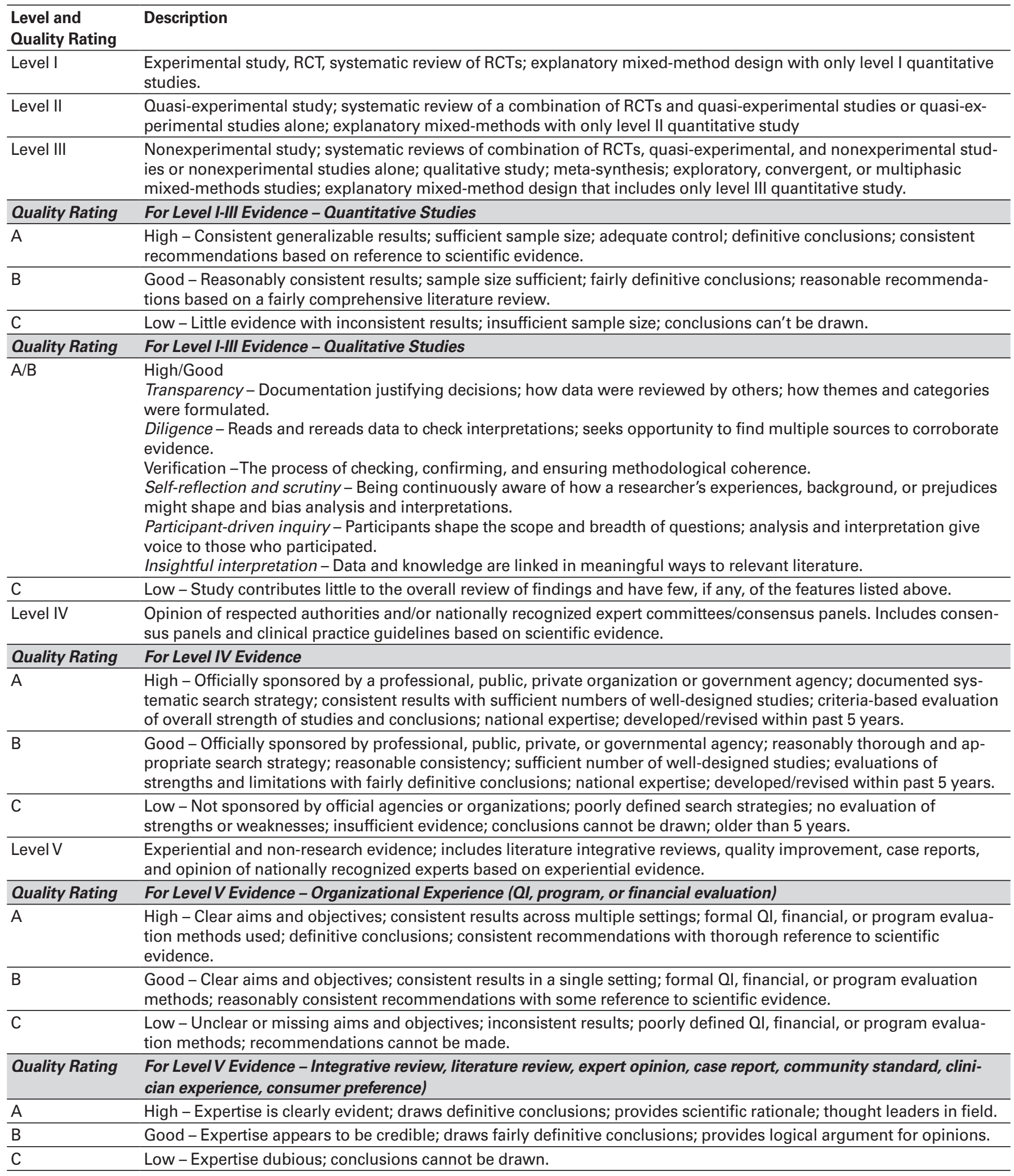

Note. $\mathrm{RCT}=$ randomized controlled trial; $\mathrm{Ql}=$ quality improvement;

Source: Dang, D., \& Dearholt, S. (2017). Johns Hopkins nursing evidence-based practice: Models and guidelines (3rd ed.). Sigma Theta Tau International. pp. 278-279. 
APPENDIX B2

\section{Evidence-Based Publications and Key Findings for Nursing Education Performance Metrics}

\begin{tabular}{|c|c|c|c|c|}
\hline Citation & $\begin{array}{l}\text { Type of } \\
\text { Publication }\end{array}$ & Purpose & Key Findings & $\begin{array}{l}\text { Evidence } \\
\text { Level }^{\mathrm{a}}\end{array}$ \\
\hline $\begin{array}{l}\text { Accreditation } \\
\text { Commission for } \\
\text { Education in Nurs- } \\
\text { ing (ACEN; 2019) }\end{array}$ & $\begin{array}{l}\text { ACEN standards } \\
\text { manual }\end{array}$ & $\begin{array}{l}\text { To provide ACEN standards and } \\
\text { criteria to nursing education pro- } \\
\text { grams obtaining accreditation. }\end{array}$ & $\begin{array}{l}\text { Standards: (1) mission and administrative capacity, } \\
\text { (2) faculty and staff, (3) students, (4) curriculum, (5) } \\
\text { resources, and (6) outcomes. }\end{array}$ & IV A* \\
\hline Alexander (2019) & Editorial & $\begin{array}{l}\text { To evaluate nursing education } \\
\text { programs. }\end{array}$ & $\begin{array}{l}\text { Several warning signs were presented from the } \\
\text { regulatory perspective. }\end{array}$ & VA \\
\hline Barrett et al. (2016) & $\begin{array}{l}\text { National Coun- } \\
\text { cil of Examiners } \\
\text { for Engineering } \\
\text { and Surveying } \\
\text { report }\end{array}$ & $\begin{array}{l}\text { To report statistics on using the ap- } \\
\text { plication of Fundamentals in Engi- } \\
\text { neering examination as an out- } \\
\text { comes assessment tool. }\end{array}$ & $\begin{array}{l}\text { Pass rates of the examination should not be used to } \\
\text { determine curricular content of any program. }\end{array}$ & $\begin{array}{l}\text { IV A vs } \\
B^{*}\end{array}$ \\
\hline $\begin{array}{l}\text { Benner et al. } \\
\text { (2010) }\end{array}$ & $\begin{array}{l}\text { Book presenting } \\
\text { a longitudinal } \\
\text { mixed-methods } \\
\text { study of preli- } \\
\text { censure (all lev- } \\
\text { els) RN educa- } \\
\text { tion programs }\end{array}$ & $\begin{array}{l}\text { To describe the changes in nursing } \\
\text { education since the Lysaught study } \\
\text { was released } 40 \text { years ago. Spon- } \\
\text { sored by the The Carnegie Founda- } \\
\text { tion for the Advancement of } \\
\text { Teaching. }\end{array}$ & $\begin{array}{l}\text { A major finding was that nurses are undereducated } \\
\text { for the current demands of practice. Other key find- } \\
\text { ings include: } \\
\text { (1) U.S. nursing programs are very effective in } \\
\text { forming professional identity and ethical beliefs. } \\
\text { (2) Clinical practice assignments provide powerful } \\
\text { learning experiences, especially in programs where } \\
\text { educators integrate clinical and classroom } \\
\text { teaching. } \\
\text { (3) U.S. nursing programs are not effective in teach- } \\
\text { ing nursing science, natural sciences, social scienc- } \\
\text { es, technology, and the humanities. }\end{array}$ & II A \\
\hline $\begin{array}{l}\text { Bernier et al. } \\
(2005)\end{array}$ & $\begin{array}{l}\text { Peer-reviewed } \\
\text { article }\end{array}$ & $\begin{array}{l}\text { To present a case for not using } \\
\text { NCLEX first-time pass rates as a } \\
\text { sole indicator of quality. }\end{array}$ & $\begin{array}{l}\text { Recommended more research in using first-time } \\
\text { NCLEX pass rates and cautioned about using them } \\
\text { as a sole indicator. }\end{array}$ & VA \\
\hline $\begin{array}{l}\text { Canadian Council } \\
\text { of Registered } \\
\text { Nurse Regulators } \\
(2018)\end{array}$ & $\begin{array}{l}\text { Draft report of } \\
\text { entry-level com- } \\
\text { petencies of } \\
\text { RNs in Canada }\end{array}$ & $\begin{array}{l}\text { To describe the competencies for } \\
\text { entry-level RN practice developed } \\
\text { by } 11 \text { jurisdictions in Canada. }\end{array}$ & $\begin{array}{l}\text { Competencies were developed under the theme of } \\
\text { clinician, communicator, collaborator, advocate, ed- } \\
\text { ucator, leader, professional, scholar, and } \\
\text { coordinator. }\end{array}$ & IV B \\
\hline $\begin{array}{l}\text { Candela \& Bowles } \\
\text { (2008) }\end{array}$ & $\begin{array}{l}\text { Peer-reviewed } \\
\text { research }\end{array}$ & $\begin{array}{l}\text { To describe a statewide study of } \\
352 \text { new graduates on their educa- } \\
\text { tional preparation for practice. }\end{array}$ & $\begin{array}{l}\text { Gaps found included insufficient pharmacology } \\
\text { content, lack of management and leadership prepa- } \\
\text { ration, and lack of preparation in electronic data } \\
\text { measurement. Graduates felt educators did not } \\
\text { prepare them for practice but instead to pass the } \\
\text { NCLEX. A majority indicated they needed more } \\
\text { clinical hours in the program. }\end{array}$ & III B \\
\hline
\end{tabular}




\begin{tabular}{lll}
\hline Citation & $\begin{array}{l}\text { Type of } \\
\text { Publication }\end{array}$ & Purpose \\
\hline $\begin{array}{l}\text { Cantlay et al. } \\
\text { (2017) }\end{array}$ & $\begin{array}{l}\text { Peer-reviewed } \\
\text { research }\end{array}$ & $\begin{array}{l}\text { To survey 183 new graduates from } \\
\text { an accelerated prelicensure mas- } \\
\text { ter's program in Australia. }\end{array}$ \\
\hline $\begin{array}{l}\text { Cohen \& Ibrahim } \\
\text { (2008) }\end{array}$ & $\begin{array}{l}\text { Higher educa- } \\
\text { tion journal arti- } \\
\text { cle but not peer } \\
\text { reviewed }\end{array}$ & $\begin{array}{l}\text { To reflect on the use of graduation } \\
\text { choice in the assessment of the } \\
\text { performance of higher education. }\end{array}$ \\
\hline $\begin{array}{l}\text { College of Nurses } \\
\text { of Ontario (2018) }\end{array}$ & $\begin{array}{l}\text { Report from the } \\
\text { College of Nurs- } \\
\text { es of Ontario }\end{array}$ & $\begin{array}{l}\text { To provide overview of nursing ed- } \\
\text { Ontario. }\end{array}$ \\
& &
\end{tabular}

Key Findings $\quad$ Evidence

Level ${ }^{\mathrm{a}}$

New graduates were weak in leadership, team

III B

management, responding to clinical emergencies, and recognizing abnormal laboratory findings; however, $94 \%$ felt equally or more prepared than other graduates in their work environments.

A new metric was proposed:The graduation effi- IV C ciency metric.

Standards were developed in the areas of nursing IV A program governance, client and student safety, qualified faculty, entry to practice competencies, clinical learning opportunities, communication with preceptors, examination first-time pass rates, graduates' rating of their preparation, and preceptors' rating of students' readiness to practice.

\begin{tabular}{ll}
\hline $\begin{array}{l}\text { Commission on } \\
\text { Collegiate Nursing } \\
\text { Education (2018) }\end{array}$ & $\begin{array}{l}\text { Commission on } \\
\text { ing Education }\end{array}$ \\
& $\begin{array}{l}\text { Toccreditation } \\
\text { manual }\end{array}$ \\
\hline $\begin{array}{l}\text { Cook \& Hartle } \\
\text { (2011) }\end{array}$ & $\begin{array}{l}\text { Report from the } \\
\text { American Coun- ation rates. } \\
\text { cil of Education }\end{array}$
\end{tabular}
Standards: (1) program quality: mission and gover- IV A nance, (2) institutional commitment and resources, (3) program quality: curriculum and teaching-learning practices, (4) program effectiveness: assessment and achievement of program outcomes. The IPEDS calculation excludes students who begin V A college part time, who enroll mid-year, and who transfer from one institution to another. Put another way, IPEDS counts only those students who enroll in an institution as full-time degree-seekers and finish a degree at the same institution within a prescribed period of time.

\begin{tabular}{lll}
\hline $\begin{array}{l}\text { Cronenwett et al. } \\
\text { (2007) }\end{array}$ & $\begin{array}{l}\text { Peer-reviewed } \\
\text { article }\end{array}$ & $\begin{array}{l}\text { To describe the QSEN initiative, } \\
\text { which includes adapting the Insti- } \\
\text { tute of Medicine competencies for } \\
\text { nursing. }\end{array}$
\end{tabular}
Definitions of essential features of a competent IV A nurse are provided within each of the QSEN competencies; knowledge, skills, and attitudes for each QSEN competency are identified; the QSEN competencies include patient-centered care, teamwork and collaboration, evidence-based practice, quality improvement, safety, and informatics.

\begin{tabular}{lll}
\hline DeAngelo et al. & Report of the & To provide data-driven information \\
(2011) & University of & on how to assess institutional \\
& California, Los & graduation rates, emphasizing the \\
& Angeles Higher & importance of taking into account \\
& Education Re- & the characteristics of students \\
& search Institute & whom institutions enroll.
\end{tabular}

Private universities have the highest raw degree completion rates and public 4-year colleges have the lowest.

By comparing expected and actual graduation rates, much of the success of private universities in degree completion comes from the strength of the students they enroll.

Instead of comparing raw degree completion rates, institutions can be evaluated by how they perform in moving students toward degree completion based on the characteristics and experiences of their students; in this manner, public institutions have lower overall graduation rates but more success in moving the students they enroll toward graduation.

\begin{tabular}{llll}
\hline $\begin{array}{l}\text { Docherty \& Dieck- } \\
\text { mann (2015) }\end{array}$ & $\begin{array}{l}\text { Peer-reviewed } \\
\text { research }\end{array}$ & $\begin{array}{l}\text { To describe a cross-sectional de- } \\
\text { scriptive study of } 84 \text { faculty on fail- } \\
\text { ing and grading of students. }\end{array}$ & $\begin{array}{l}\text { The majority of faculty feel confident in their grad- } \\
\text { ing practices; however, the findings also suggest } \\
\text { that faculty fail to fail students in both didactic and } \\
\text { clinical courses. }\end{array}$ \\
\hline $\begin{array}{lll}\text { Eberle-Sudré et al. } \\
\text { (2015) }\end{array}$ & $\begin{array}{l}\text { Research brief } \\
\text { from The Educa- } \\
\text { tionTrust }\end{array}$ & $\begin{array}{l}\text { To question whether college grad- } \\
\text { uation rates benefit the diversity of } \\
\text { students. }\end{array}$ & $\begin{array}{l}\text { Validating with statistics, the article asserts that us- } \\
\text { ing graduation rates for student outcomes uneven- } \\
\text { ly benefits students with certain demographics. }\end{array}$ \\
\hline
\end{tabular}




\begin{tabular}{|c|c|c|c|c|}
\hline Citation & $\begin{array}{l}\text { Type of } \\
\text { Publication }\end{array}$ & Purpose & Key Findings & $\begin{array}{l}\text { Evidence } \\
\text { Level }^{\mathrm{a}}\end{array}$ \\
\hline $\begin{array}{l}\text { El Haddad et al. } \\
\text { (2017) }\end{array}$ & $\begin{array}{l}\text { Peer-reviewed } \\
\text { research }\end{array}$ & $\begin{array}{l}\text { Using grounded theory, to exam- } \\
\text { ine practice readiness from the } \\
\text { perspective of nurse unit manag- } \\
\text { ers from the acute care practice } \\
\text { sector and nursing program coor- } \\
\text { dinators from the education sector. }\end{array}$ & $\begin{array}{l}\text { The authors strongly advocate for nursing pro- } \\
\text { grams to have collaborative education-practice } \\
\text { partnerships. }\end{array}$ & III A/B \\
\hline $\begin{array}{l}\text { Feeg \& Mancino } \\
\text { (2018) }\end{array}$ & $\begin{array}{l}\text { National Stu- } \\
\text { dent Nurses' } \\
\text { Association } \\
\text { newsletter }\end{array}$ & $\begin{array}{l}\text { To provide data on the } 2017 \text { job } \\
\text { market and insight into education } \\
\text { and health care trends. }\end{array}$ & $\begin{array}{l}\text { Data on employment provided by region and type } \\
\text { of program, as well as staying in their current posi- } \\
\text { tion, job market challenges, and student debt. }\end{array}$ & III B \\
\hline Foreman (2017) & $\begin{array}{l}\text { Peer-reviewed } \\
\text { research }\end{array}$ & $\begin{array}{l}\text { To compute a } 95 \% \text { confidence in- } \\
\text { terval for } 1,792 \text { nursing program } \\
\text { pass rates from } 2010-2014 \text { to deter- } \\
\text { mine whether programs that met } \\
\text { or failed to meet pass rate stan- } \\
\text { dards may have done so by } \\
\text { accident. }\end{array}$ & $\begin{array}{l}\text { Application of confidence intervals to nursing pro- } \\
\text { gram pass rates suggests that use of pass rate stan- } \\
\text { dards to evaluate nursing program quality may not } \\
\text { be appropriate. }\end{array}$ & III A \\
\hline Gonzalez (2018) & $\begin{array}{l}\text { Peer-reviewed } \\
\text { article }\end{array}$ & $\begin{array}{l}\text { To develop a concept-based learn- } \\
\text { ing method for clinical reasoning. }\end{array}$ & $\begin{array}{l}\text { The author developed strategies to integrate clini- } \\
\text { cal reasoning into teaching, such as focusing on } \\
\text { documentation, diagnosis, communication, inter- } \\
\text { ventions, prioritization, putting it all together, and } \\
\text { reflection. }\end{array}$ & VA \\
\hline Grant (2015) & Doctoral thesis & $\begin{array}{l}\text { To identify the relationship be- } \\
\text { tween NCLEX-RN success and the } \\
\text { following: (1) prenursing GPA and } \\
\text { final GPA, (2) age and gender, (3) } \\
\text { ATI predictor scores. }\end{array}$ & $\begin{array}{l}\text { The study findings include no relationship between } \\
\text { NCLEX success and prenursing GPA, final GPA, and } \\
\text { gender, but there was a relationship between } \\
\text { NCLEX success and age and ATI predictor scores. }\end{array}$ & III B \\
\hline $\begin{array}{l}\text { Hayden et al. } \\
(2014)\end{array}$ & $\begin{array}{l}\text { Peer-reviewed } \\
\text { research }\end{array}$ & $\begin{array}{l}\text { Randomized controlled trial to in- } \\
\text { vestigate replacing clinical hours } \\
\text { with simulation in prelicensure } \\
\text { nursing education. }\end{array}$ & $\begin{array}{l}\text { Provides evidence that substituting high-quality } \\
\text { simulation experiences for up to half of traditional } \\
\text { clinical hours produces comparable educational } \\
\text { outcomes and new graduates who are ready for } \\
\text { clinical practice. }\end{array}$ & IA \\
\hline $\begin{array}{l}\text { Hickerson et al. } \\
\text { (2016) }\end{array}$ & $\begin{array}{l}\text { Peer-reviewed } \\
\text { article }\end{array}$ & $\begin{array}{l}\text { To describe an integrative review } \\
\text { of } 50 \text { articles related to the exis- } \\
\text { tence, extent, and significance of a } \\
\text { preparation-practice gap. }\end{array}$ & $\begin{array}{l}\text { The following three main themes were identified: a } \\
\text { preparation-practice gap exists; this gap is costly; } \\
\text { and closing the gap will likely rely on changes in } \\
\text { undergraduate education and on-the-job remedia- } \\
\text { tion, such as nurse residencies and preceptorship } \\
\text { programs. }\end{array}$ & VA \\
\hline
\end{tabular}




\begin{tabular}{|c|c|c|c|c|}
\hline Citation & $\begin{array}{l}\text { Type of } \\
\text { Publication }\end{array}$ & Purpose & Key Findings & $\begin{array}{l}\text { Evidence } \\
\text { Level }^{a}\end{array}$ \\
\hline $\begin{array}{l}\text { Hooper \& Ayars } \\
(2017)\end{array}$ & $\begin{array}{l}\text { Peer-reviewed } \\
\text { article }\end{array}$ & $\begin{array}{l}\text { To summarize findings from a re- } \\
\text { view of } 88 \text { nursing education self- } \\
\text { study reports across a } 3 \text {-year peri- } \\
\text { od (2013-2015) and survey the } \\
\text { programs regarding which inter- } \\
\text { ventions were most effective. }\end{array}$ & $\begin{array}{l}\text { Three common interventions found to be extremely } \\
\text { effective were (1) identifying at-risk students earlier, } \\
\text { (2) providing timely remediation for at-risk stu- } \\
\text { dents, and (3) enforcing program policies. }\end{array}$ & VA \\
\hline $\begin{array}{l}\text { Jamshidi et al. } \\
\text { (2016) }\end{array}$ & $\begin{array}{l}\text { Peer-reviewed } \\
\text { research }\end{array}$ & $\begin{array}{l}\text { Using a qualitative study, to identi- } \\
\text { fy how the clinical learning envi- } \\
\text { ronment could improve students' } \\
\text { readiness to practice in Iran. }\end{array}$ & $\begin{array}{l}\text { The following challenges exist: lack of communica- } \\
\text { tion skills, lack of theoretical knowledge and practi- } \\
\text { cal skills, stress, and inferiority complexes. }\end{array}$ & III $A / B$ \\
\hline $\begin{array}{l}\text { Kavanagh \& Sz- } \\
\text { weda (2017) }\end{array}$ & $\begin{array}{l}\text { Peer-reviewed } \\
\text { research }\end{array}$ & $\begin{array}{l}\text { Posthire and prestart performance- } \\
\text { based development system as- } \\
\text { sessments were administered to } \\
\text { more than 5,000 new graduate } \\
\text { nurses to assess entry-level com- } \\
\text { petency and practice readiness. }\end{array}$ & $\begin{array}{l}\text { Aggregate baseline data indicate that only } 23 \% \text { of } \\
\text { new graduate nurses demonstrate entry-level com- } \\
\text { petencies and practice readiness. }\end{array}$ & III C \\
\hline $\begin{array}{l}\text { Libner \& Kubala } \\
\text { (2017) }\end{array}$ & $\begin{array}{l}\text { Peer-reviewed } \\
\text { article }\end{array}$ & $\begin{array}{l}\text { To describe the response of the IIIi- } \\
\text { nois Board of Nursing when } \\
\text { NCLEX pass rates fall below } \\
\text { standards. }\end{array}$ & $\begin{array}{l}\text { Major themes include improvement in curriculum } \\
\text { and resources, faculty and professional develop- } \\
\text { ment, student-to-faculty ratios, and academic and } \\
\text { administrative support. }\end{array}$ & VA \\
\hline Linaker (2015) & $\begin{array}{l}\text { Peer-reviewed } \\
\text { research }\end{array}$ & $\begin{array}{l}\text { Narrative literature review of } 54 \text { ar- } \\
\text { ticles to examine radiology student } \\
\text { evaluation and outcome assess- } \\
\text { ments including national board } \\
\text { examinations. }\end{array}$ & $\begin{array}{l}\text { There are no definitive conclusions between mas- } \\
\text { tery of radiology with any specific evaluation, out- } \\
\text { come, or preprofessional/clinical grades. }\end{array}$ & $V A^{*}$ \\
\hline Longabach (2012) & Master's thesis & $\begin{array}{l}\text { To examine the relationship be- } \\
\text { tween NCLEX pass rates and the } \\
\text { number of clinical hours complet- } \\
\text { ed by a student in } 92 \text { nursing pro- } \\
\text { grams in the states of Kansas and } \\
\text { Missouri. }\end{array}$ & $\begin{array}{l}\text { No statistically significant correlation was found be- } \\
\text { tween NCLEX pass rates and the number of clinical } \\
\text { clock hours. Increased NCLEX pass rates were } \\
\text { found with doctorally prepared faculty, but this was } \\
\text { not statistically significant. }\end{array}$ & III B \\
\hline
\end{tabular}




\begin{tabular}{|c|c|c|c|c|}
\hline Citation & $\begin{array}{l}\text { Type of } \\
\text { Publication }\end{array}$ & Purpose & Key Findings & $\begin{array}{l}\text { Evidence } \\
\text { Level }^{\mathrm{a}}\end{array}$ \\
\hline Luhanga (2014) & $\begin{array}{l}\text { Peer-reviewed } \\
\text { research }\end{array}$ & $\begin{array}{l}\text { Qualitative descriptive study to ex- } \\
\text { plore "failure to fail" in Canadian } \\
\text { professional programs, including } \\
\text { nursing, education, and social } \\
\text { work. }\end{array}$ & $\begin{array}{l}\text { Results include (1) failing a student is a difficult pro- } \\
\text { cess; (2) both academic and emotional support are } \\
\text { required for students and field instructors/precep- } \\
\text { tors/faculty advisors; (3) there are consequences for } \\
\text { programs, faculty, and students when a student has } \\
\text { failed a placement; (4) sometimes personal, profes- } \\
\text { sional, and structural reasons exist for failing to fail } \\
\text { a student; and (5) the reputation of the professional } \\
\text { program can be diminished as a result of failing to } \\
\text { fail a student. }\end{array}$ & III A/B \\
\hline $\begin{array}{l}\text { Missen et al. } \\
(2016)\end{array}$ & $\begin{array}{l}\text { Peer-reviewed } \\
\text { research }\end{array}$ & $\begin{array}{l}\text { To provide descriptive quantitative } \\
\text { study of qualified nurses' }(n=201) \\
\text { perceptions of new graduate nurs- } \\
\text { es' abilities. }\end{array}$ & $\begin{array}{l}\text { New graduates were lacking in advanced clinical } \\
\text { skills (those in the last year of their programs) and } \\
\text { coping with nursing practice. Additionally, signifi- } \\
\text { cant differences were found in the evaluators of the } \\
\text { new graduates' abilities based on the evaluators' } \\
\text { demographic and clinical characteristics (e.g., age, } \\
\text { length of registration/licensure, role, clinical set- } \\
\text { ting). New graduate nurses generally were rated } \\
\text { lower by evaluators who were older, have been } \\
\text { registered/licensed for a longer period of time, and } \\
\text { whose roles include nurse manager and nurse edu- } \\
\text { cator, thus illustrating the need to establish reliabili- } \\
\text { ty on all who evaluate new graduates. }\end{array}$ & III B \\
\hline NASEM (2018) & $\begin{array}{l}\text { Proceedings of } \\
\text { a workshop }\end{array}$ & $\begin{array}{l}\text { To provide an in-depth discussion } \\
\text { of graduate medical education out- } \\
\text { comes and metrics. }\end{array}$ & $\begin{array}{l}\text { Seven themes: (1) measuring outcomes is impor- } \\
\text { tant for professional accountability; (2) data are } \\
\text { readily available; (3) information is needed on how } \\
\text { they are performing in clinical and academic set- } \\
\text { tings; (4) challenges with assessing and guiding the } \\
\text { physician workforce were outlined; (5) gathering } \\
\text { and using data is complicated; (6) more funding is } \\
\text { needed; and (7) a data repository is needed. }\end{array}$ & IV A \\
\hline $\begin{array}{l}\text { NASEM (2016, pp. } \\
57-80)\end{array}$ & $\begin{array}{l}\text { Essay provided } \\
\text { for an NASEM } \\
\text { workshop on } \\
\text { quality of higher } \\
\text { education }\end{array}$ & $\begin{array}{l}\text { To outline how student and broad- } \\
\text { er societal outcomes should be pri- } \\
\text { oritized as the general measure for } \\
\text { assessing quality. }\end{array}$ & $\begin{array}{l}\text { Many data elements measuring quality are not } \\
\text { comparable across institutions due to different con- } \\
\text { ceptual definitions and populations. College quality } \\
\text { is multidimensional because students and society } \\
\text { expect many different outcomes. }\end{array}$ & VA \\
\hline $\begin{array}{l}\text { National League } \\
\text { for Nursing (2016) }\end{array}$ & $\begin{array}{l}\text { National League } \\
\text { for Nursing } \\
\text { Commission for } \\
\text { Nursing Educa- } \\
\text { tion Accredita- } \\
\text { tion's accredita- } \\
\text { tion manual }\end{array}$ & $\begin{array}{l}\text { To provide standards to nursing } \\
\text { education programs obtaining } \\
\text { accreditation. }\end{array}$ & $\begin{array}{l}\text { Standards include program outcomes, mission } \\
\text { governance and resources, faculty, students, curric- } \\
\text { ulum, and evaluation processes. }\end{array}$ & IV A \\
\hline
\end{tabular}




\begin{tabular}{|c|c|c|c|c|}
\hline Citation & $\begin{array}{l}\text { Type of } \\
\text { Publication }\end{array}$ & Purpose & Key Findings & $\begin{array}{l}\text { Evidence } \\
\text { Level }^{\mathrm{a}}\end{array}$ \\
\hline NCSBN (2005) & $\begin{array}{l}\text { NCSBN position } \\
\text { paper }\end{array}$ & $\begin{array}{l}\text { To provide guidance to nursing } \\
\text { regulatory bodies for evaluating } \\
\text { the clinical experience component } \\
\text { of prelicensure programs. }\end{array}$ & $\begin{array}{l}\text { The positions include the following: } \\
\text { (1) Prelicensure nursing educational experiences } \\
\text { should be across the lifespan. } \\
\text { (2) Prelicensure nursing education programs shall } \\
\text { include clinical experiences with actual patients; } \\
\text { they might also include innovative teaching strate- } \\
\text { gies that complement clinical experiences for entry } \\
\text { into practice competency. } \\
\text { (3) Prelicensure clinical education should be super- } \\
\text { vised by qualified faculty who provide feedback and } \\
\text { facilitate reflection. } \\
\text { (4) Faculty members retain the responsibility to } \\
\text { demonstrate that programs have clinical experienc- } \\
\text { es with actual patients that are sufficient to meet } \\
\text { program outcomes. } \\
\text { (5) Additional research needs to be conducted on } \\
\text { prelicensure nursing education and the develop- } \\
\text { ment of clinical competency. }\end{array}$ & IV C* \\
\hline NCSBN (2006) & $\begin{array}{l}\text { NCSBN re- } \\
\text { search brief }\end{array}$ & $\begin{array}{l}\text { To describe the elements of nurs- } \\
\text { ing education that lead to better } \\
\text { preparation of new nurse } \\
\text { graduates. }\end{array}$ & $\begin{array}{l}\text { Graduates were more likely to believe their pro- } \\
\text { gram adequately prepared them for practice when } \\
\text { programs: } \\
\text { Taught use of information technology and evi- } \\
\text { dence-based practice. } \\
\text { Integrated pathophysiology and critical thinking } \\
\text { throughout the curriculum. } \\
\text { Taught content related to the care of specific client } \\
\text { populations as independent courses. } \\
\text { Had a higher percentage of faculty teaching both di- } \\
\text { dactic and clinical components of the curriculum. }\end{array}$ & III A \\
\hline
\end{tabular}

\begin{tabular}{|c|c|c|}
\hline $\begin{array}{l}\text { Nursing Education } \\
\text { Outcomes and } \\
\text { Metrics Commit- } \\
\text { tee (2017) }\end{array}$ & $\begin{array}{l}\text { NCSBN commit- } \\
\text { tee report }\end{array}$ & $\begin{array}{l}\text { To survey U.S. nursing regulatory } \\
\text { bodies on their quality indicators, } \\
\text { warning signs, and outcomes } \\
\text { when approving programs. }\end{array}$ \\
\hline
\end{tabular}

Odom-Maryon et Peer-reviewed National study to examine institual. (2018) research
National study to examine institu-
tional characteristics among nursing programs associated with NCLEX-RN first-time pass rates.
Eight quality indicators and nine warning signs were provided. The NCLEX first-time pass rates and noncompliance with rules/regulations were the leading outcome criteria used when approving programs.

The results showed a statistically significant inIII A crease in NCLEX pass rates with public schools, semester schedules, larger admission cohorts, more students per didactic faculty, a higher percentage of full-time faculty, and no use of standardized progression examinations. Predictor examinations did not predict success on the NCLEX. No curricular characteristics were associated with higher pass rates, including the use of simulation, an integrated curriculum (specialties are not offered as separate courses) and online environments. No significant differences were found between pass rates and progression in the program, including individual course grades, minimal course grades, clinical evaluations, and allowing students to repeat courses. Faculty certification in nursing education did not lead to higher NCLEX pass rates. 


\begin{tabular}{|c|c|c|c|c|}
\hline Citation & $\begin{array}{l}\text { Type of } \\
\text { Publication }\end{array}$ & Purpose & Key Findings & $\begin{array}{l}\text { Evidence } \\
\text { Level }^{\mathrm{a}}\end{array}$ \\
\hline Oermann (2017) & Book & $\begin{array}{l}\text { To provide a comprehensive guide } \\
\text { to systematic and ongoing nursing } \\
\text { program evaluation. }\end{array}$ & $\begin{array}{l}\text { Assists nurse educators to understand program } \\
\text { evaluation beyond accreditation; decide how pro- } \\
\text { gram evaluation data should be collected; develop } \\
\text { and implement a program evaluation plan; prepare } \\
\text { for the accreditation process; and use data to make } \\
\text { sound program decisions. }\end{array}$ & VA \\
\hline $\begin{array}{l}\text { Papes \& Lopez } \\
\text { (2007) }\end{array}$ & $\begin{array}{l}\text { Peer-reviewed } \\
\text { research }\end{array}$ & $\begin{array}{l}\text { To develop a tracking system for } \\
\text { persistence/retention rates and use } \\
\text { the findings as part of ongoing } \\
\text { program improvement activities. }\end{array}$ & $\begin{array}{l}\text { Tracking of persistence rates over time is important } \\
\text { for program review, evaluation, and ongoing im- } \\
\text { provement. Persistence rates can be an indicator of } \\
\text { growing issues. }\end{array}$ & VA \\
\hline Randolph (2013) & $\begin{array}{l}\text { NCSBN } \\
\text { newsletter }\end{array}$ & $\begin{array}{l}\text { To describe the Program Outcome } \\
\text { Index, which is a nursing pro- } \\
\text { gram's self-reported on-time grad- } \\
\text { uation rate plus the first-time } \\
\text { NCLEX pass rate within the calen- } \\
\text { dar year. }\end{array}$ & $\begin{array}{l}\text { In 2011, the mean index was } 157 \text { (percentage } \\
\text { NCLEX first-time pass rate and on-time graduation; } \\
\text { maximum is 200). The mean index was } 165 \text { for bac- } \\
\text { calaureate programs, } 155 \text { for associate degree pro- } \\
\text { grams, and } 154 \text { for licensed practical nurse } \\
\text { programs. }\end{array}$ & V B \\
\hline Randolph (2016) & $\begin{array}{l}\text { Peer-reviewed } \\
\text { article }\end{array}$ & $\begin{array}{l}\text { To describe standardized testing } \\
\text { practices across nursing programs } \\
\text { in one state and determine wheth- } \\
\text { er a cut score or oversight remedi- } \\
\text { ation had any effect on (1) first- } \\
\text { time NCLEX pass rates, (2) on-time } \\
\text { graduation, or (3) a combination of } \\
\text { both. }\end{array}$ & $\begin{array}{l}\text { The use of standardized examinations as high- } \\
\text { stakes testing is not supported. }\end{array}$ & III B \\
\hline Rusch et al. (2019) & $\begin{array}{l}\text { Peer-reviewed } \\
\text { research }\end{array}$ & $\begin{array}{l}\text { Descriptive, exploratory study of } \\
15 \text { cohorts }(N=856) \text { to determine } \\
\text { strengths and weaknesses of se- } \\
\text { nior-level nursing students related } \\
\text { to readiness for practice before } \\
\text { graduation. }\end{array}$ & $\begin{array}{l}\text { Students scored highest in professional attributes } \\
\text { but lowest in time management, prioritization, } \\
\text { management of multiple patients, and pharmacolo- } \\
\text { gy knowledge. }\end{array}$ & III B \\
\hline Sax (1978) & $\begin{array}{l}\text { Australian Re- } \\
\text { port of the Com- } \\
\text { mittee of Inquiry } \\
\text { Into Nurse Edu- } \\
\text { cation and Train- } \\
\text { ing to the Tertia- } \\
\text { ry Education } \\
\text { Commission }\end{array}$ & $\begin{array}{l}\text { Describe the recommendations } \\
\text { made to the Tertiary Education } \\
\text { Commission on possible develop- } \\
\text { ments and changes in nurse edu- } \\
\text { cation and training, including } \\
\text { whether nurse education should } \\
\text { take place in hospitals, education } \\
\text { institutions, or both. }\end{array}$ & $\begin{array}{l}\text { The Committee considered three approaches (com- } \\
\text { mon portal of entry, common baseline, and core } \\
\text { curriculum) for allowing commonality of training } \\
\text { between nurses but believed that none were practi- } \\
\text { cable at the time. }\end{array}$ & IV C \\
\hline
\end{tabular}




\section{APPENDIX C}

\section{Final Codebook for Program Analysis}

\section{Students}

- Recruitment

- Demographics (i.e., characteristics that may present teaching and learning challenges, such as English as a foreign language, learning disabilities, etc.)

- Admission criteria (or lack thereof)

- Financial aid

- Services

- Policies

- Performance

- School-student communication

- Postgraduation outcomes

Faculty

- Credentials

- Credentials management

- Content expertise

- Staffing

Student-to-faculty ratio

- Workload

- Relationships

- Development/continuing education

- Incentives/remuneration/ compensation
- Turnover

- Clinical instructors and instruction

- Administrative support

- Teaching quality

- Faculty work space

- Recruitment/retention

- Adequate faculty candidate pool

Leadership

- Program director qualifications

- Program director (not a nurse)

- Physical resources to conduct the job

- Administrative support (time away from teaching)

- Turnover

- Advocacy for resources

- Administration of broader institution/company

Program Management/Implementation

- Administrative support (or lack thereof)

- Use of data

- Poor record keeping

- Faculty and curricular control

- Site visit triggers
- Students get materials at the beginning of the semester

- Program and curriculum evaluation

- Faculty and student input toward policies and procedures

- Appropriate and sufficient clinical sites

- Comprehensive policies

Teaching and Learning Resources

- Teaching resources

- NCLEX preparation materials - Online supplemental tools

- Physical instructional resources

- Simulation laboratory

- Quality of resources

- Office space

- Materials prepared and managed according to internal policies

Organizational Culture

- Higher administration relationships

- Program leadership and faculty relationships

- Student perceptions of the program and faculty

\section{APPENDIX D}

\section{Site Visit Template}

\section{Use of the Site Visit Template:}

This template was developed based on the qualitative 5-year site visit study that NCSBN conducted, looking at programs that were not fully approved by boards of nursing. Each of the items below were found to be lacking in those programs not meeting regulatory standards. Nursing regulatory bodies (NRBs) could use this template as a guide when making a focused site visit. NRBs may choose to adapt this template to customize it to their particular needs.

Date of Site Visit

Name of Education Consultant

Name of Program

Address of Program

Director of Program

Contact Information of Director

NCLEX ${ }^{\circledR}$ Program Code

\section{Program}

1. Current approval status

2. Age of program

3. Ownership of program (for-profit; nonprofit; public)

4. Trend of program's NCLEX ${ }^{\circledR}$ pass rates for 3 years Current year Year 2 Year 3

\section{Administration}

1. Written policies and procedures are available to faculty and students. Yes/No/Comments

2. There is evident student and faculty input into policies and procedures. Yes/No/Comments

3. Record keeping is in place for faculty credentials, course evaluations, and student records. Yes/No/Comments

4. Quality improvement strategies are in place, particularly related to student outcomes and course evaluations. Yes/No/ Comments

5. Students have the educational materials (books, uniforms, software, internet access, syllabi, etc.) they need to be successful.Yes/No/Comments 
6. Data are used to set admission, progression, and student performance. Yes/No/Comments (Below are some key areas to check.)

a. Student socioeconomic status.

b. English as a second language.

c. Presence of children younger than 18 years in the home.

d. Need to work while attending program.

e. Program admission, such as grade point average (GPA), SAT ${ }^{\circledR} /$ ACT $^{\circledR}$, secondary education.

f. Remediation programs, including remediation for clinical errors/near misses, are in place.

g. Program progression (GPA standards, minimum course grades, pass/fail, etc.).

\section{Program Director}

1. How many directors has the program had in the past 5 years (including interim directors)?

2. Is the director in charge of other allied health and/or vocational programs? Yes/No

3. If the answer to \#12 is yes, is there an assistant director for managing the day-to-day operations of the nursing program?Yes/No Explain

4. What is the highest academic degree of the program director?

5. Is the program director a nurse?Yes/No

\section{Faculty}

1. Total number of faculty (including full-time, part-time, adjunct clinical faculty each academic cycle, etc.) is

2. Number of full-time faculty

3. Credentials of faculty (provide separately)

4. Faculty have a basic knowledge of pedagogical methods. Yes/No Comments

5. Workload for faculty is reasonable (average number of courses taught in an academic year). Yes/No Comments

6. All faculty teaching in clinical experiences have performed direct patient care in the past 5 years. Yes/No Comments

7. Formal orientation plan for new full-time/part-time faculty is in place. Yes/No Explain

8. Formal orientation plan for adjunct faculty is in place.Yes/ No Explain

9. There is administrative support for ongoing faculty development. Yes/No Explain

10. All faculty who teach simulation are certified. Yes/No
11. Faculty have control over the curriculum. Yes/No Explain

12. Full-time faculty turnover during the past academic year was

\section{Students}

1. English as a second language assistance is provided on an ongoing basis, when appropriate. Yes/No Comments

2. Resources are available for student learning disabilities. Yes/No/Comments

3. Throughout the program books and resources are provided. Yes/No/Comments

a. When students can't afford books and other required resources, strategies are in place to help them.

4. Remediation strategies are in place so that students are aware of how to seek help. Yes/No/Comments

a. Remediation strategies include errors/near misses made in clinical experiences.

\section{Curriculum and Clinical Experiences}

1. $50 \%$ or more of clinical experiences in each course are direct care with patients. Yes/No

2. Variety of clinical settings with diverse patients. Yes/No Comment

3. Opportunities in clinical experiences for promoting safety and quality. Yes/No/Comment

Evidence-based examples include:

a. Delegation

b. Emergency procedures

c. Interprofessional communication

d. Time management

\section{Teaching and Learning Resources}

1. The simulation laboratory is accredited. Yes/No

a. Simulation laboratory is in working order with up-todate equipment. Yes/No Comment

2. Syllabi are consistent in their design and with internal policies. Yes/No/Comment

a. Course descriptions match the course content and expected outcomes. Yes/No/Comment

3. Physical instructional resources are adequate. Yes/No

a. Full- and part-time faculty have private office space for student meetings. Yes/No/Comment

b. Adjunct faculty have the ability to reserve conference rooms to meet with students. Yes/No/Comment 


\section{APPENDIX E}

\section{Annual Report Core Data Template}

\section{Prelicensure Annual Report Core Data}

\section{Introduction}

In collaboration with your board of nursing (BON), the National Council of State Boards of Nursing (NCSBN) is assisting with collecting their annual report data this year. The survey was designed based on the core data results of a large, mixed-methods study of nursing program quality indicators and warning signs. Your BON may include some additional questions at the end of the survey.

Your BON will receive descriptive results of the nursing programs in their state/jurisdiction, as well as a report of the raw data of each program. Annually, they will receive an aggregate report of all participating BONs so that they can compare their programs to the aggregate.

We are considering this the pilot year for collecting the BONs' annual report data, and we'll be interested in any suggestions you might have as we go forward in future years.

\section{Directions}

Please complete the following survey for each NCLEX code that you have. Since these are core data, all fields are required before you can proceed to the next question. You may go back and make changes, and you may stop, save the survey and then return. You will have 30 days to complete the survey, and we'll send the results to your BON 2 weeks after the survey is due. If you have any questions, please email Qiana Mclntosh at NCSBN at qmcintosh@ncsbn.org.

\section{Contact Information}

Full Name of Program \{Free-text entry\}

Mailing Address of the Program \{Free-text entry\}

City

State

Zip Code

First and Last Name of Person Completing Form \{Free-text entry\}

Direct Phone \# of Person Completing Form \{Numeric response\}

NCLEX ${ }^{\circledR}$ Program Code $\{10$-character alphanumeric code (e.g., US99999999)\}

\section{Program}

1. Does the program have national nursing accreditation? _Yes _No

2. What is the program's current approval status? [Board of nursing or state-designated program approval status.]

$\square$ Full approval

$\square$ Conditional/probationary approval

$\square$ Non-approved

$\square$ Other

3. What best describes the program's geographic location?
$\square$ Urban
$\square$ Suburban
$\square$ Rural
$\square$ Other

4. What is the institutional ownership?
$\square$ Public
$\square$ Private nonprofit
$\square$ Private for-profit

5. What is the program type?

$\square$ Licensed practical nurse/licensed vocational nurse
$\square$ Diploma
$\square$ Registered nurse - associates
$\square$ Registered nurse - bachelor's
$\square$ Registered nurse - accelerated bachelor's
$\square$ Master's entry
$\square$ Other

6. In what year was the program founded? [Year the nursing program started (might be different than the year the col- lege/university was founded).] \{4-digit year\}

7. Does the program have any satellite sites? Yes $\{08\} \quad$ No $\{$ Skip to Q9\}

8. \{If yes to 07$\}$ How many total sites, including the home site, does the program have?

9. What types of learning modalities does the program offer? [Hybrid is defined as a program that combines elements of online learning and traditional in-person learning.]

$\square$ In-person only \{Skip to Q11\}

Online only $\{\mathrm{Q} 10\}$

Hybrid $\{010\}$

10. What percentage of your program is online? \{Sliding scale percentage\}

11. What best describes the program's academic schedule? [A quarter system divides the academic year into four sessions. A trimester divides the academic year into three sessions. A semester system divides the academic year into two sessions.]

$\square$ Quarters
$\square$ Trimesters
$\square$ Semesters
$\square$ Other

12. Does the program administer a formal student orientation process? [A formal student orientation is the process of introducing new nursing students to program and healthcare facility policies, procedures, and technologies. This may include, but is not limited to, the following with the student: 
student responsibilities/expectations, professional dress/ behavior codes, etc]

-Yes_No

13. Does the program offer English as a second language services for non-native English speakers? [Program offers resources where students with English as a second language can practice reading, listening, speaking, and writing.] _Yes_No

14. Does the program offer disability support services? [Nursing program has procedures for making reasonable accommodations for students who qualify under the American Disabilities Act.] _Yes_No

15. Does the program offer support services to help low socioeconomic students access available resources (e.g., peer mentoring services, tuition assistance, a work-study program, etc.)? [Students have books and resources throughout the program and the program has strategies to help students who can't afford books and resources.] -Yes _No

16. Does the program have a formal remediation process in place for students needing academic support? [The remediation process is designed to promote success for students who are at risk of failure and should include the following elements: description of the deficient areas; an outline of specific, measurable goals to demonstrate success; individualized plan for each student; time frame for completion, agreed upon by the faculty and student.] -Yes_No

17. Does the program have a formal remediation process in place for students who commit errors/near misses in their clinical experiences? [Program has policies and procedures in place for keeping track of errors and near misses in student clinical experiences and taking action to make system/ educational improvements.]

_Yes_No

18. $\bar{H}$ as the nursing program experienced major organizational changes over the past year)? [Major organizational changes may include, but are not limited to, new director, new assistant/associate director, staff layoff, faculty layoff, change in university leadership (e.g., provost or president), collapsing programs, economic efficiencies, etc.] _Yes $\{$ Q19\} _No $\{$ Skip to Q20\}

19. What major organizational changes has the nursing program experienced in the past year?

$\square$ New director

New assistant/associate director

Staff layoff

Faculty layoff

Change in university leadership (e.g., provost or president)

$\square$ Collapsing programs (such as downsizing or merging programs)

$\square$ Economic efficiencies/budget reductions

$\square$ Other

20. Does the program offer simulated clinical experience? ["A technique that creates a situation or environment to allow persons to experience a representation of a real event for the purpose of practice, learning, evaluation, testing, or to gain an understanding of systems or human actions." From Healthcare Simulation Dictionary (2nd ed.) (AHRQ, 2020).] _Yes $\{021\}$ _No $\{$ Skip to Q23\}
21. \{lf yes to Q20\} Are simulation faculty certified? [The Society for Simulation in Healthcare (SSH) provides the Certified Healthcare Simulation Educator (CHSE) certification.] Yes_No

22. 22 . $\{$ If yes to $\mathrm{Q} 20\}$ Is the simulation laboratory accredited by the Society for Simulation in Healthcare (SSH)?

Y Yes_No

23. How many hours do students spend in direct client care? [Faculty-supervised care directly with clients.] \{lnteger\}

24. How many hours do students spend in simulation? ["A technique that creates a situation or environment to allow persons to experience a representation of a real event for the purpose of practice, learning, evaluation, testing, or to gain an understanding of systems or human actions." From Healthcare Simulation Dictionary (2nd ed.) (AHRQ, 2020).] \{lnteger\}

25. How many hours do students spend in the skills laboratory? [A skills laboratory is equipped with manikins, task trainers, and hospital equipment where students can apply basic procedural skills such as administering injections.] \{lnteger\}

\section{Program Director Data}

26. Is the program director a nurse? [This would include a nurse with an active or inactive license.]

_. Yes $\{027\} \quad$ _No $\{$ Skip to 228$\}$

27. $\{$ If yes to $\mathrm{Q} 27\}$ What is the program director's highest nursing degree achieved?
$\square$ Diploma
Associate degree in nursing
Baccalaureate of science in nursing
Master of science in nursing
Doctor of nursing practice
Doctor of philosophy in nursing
Other

28. What is the program director's highest non-nursing degree achieved?
Associate degree
Bachelor degree
Master of education
Other master's degree
Doctor of education
Doctor of philosophy
Other doctoral degree
N/A
Other

29. In the past 5 years, how many directors, including interim directors, has the program had? \{Integer\}

30. Does the program director have administrative responsibility for allied health? [Allied health is a broad field of health care professions made up of specially trained individuals such as physical therapists and respiratory therapists.] -Yes_No

31. Does the program have an assistant/associate director? Yes_No

32. Does the program director have dedicated administrative support? [Administrative support includes general office management such as answering phones, doing clerical work, and a variety of other tasks.]

_Yes _No 


\section{Faculty Data}

33. How many full-time faculty are in the prelicensure program? [Full time equivalent (FTE) faculty are expected to work at least 40 hours per week and to teach, participate in curriculum development, hold office hours for student advisement, attend faculty meetings, participate in campuswide events, attend professional development events, take part in scholarly activities, etc.] \{lnteger\}

34. How many clinical adjunct faculty are in the prelicensure program? [Clinical adjunct faculty are typically staff at the clinical facility that hosts students, and they supervise students during clinical rotations.]

a. Employed by the nursing program \{Integer\}

b. Not employed by the nursing program $\{$ Integer $\}$

35. How many part-time faculty are in the prelicensure program? [Part-time faculty work less than 40 hours per week and are responsible for assuming teaching responsibilities, usually collaborating with the full-time faculty. They maintain availability to students and communicate effectively with students and colleagues.] \{lnteger\}

36. How many of the full-time faculty have a graduate-level education?

$\square$ Master of science in nursing \{lnteger\}

Master of science (other than nursing) \{Integer\}

Other aster's $\{$ Integer $\}$

Doctor of nursing practice $\{$ Integer $\}$

Doctor of philosophy \{Integer\}

Other doctoral degree $\{$ Integer\}

37. Please specify the typical number of students to one faculty member for didactic/theory courses. \{Integer\}

38. Please specify the number of students to one clinical faculty member. [All levels of faculty (full time, part time, and clinical adjunct) in all types of clinical experiences.] \{Integer\}

39. Does the program offer formal orientation for new adjunct clinical faculty? [Formal orientation for new adjunct clinical faculty includes overview of the program and the particular course they're teaching, policies and procedures, teaching responsibilities, supervision of students, role modeling, planning post conferences, evaluation of students, etc.] _Yes_No

For questions 40-42 below, we are going to ask you about formal orientation for new faculty. Formal orientation of new faculty includes an overview of the program and faculty resources, policies and procedures, workload, faculty appraisal, curriculum and syllabus development, student assessment, didactic and clinical teaching responsibilities, student advisement, etc.

40. Does the program offer formal orientation for new parttime faculty?

_Yes_No
41. Does the program offer formal orientation for new full-time faculty?

Yes _No

42. Does the program offer formal mentoring for new full-time faculty? [Formal mentoring includes assignment of a seasoned (at least 1 year of teaching) faculty member who has taught at the same level for the purpose of providing ongoing support, coaching, guidance, and faculty development for new full-time faculty.] _Yes_No

\section{Student Data}

43. How many students are enrolled in the nursing program as of the beginning of the current academic year? [Includes all prelicensure students.] \{Integer\}

44. Do you have a maximum enrollment capacity? Y Yes $\{$ Q45 $\} \quad$ No $\{$ Skip to 046$\}$

45. What is the maximum nursing enrollment capacity for the current academic year? \{Integer\}

46. What is the total number of students who started in your most recent graduating cohort? \{nteger\}

47. In your most recent graduating cohort, how many students graduated? \{Integer\}

48. In your most recent graduating cohort, how many students did not graduate and are still actively pursuing coursework? \{lnteger\}

49. What is the average age of a student enrolled in the program as of the beginning of the current academic year? \{Sliding scale, integer\}

50. Please provide a detailed breakdown of the racial composition (number in each category) of the students currently enrolled in the program.

$\square$ American Indian or Alaska Native \{Numeric response field, integer\}

Asian \{Numeric response field, integer\}

Black or African American \{Numeric response field, integer\}

Native Hawaiian or other Pacific Islander \{Numeric response field, integer\}

White $\{$ Numeric response field, integer $\}$

Multi-racial \{Numeric response field, integer\}

Other $\{$ Numeric response field, integer\}

51. Please provide a detailed breakdown (number of students in each category) of the ethnic composition of the students currently enrolled in the program.

Hispanic or Latino or Spanish origin \{Numeric response field, integer\}

$\square$ Non-Hispanic or Latino or Spanish origin \{Numeric response field, integer\}

52. Please provide a detailed breakdown (number of students in each category) by student sex.

$\square$ Female \{Numeric response field, integer\}

Male \{Numeric response field, integer\}

Other $\{$ Numeric response field, integer\} 